OPEN ACCESS

Edited by:

Esra Capanoglu,

Istanbul Technical University, Turkey

Reviewed by:

Francisco José Roma Paumgartten, Oswaldo Cruz Foundation

(Fiocruz), Brazil

Gokhan Zengin,

Selçuk University, Turkey

*Correspondence:

Orish Ebere Orisakwe

orishebere@gmail.com; orish.orisakwe@uniport.edu.ng

Specialty section:

This article was submitted to Nutrition and Microbes,

a section of the journal

Frontiers in Nutrition

Received: 15 September 2020 Accepted: 15 January 2021

Published: 09 February 2021

Citation:

Umeoguaju FU,

Ephraim-Emmanuel BC,

Patrick-Iwuanyanwu KC, Zelikoff JT and Orisakwe OE (2021) Plant-Derived

Food Grade Substances (PDFGS) Active Against Respiratory Viruses: A

Systematic Review of Non-clinical Studies. Front. Nutr. 8:606782. doi: 10.3389/fnut.2021.606782

\section{Plant-Derived Food Grade Substances (PDFGS) Active Against Respiratory Viruses: A Systematic Review of Non-clinical Studies}

\author{
Francis U. Umeoguaju ${ }^{1}$, Benson C. Ephraim-Emmanuel ${ }^{1,2}$, \\ Kingsley C. Patrick-Iwuanyanwu ${ }^{1}$, Judith T. Zelikoff ${ }^{3}$ and Orish Ebere Orisakwe ${ }^{1,4 *}$ \\ ${ }^{1}$ World Bank Africa Centre of Excellence in Public Health and Toxicological Research (ACE-PUTOR), University of Port \\ Harcourt, Port Harcourt, Nigeria, ${ }^{2}$ Department of Dental Health Sciences, Ogbia, Bayelsa State College of Health \\ Technology, Otakeme, Nigeria, ${ }^{3}$ Department of Environmental Medicine, New York University Grossman School of Medicine, \\ New York, NY, United States, ${ }^{4}$ Department of Experimental Pharmacology and Toxicology, Faculty of Pharmacy, University of \\ Port Harcourt, Port Harcourt, Nigeria
}

Human diet comprises several classes of phytochemicals some of which are potentially active against human pathogenic viruses. This study examined available evidence that identifies existing food plants or constituents of edible foods that have been reported to inhibit viral pathogenesis of the human respiratory tract. SCOPUS and PUBMED databases were searched with keywords designed to retrieve articles that investigated the effect of plant-derived food grade substances (PDFGS) on the activities of human pathogenic viruses. Eligible studies for this review were those done on viruses that infect the human respiratory tract. Forty six (46) studies met the specified inclusion criteria from the initial 5,734 hits. The selected studies investigated the effects of different PDFGS on the infectivity, proliferation and cytotoxicity of different respiratory viruses including influenza A virus (IAV), influenza B virus (IBV), Respiratory syncytial virus (RSV), human parainfluenza virus (hPIV), Human coronavirus NL63 (HCoV-NL63), and rhinovirus (RV) in cell lines and mouse models. This review reveals that PDFGS inhibits different stages of the pathological pathways of respiratory viruses including cell entry, replication, viral release and viral-induced dysregulation of cellular homeostasis and functions. These alterations eventually lead to the reduction of virus titer, viral-induced cellular damages and improved survival of host cells. Major food constituents active against respiratory viruses include flavonoids, phenolic acids, tannins, lectins, vitamin D, curcumin, and plant glycosides such as glycyrrhizin, acteoside, geniposide, and iridoid glycosides. Herbal teas such as guava tea, green and black tea, adlay tea, cistanche tea, kuding tea, licorice extracts, and edible bird nest extracts were also effective against respiratory viruses in vitro. The authors of this review recommend an increased consumption of foods rich in these PDFGS including legumes, fruits (e.g berries, citrus), tea, fatty fish and curcumin amongst human populations with high prevalence of respiratory viral infections in order to prevent, manage and/or reduce the severity of respiratory virus infections.

Keywords: IAV, RSV, HCoV, Antiviral agent, Respiratory Tract Infection (RTI), functional foods, Viral lifecyle, polyphenols 


\section{INTRODUCTION}

Several people suffer yearly from respiratory tract infections caused by viruses and a host of other organisms (1). Infections of the respiratory tracts are leading cause of death in children below 5 years with up to 500,000 annual deaths globally (2). Respiratory viruses are major contributor to respiratory tract infections. Influenza viruses alone is reported to affect about $20 \%$ of the world's population resulting in an annual mortality of over 500,000 globally $(3,4)$. Human respiratory syncytial virus (RSV) is also reported to cause over 30 million cases of lower respiratory tract infection amongst children every year. This consequently leads to over 3 million hospitalization

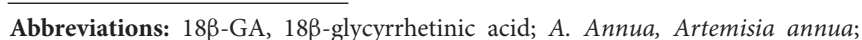
A. digitata, Adansonia digitata; A. melanocarpa, Aronia melanocarpa; ACE, Angiotensin-converting enzyme; ACE2, Angiotensin-converting enzyme 2; AdV, Adenovirus; AKT, Protein kinase B; AP-1, Activator protein-1; CC50, 50\% cytotoxic concentration; Cmax, Peak plasma level; COPD, Chronic obstructive pulmonary disease; DMO-CAP, 6-demethoxy-4'-O-methylcapillarisin; EBN, edible bird nest (EBN); EGCG, Epigallocatechin gallate; ERK, Extracellular signalregulated kinase; G. thunbergii, Geranii thunbergii; G. uralensis, Glycyrrhiza uralensis; GSP, Grape seed proanthocyanidin; H. cordata, Houttuynia cordata; HA, hemagglutinin; HA2, Fusion peptide; HCoV-NL63, Human coronavirus NL63; hPIV, Human parainfluenza virus; hPIV-2, Human parainfluenza virus type 2; hPIV-2-F, hPIV-2 fusion protein; hPIV-3, Human parainfluenza virus type 3; HS, Hibiscus sabdariffa; i.p, Intraperitoneal; IAV, Influenza A virus; IAV$\mathrm{M}$, IAV matrix protein; IAV-P, IAV polymerase; IBV, Influenza B virus; IC50, Half maximal inhibitory concentration; IFITM, IFN-induced transmembrane; IFN, Interferons; IFN- $\alpha$, Interferon $\alpha$; IFN- $\beta$, Interferon $\beta$; IFN- $\gamma$, Interferon $\gamma$; IKK, IkB kinase; IL-18, Interleukin 18; IL-1 $\beta$, Interleukin $1 \beta$; IL-6, Interleukin 6; iNOS, Inducible nitric oxide synthase; IRF, Interferon regulatory factor; IRF3, Interferon regulatory factor 3; ISGs, Interferon-stimulated genes; JAK1, Janus kinase 1; LLC-MK2, Rhesus Monkey Kidney Epithelial Cells; M1, Matrix protein 1; M2, matrix protein 2; MAPK, Mitogen-activated protein kinase; MDA-5, Melanoma differentiation-associated protein 5; MHV, Mouse hepatitis virus; MMP, Pulmonary matrix metalloproteinase; mRNA, Messenger ribonucleic acid; MxA, Myxovirus Resistance Gene A; MxB, Myxovirus Resistance Gene

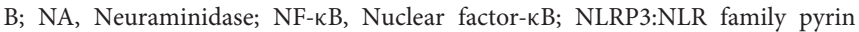
domain containing 3; NP, nucleoprotein; Nrf2, Nuclear factor erythroid 2related factor 2; NS1, Non-structural protein 1; NS2, Non-structural protein 2; OAS, $2^{\prime}-5^{\prime}$ oligoadenylate synthetase; P. oleracea, Portulaca oleracea; PA, Polymerase acidic protein; PABPII, Polyadenine binding protein II; PAMP, Pathogenic associated molecular patterns; PB1, Polymerase basic protein 1; PB1F2, Polymerase basic protein 1-F2; PB2, Polymerase basic protein 2; PDFGS, Plant-derived food grade substances; PI3K, Phosphatidylinositol-3-kinase; PIVs, Parainfluenza viruses; PKR, Protein kinase R; PPR, Pattern recognition receptors; R. acetosa, Rumex acetosa; RANTES, Regulated on activation normal T cell expressed and secreted; RIG-1, Retinoic acid-inducible gene I; RNA, Ribonucleic acid; RNase L, Ribonuclease L; RNP, Ribonucleoprotein; ROS, Reactive oxygen species; rPR8-GFP, Recombinant H1N1/PR8 expressing green fluorescent protein; RSV, Respiratory syncytial virus; RSV-F, RSV fusion protein; RSV-G, Glycoprotein; RSV-L, RSV RNA-dependent RNA polymerase; RSV-M21, RSV matrix M2-1; RSV-M2-2, RSV matrix M2-2; RSV-N, RSV nucleoprotein; RSV-NS2, RSV non-structural protein 2; RSV-P, RSV phophoprotein; RSV-RNP, RSV ribonucleoprotein; RSV-SH, RSV hydrophobic protein; RV, Rhinovirus; RV1A, Rhinovirus 1A; RV1B, Rhinovirus 1B; SARS-CoV-2, Severe acute respiratory syndrome coronavirus 2; ssRNA, Single-stranded RNA; STAT1/2, Signal transducer and activator of transcription 1/2; T-bet, T-box expressed in T cells; TCCM, Tissue culture cell monolayers; TLR, Toll-like receptor; TLR4, Toll-like receptor 4; TNF- $\alpha$, Tumor necrosis factor- $\alpha$; TRAF6, Tumor necrosis factor receptor (TNFR)-associated factor 6; TRIF, TIR-domain-containing adapter-inducing interferon- $\beta$; TRIM25, Tripartite motif containing 25 ; TYK2, Non-receptor tyrosine-protein kinase; U. lactuca, Ulva lactuca; Vit D, vitamin D; vRNP, Viral ribonucleoprotein; wnt3a, Wnt family member 3a; Z. officinale, Zingiber officinale. and about 60,000 deaths amongst infected persons (5). Over 200 strains of Respiratory viruses belonging to the families of adenoviridae, parvoviridae, orthomyxoviridae, paramyxoviridae, picornaviridae, and coronaviridae have been reported (2). Some notable examples of pathogenic viruses known to infect human respiratory tract includes influenza viruses, human parainfluenza virus (hPIV), RSV, adenovirus (AdV), rhinovirus (RV), enterovirus, parechovirus, human metapneumovirus, coronavirus, human bocavirus, parvovirus (type 4 and 5), and mimivirus $(2,6,7)$.

Respiratory viruses are highly infective and are transmitted through contact with virus containing substances such as respiratory secretions, stools and urine (6). These viruses readily infect the upper respiratory tracts and cause mild infections including cold and flu. However, symptoms aggravates once infections gets to the lower respiratory tracts $(2,8)$. Most respiratory viruses have seasonal outbreaks while some like hPIV infection occurs all year round (7). Some of the general symptoms of respiratory viruses include seasonal colds, bronchiolitis (especially with RSV), acute otitis, sinisitis, croup (mainly by hPIV), worsening of chronic obstructive pulmonary disease (COPD) and asthma, pneumonia (7). The most vulnerable groups to respiratory virus infection include immunocompromised patients, elderly, and infants $(2,7,9)$.

Some of these viruses have been reported to cause pathology by inducing severe oxidative stress and significantly reducing the expressions of nuclear factor erythroid 2-related factor 2 (Nrf2) and heme oxygenase- 1 as well as cause the activation of toll-like receptor (TLR) signaling pathways amongst other pathological mechanisms $(10,11)$. This notwithstanding, in the event of occurrence of a viral infection, the body's immune system stages innate and adaptive immune responses that recognize and destroy the viral threat as well as resolve inflammation and repair the damages caused by these viruses in the body (12).

Over the years in different continents of the world, natural plant products which are edible and known to possess medicinal properties have been continually used for the treatment of infections and disease ailments (13). Research on these plantderived food grade substances (PDFGS) has come at a time when there are increasing cases of resistance to conventional antimicrobials as well as issues with potency, safety amongst others (13). These PDFGS provide a wide variety of treatment options that can be applied in modern medicine as either a supplementary or a main treatment modality. In actual fact, up to $80 \%$ of populations resident in developing countries apply these natural remedies in one way or the other for the treatment of diseases, supplementation of body nutrition, boosting the immune system amongst other applications (1315). Some PDFGS such as adlay tea, Houttuynia cordata $(H$. cordata) Thunb are widely used in traditional medicine in the management of different respiratory tract infections $(16,17)$.

It is also necessary to point out the relevance of adequate nutrition in boosting immune function by supporting the innate and adaptive immunity systems of the body $(18,19)$. Nutrition supports innate immunity through the development and maintenance of physical barriers; production of antimicrobial proteins; growth, differentiation and chemotaxis of innate 
cells. It also helps in mediating the phagocytic and killing activities of neutrophils and macrophages as well as encourages the promotion of and recovery from inflammation $(12,19)$. On the other hand, nutrition supports the adaptive immune system by enhancing lymphocyte differentiation, proliferation, and homing as well as anti-viral cytokine production. It also supports antibody production; and the generation of memory cells which are essential antiviral defense mechanisms of the body $(12,19,20)$. This is made possible by the presence of several vitamins, including vitamins A, B6, B12, C, D, E, and folate; and trace elements, including zinc, iron, selenium, magnesium, and copper; most of which can be gotten from adequate nutrition (12).

Apart from boosting the immune system for an effective immune response, some edible food substances such as $H$. cordata (21), green tea (22), Ulva lactuca (U. lactuca) (23), Glycyrrhiza uralensis (G. uralensis) (20) have been shown to possess in vitro virucidal and virus-inhibitory effects on human pathogenic viruses $(24,25)$. The observed antiviral effects of these food substances may be associated with their constituent phytochemicals, micronutrients and vitamins (14, 21, 26-29).

Presently, a number of synthetic antiviral medications are been used in the treatment of viral diseases for which a good number have shown promising results (27). Among these include lopinavir, arbidol, hydroxychloroquine and choloroquine phosphate, nucleoside analogs, neuraminidase inhibitors, and azithromycin $(15,30)$. However, there are still certain viral strains against which effective antiviral vaccines/medication have not yet being produced; especially viral strains belonging to the coronavirus family of viruses $(27,30)$. In addition to this, limited antiviral medications exist for combating certain respiratory viral infections including those caused by the human RSV (6). Incidences of drug resistant strains of different respiratory viruses makes it necessary to continually search for new therapeutics to combat respiratory viral infections $(31,32)$. There is thus a need to delve into research that would identify safer and more effective antiviral agents from natural products in order to augment the existing antiviral medications.

The prevalence and severity of different diseases is known to vary across different geographical regions and human populations $(33,34)$. Such difference has been attributed to factors including climatic, socioeconomic, political, and environmental factors $(33,34)$. Recent evidences are suggesting that nutrition plays important roles in the transmission and severity of viral infections $(35,36)$. We were interested in determining whether plant-derived food substances or their products would alter the course of respiratory virus's infection as well as understand possible mechanism involved in such effect. We reasoned that the presence of some vitamins and phytochemicals in foods may both boost the body's immunity to respiratory virus infection as well as suppress the proliferations of respiratory viruses. This systematic review is therefore an attempt to identify plant-derived edible food substances or their constituents, demonstrated to be active against viruses that infect human respiratory tracts as well as report potential mechanisms involved in such antiviral effects. To our knowledge, there is no prior systematic review on the antiviral efficacy of edible plant substances on respiratory viruses. Availability of this information will bring to light previously untapped antiviral benefits of plantderived food substances thereby facilitating the development of additional layer of defense against respiratory viral infections.

\section{METHOD}

This systematic review was aligned with the Preferred Reporting Items for Systematic Reviews and Meta-Analyses (PRISMA) guidelines (37). PUBMED and SCOPUS databases were searched systematically between April and May 2020, for articles that investigated the antiviral effects of natural products against human pathogenic viruses. Literature search was conducted independently by two of the authors (FU, BE-E) across the two databases. The database search covered all available publications from inception to the date of search. The search strategy used in the retrieval of literature for this review included different search terms that denote antiviral properties, human pathogenic viruses, natural products and edible substances. Search terms used to designate antiviral properties included "viral inhibition," "inhibit virus," "antiviral," "antivirus." Search terms used to designate human pathogenic viruses included "human virus," "virus," "human pathogenic." Search terms used to designate edible, plant-based or natural products included "anthocyanin," "apigenin," "beverage," "carbohydrate," "catechin," “cereal," “coumarin,” “curcumin,” “edible," “epigallocatechin," "extract," "flavonoid," “food," "fruit," "gallic acid," "glycoside," "grain," "indole," "lectin," "legumes," "lignans," "medicinal plant," "medicinal," "natural product," "neutraceutical," "nutraceutical," “oil," “peptides," "phenol*," "phytochemical," "plant extract," "plant product," "plant," "polyphenol," "polysaccharide," "proanthocyanidin," "protease inhibitor," "proteins," "quercetin," "quinoline," “quinone," “steroids," “supplement," “tannin," "tea," “terpenes," "thymoquinone," "traditional," "ursolic acid," "vegetable," "vitamin," "alkaloid." These search terms were combined together in a search engine dependent boolean format to give the complete search strategy used for retrieving the literature used in this review. The construction of the search strategy (Figure 1) and the detailed strategy used to search PUBMED and SCOPUS is detailed below.

\section{SCOPUS}

((TITLE-ABS-KEY (antivir* OR anti-vir* OR antivir* OR "viral inhibition" OR (inhibit* AND virus)) AND TITLE-ABS (human OR "human viruses" OR "human pathogenic"))) AND (TITLEABS ("gallic acid" OR "natural product" OR "plant product" OR "protease inhibitor" OR "ursolic acid” OR alkaloid OR anthocyanin OR apigenin OR carbohydrates OR catechin OR coumarin OR curcumin OR epigallocatechin OR extract OR flavonoid OR glycoside OR indole OR quinoline OR lectin OR lignans OR medicinal OR peptides OR phenol* OR phytochemical OR plant OR polyphenol OR polysaccharide OR proanthocyanidin OR proteins OR quercetin OR quinone OR steroids OR tannin OR terpenes OR thymoquinone OR traditional OR nutraceutical OR neutraceutical OR tea 


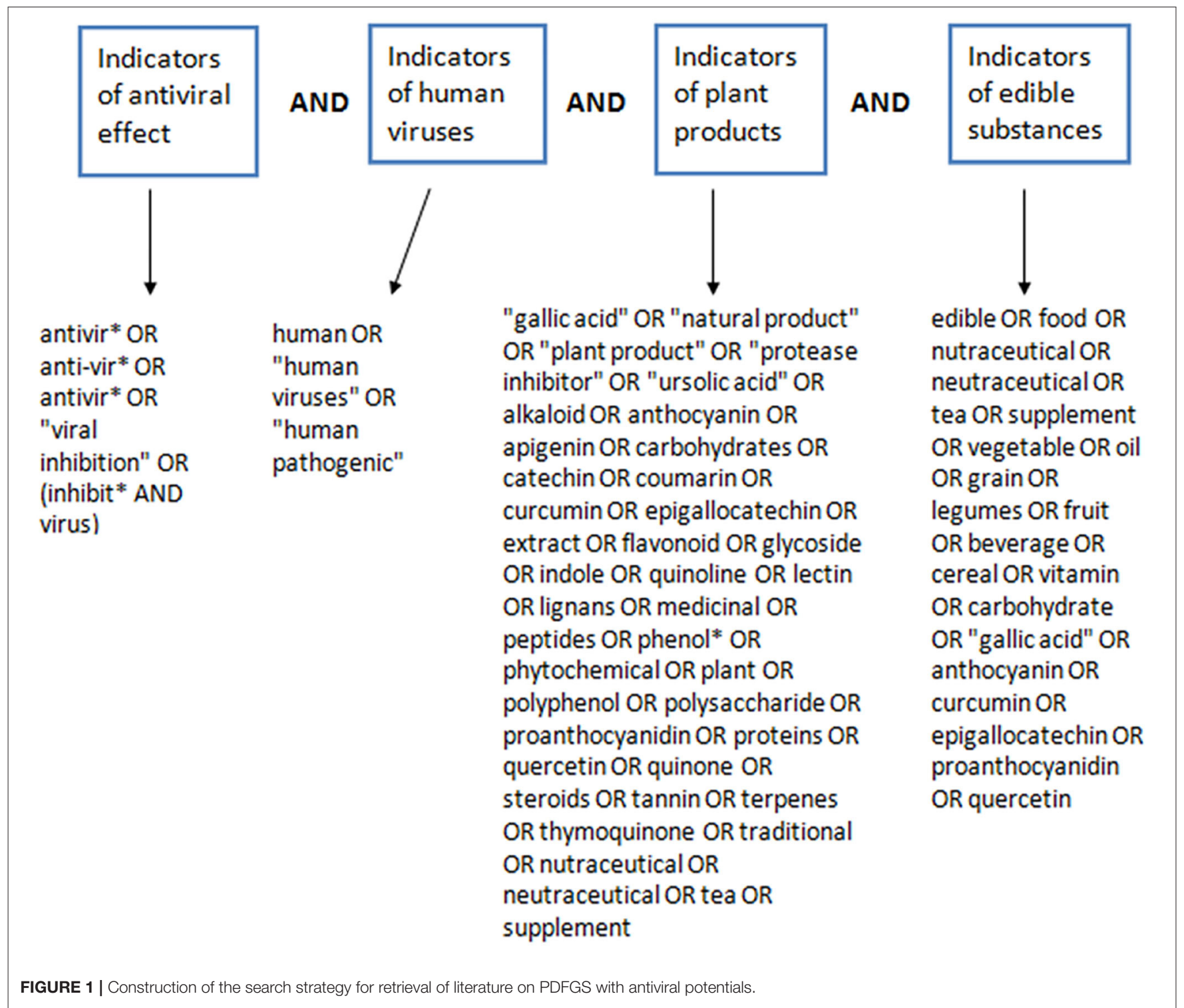

OR supplement)) AND TITLE-ABS (edible OR food OR nutraceutical OR neutraceutical OR tea OR supplement OR vegetable $\mathrm{OR}$ grain $\mathrm{OR}$ legumes $\mathrm{OR}$ fruit $\mathrm{OR}$ beverage $\mathrm{OR}$ cereal OR vitamin OR carbohydrate OR gallic OR anthocyanin OR curcumin OR epigallocatechin OR proanthocyanidin OR quercetin OR dietary OR spice OR additives).

\section{PUBMED}

((( antivir*[ti] OR anti-vir*[ti] OR antivir*[ti] OR "viral inhibition"[ti] OR (inhibit*[ti] AND virus[ti]))) AND (human OR "human viruses" OR "human pathogenic")) AND ("gallic acid" OR "natural product" OR "plant product" OR "protease inhibitor" OR "ursolic acid” OR alkaloid OR anthocyanin OR apigenin OR carbohydrates OR catechin OR coumarin OR curcumin OR epigallocatechin OR extract OR flavonoid OR glycoside OR indole OR quinoline OR lectin OR lignans OR medicinal OR peptides OR phenol* OR phytochemical OR plant OR polyphenol OR polysaccharide OR proanthocyanidin OR proteins OR quercetin OR quinone OR steroids OR tannin OR terpenes OR thymoquinone OR traditional OR nutraceutical OR neutraceutical OR tea OR supplement)) AND (edible OR food OR nutraceutical OR neutraceutical OR tea OR supplement OR vegetable $O R$ oil $O R$ grain $O R$ legumes $O R$ fruit $O R$ beverage OR cereal OR vitamin OR carbohydrate OR "gallic acid” OR anthocyanin OR curcumin OR epigallocatechin OR proanthocyanidin OR quercetin).

\section{Eligibility Criteria}

Studies included in this review were those that either reported on viruses that infects human or on surrogate of human viruses adapted for different experimental models. The human viruses considered were those that belong to any of the classes of viruses 
known to infect the human respiratory tract including influenza viruses, RSV, parainfluenza viruses (PIVs), metapneumovirus, coronavirus, respiratory $\mathrm{AdV}, \mathrm{RV}$, bocavirus, enterovirus, and parechovirus $(2,6,7)$. Only studies done on animals, humans or cell lines, those that utilized constituents of edible foods as an antiviral intervention agent and those that reported some forms of outcome following treatment of virus-infected models with the intervention agents were considered for inclusion. Extracts obtained from non-edible plant parts were excluded. Studies that did not report a comparative untreated group were excluded from the review. There was no restriction on the year of publication or location of study. Only original research articles published in English language whose full texts are accessible online were included.

\section{Selection of Relevant Article}

The titles and abstract of all the articles retrieved from each of the databases were screened against the aforementioned criteria. The selected articles were pooled together and duplicate entries were removed manually. The full texts of these selected articles were subsequently retrieved and subjected to full text screening for eligibility. Eligible articles were screened independently by two authors (FU, BE-E). The list of selected eligible articles, obtained by the two authors, were compared, and collated. In cases of differing opinion on the eligibility of any particular article, the article in question was discussed amongst the authors until a consensus was reached. Where the edibility status of a particular intervention agent is in doubt, additional literature search was conducted to establish whether such agent was edible or whether they are commonly found in edible foods.

\section{Assessment of the Quality of Selected Studies}

The quality of the in vitro studies used for this review was assessed using an adapted version of the CONSORT statement similar to what was reported by Seyedpour et al. (38). Each of the included study was assessed whether it reported each of the 21 items of the study assessment checklist. They are assigned either a "yes" or "no" value for each items of the checklist depending on the authors' judgement. Assessment was done on the inclusion of relevant background information, statement of study's objectives as well availability of detailed information on the participants (particularly, the cell models and viruses). Availability of details on the virus strains, culture conditions, viability of the model organism (in the absence of viral infection) as well as evidence of successful viral infection following exposure of the virus to the model cells were also assessed. Availability of adequate information on the intervention agent (in this case, PDFSG) including its concentration and cytotoxicity were assessed. Reportage of methods for all intended outcomes, statement of sample sizes or numbers of repetition of experimental procedures, description of statistics used and appropriateness of the experimental methods/procedures to detect viral inhibitory effect were assessed for each included study. Each study was also assessed for the reportage of sufficient result for all outcomes investigated, demonstration of dosegraded effect, reportage of study limitation, and appropriate interpretation of observed result. Possible presence of sampling and detection bias was assessed by checking if the study reported randomization and blinding in their experimental procedures. Reportage of information on funding and potential conflict of interest were also assessed.

The quality of the included animal studies was assessed using the Systematic Review Center for Laboratory Animal Experimentation (SYRCLE) risk of bias tool (39). Each of the study was screened against a 9 item checklist and was assigned either a "high," "low," or "uncertain" risk depending on the outcome of the assessment by the authors.

\section{Data Extraction}

Each of the eligible articles was read independently by two of the authors (FU, BE-E). The authors extracted a previously agreed set of relevant information from each of the articles under review and completed a predesigned form. The extracted information included the intervention antiviral agent, sources of the agent, test virus, experimental model, assay methodology for antiviral effects, antiviral concentrations, cytotoxic concentrations, antiviral mechanism (where available), author's information. The extracted information was reviewed by all the authors and was used to complete the summary table.

\section{RESULT AND DISCUSSION}

A total of 5,734 papers were retrieved from both SCOPUS (2965) and PUBMED (2769) databases. Abstract and title screening yielded 299 publications (PUBMED: 193, SCOPUS: 106) with 244 unique articles after removing duplicates. Of these articles, only 228 were downloaded. The full text of the remaining 16 articles could not be accessed online. Forty (40) eligible articles were identified after screening the full text of the downloaded articles against the eligibility criteria (Figure 2). Forty-one (41) of the included studies were on cell lines, 11 were on mice, and 1 was on chicken egg.

\section{Outcome of Study Quality Evaluation}

The findings from our evaluation of the quality of the included in vitro studies is shown in Figure 3. Most of the included studies provided sufficient information on study's background and objectives. Almost all the included studies provided adequate description of the virus strain, test cell line model and intervention agent (that is, PDFGS). However, only $84 \%$ of the included studies demonstrated the viability of the virus in the experimental models, $80 \%$ of the studies gave information on the cytotoxicity of the intervention agent to the un-infected cell model. Majority $(87 \%)$ of the included studies used appropriate procedure to show the viral inhibition, provided a complete description of the methods used to estimate all intended outcome (100\%), reported the numbers of repetition carried out for each effects estimate (98\%), as well as reported outcome for all the investigated parameters (96\%). Only about half of the studies presented statistical description in the methodology (64\%). Dosegraded effect was reported in $73 \%$ of the included studies. 


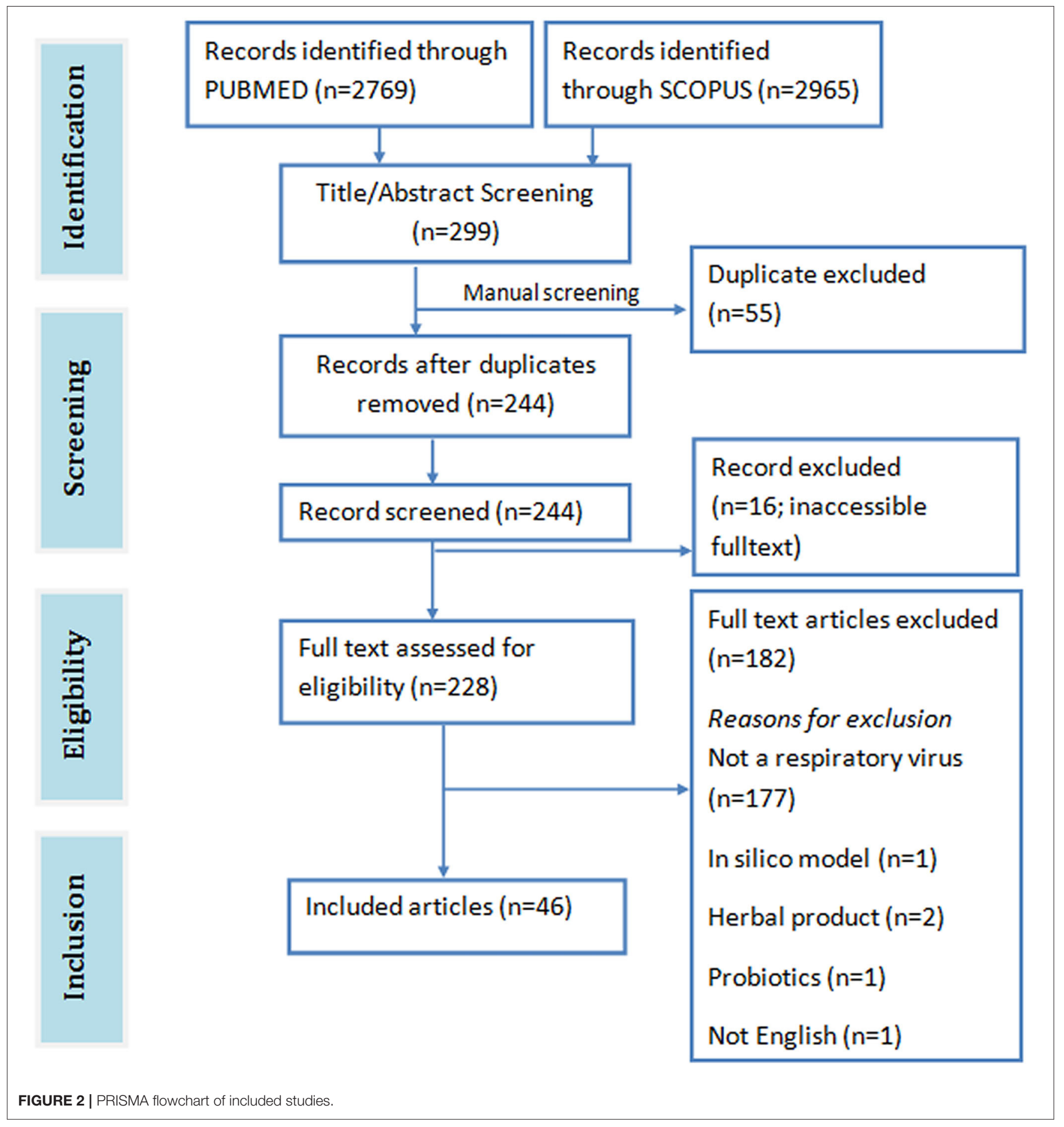

All the included studies gave an interpretation consistent with their results.

None of the studies reported a study limitation. Just one of the included studies reported a form of randomization in the experimental procedure. None of the included study reported blinding or concealing the allocation from the investigator. Information on study funding and potential conflict of interest were reported by 67 and $56 \%$ of the included studies, respectively. Overall, the included studies was scored an average of $70 \%$ from a possible $100 \%$.

The findings following the assessment of the study quality of the included in vivo studies is shown in Figure 4. The findings indicate that the included studies had an unclear and potentially significant risk of selection bias. Only 4 out of the 11 studies 


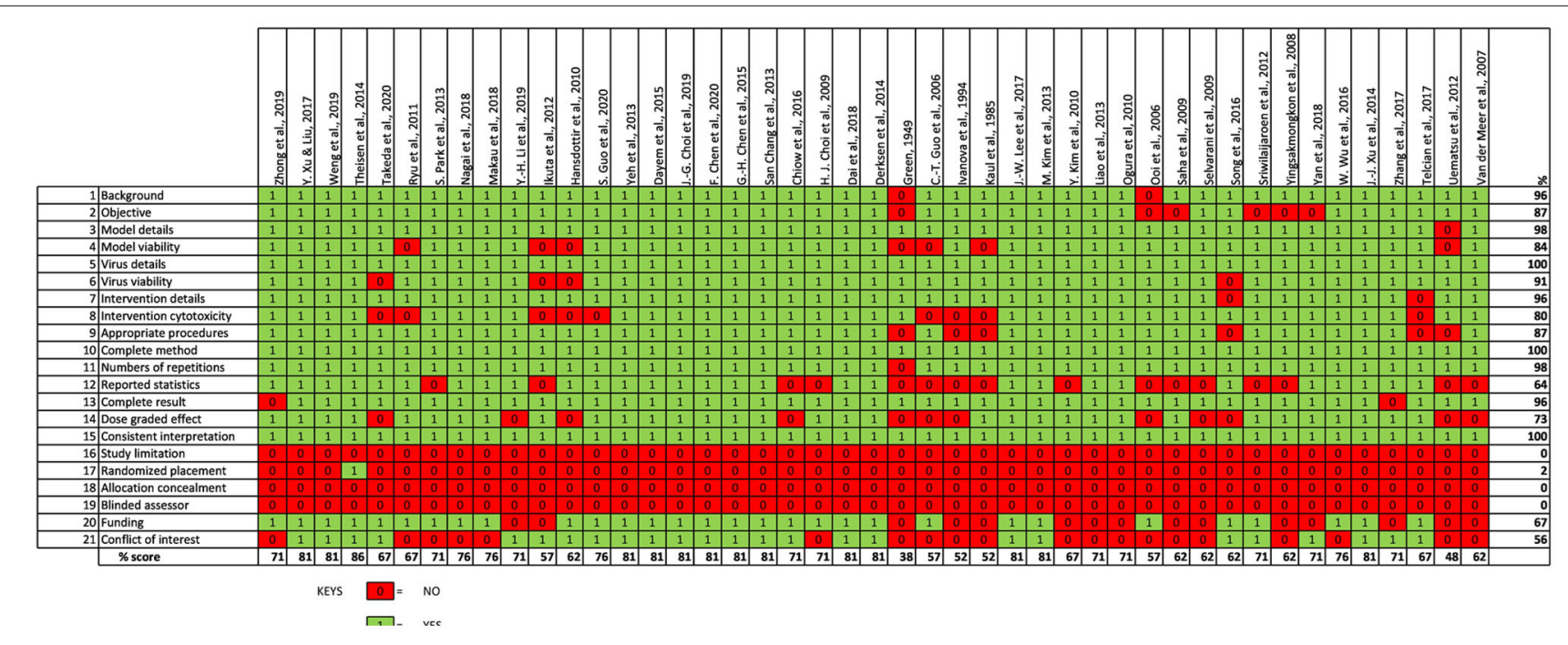

FIGURE 3 | Quality assessment of included in vitro studies.

\begin{tabular}{|c|c|c|c|c|c|c|c|c|c|c|c|}
\hline & 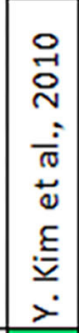 & 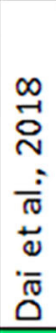 & 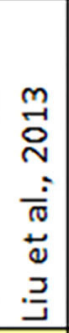 & 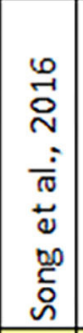 & 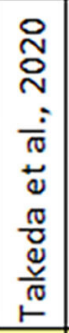 & 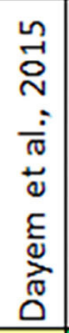 & 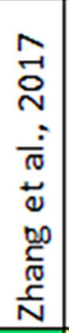 & 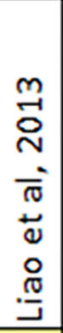 & 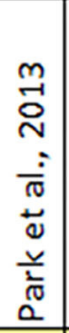 & 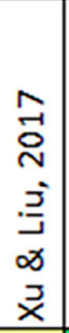 & 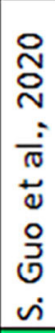 \\
\hline Random sequence generation (Selection bias) & + & + & $?$ & $?$ & $?$ & $?$ & + & $?$ & $?$ & $?$ & + \\
\hline Baseline characteristics (Selection bias) & + & + & + & + & + & + & + & + & + & + & + \\
\hline Allocation concealment (Selection bias) & $?$ & $?$ & $?$ & $?$ & $?$ & $?$ & $?$ & $?$ & $?$ & $?$ & $?$ \\
\hline Random Housing (Performance bias) & $?$ & $?$ & $?$ & $?$ & $?$ & $?$ & $?$ & $?$ & $?$ & $?$ & $?$ \\
\hline Blinding of personel (Performance bias) & $?$ & $?$ & $?$ & $?$ & $?$ & $?$ & $?$ & $?$ & $?$ & $?$ & $?$ \\
\hline Random outcome assessment (Detection bias) & $?$ & $?$ & $?$ & + & $?$ & $?$ & $?$ & $?$ & $?$ & $?$ & $?$ \\
\hline Blinding of outcome assessment (Detection bias) & $?$ & $?$ & $?$ & $?$ & $?$ & $?$ & $?$ & $?$ & $?$ & $?$ & $?$ \\
\hline Incomplete outcome data (Attrition bias) & + & + & + & + & + & + & + & + & + & + & + \\
\hline Selective reporting (Reporting bias) & + & + & + & + & + & + & + & + & + & + & + \\
\hline & \multirow{2}{*}{\multicolumn{2}{|c|}{ Keys: }} & ? & \multirow{2}{*}{\multicolumn{8}{|c|}{ Unclear Risk }} \\
\hline & & & & & & & & & & & \\
\hline
\end{tabular}

carried out a randomization of their experimental setup. All the included studies provide sufficient baseline information on the experimental animal and experimental conditions. But none of the studies reported a concealment of allocations from the investigator. The included animal studies had an unclear risk of performance bias since none of them reported a random housing of the animals or the blinding of the caregiver. An unclear risk of detection bias was also observed in the included animal studies. 
However, the included studies had a low risk of attrition or reporting bias. The overall assessment indicates that the included studies had a potentially high risk of selection, performance and detection bias.

\section{PDFGS Were Effective Against Different Strains of Respiratory Viruses}

Some strains of human pathogenic influenza A virus (IAV), influenza B virus (IBV), RSV, human parainfluenza virus (hPIV), human coronaviruses, RVs and AdV are susceptible to different PDFGS (Table 1). Majority of the included studies investigated the antiviral effect of PDFGS on different subtypes of IAV, including H1N1 strains such as influenza A/Puerto Rico/8/34 (67, 70), influenza A/Jiangsu/1/2009 (71), influenza A/Fort Monmouth/1/1947 (68), and Amantadine resistant influenza A/WSN/33/S31N (60); H3N2 strains such as influenza $\mathrm{A} / \mathrm{Memphis} / 1 / 71$, influenza A/Aichi/2/68 (67), and influenza A/JiangXi/312/2006 (68); H2N2 subtypes (58); H9N2 subtypes (10, 40) and H5N1 subtypes (10). Strains of IBV such as B/Nagasaki/1/87, B/Shanghai/261/2002 (16), and influenza B/human/Hubei/1/2007 (60) were also susceptible to PDFGS. Other susceptible respiratory viruses reported in this review included human coronavirus NL63 (HCoV-NL63) (44), RSV (A2, Long and B strains) $(20,59,69)$, human parainfluenza virus type 2 (hPIV-2 Toshiba strain) (73), human parainfluenza virus type 3 (hPIV-3) (58), mouse hepatitis virus (21), rhinovirus 1B (RV1B) (72), AdV (type 5 prototype strain) (48).

\section{Life Cycle of IAV}

The evidence presented in this review indicates that PDFGS affected different stages in the lifecycle of respiratory viruses. A brief overview of the lifecycle of IAV and RSV is presented to serve as a background for subsequent discussion on the antiviral mechanism of these PDFGS, at each stages of respiratory virus's lifecycle. The choice of IAV and RSV is because majority of the evidence presented in this review are based on these two viruses.

An overview of IAV life cycle is illustrated in Figure 5. IAV infections are initiated following exposure to infectious IAV particles. Once an infective IAV particle gets into the respiratory tract environment, it utilizes its viral hemagglutinin (HA) protein to interact with sialic acid residues of membrane glycoproteins on host epithelial cells. Following successful host-virus interaction, IAV particles are taken up into the cell through endocytosis or macropinocytosis within an endosome (75). The low $\mathrm{pH}$ of the endosome induces a conformational change in IAV HA leading to the exposure of IAV fusion peptide (HA2) and subsequent fusion of the virus particle to the endosomal membrane $(76,77)$. The low $\mathrm{pH}$ also favors the activation of matrix protein 2 (M2) ion channel leading to the acidification of the viral core. This acidification leads to the dissociation of viral ribonucleoprotein (vRNP) from its associated matrix protein 1 (M1), as such, facilitating the cytoplasmic release and nuclear import of the vRNP $(76,77)$. IAV utilizes host nuclear import factors to facilitate the importation of vRNP into the nucleus (76).

IAV genome consists of an aggregate of eight individual, negative-sense vRNP complexes which encodes a total of 11 viral genes including neuraminidase (NA), M1, M2, HA, nucleoprotein (NP), non-structural protein 1 (NS1), nonstructural protein 2 (NS2), polymerase acidic protein (PA), polymerase basic protein 1 ( $\mathrm{PB} 1)$, polymerase basic protein 2 (PB2), and polymerase basic protein 1-F2 (PB1-F2) (78). Each of the vRNP are wrapped around multiple copies of NP and are collectively held together by the heterotrimeric viral polymerase, consisting of the PB1, PB2, and PA $(76,78)$. The heterotrimeric viral RNA-dependent RNA polymerase catalyzes the replication of $\mathrm{vRNP}$ in a reaction that involves an initial synthesis of a complimentary RNA which serves as template for synthesis of the new viral ribonucleic acid (RNA) (76). IAV polymerases also produce messenger ribonucleic acid (mRNA) transcript from each of the vRNP. The presence of splice sites on some IAV mRNA transcripts triggers the host cell spliceosome to generate spliced transcripts such as those that encodes M2 and NS2 from IAV $\mathrm{M}$ and NS mRNA transcripts, respectively. The IAV mRNA transcripts are subsequently exported to the cytoplasm and are translated using both endoplasmic reticulum-associated and cytosolic host ribosomes (76). Some of the synthesized viral proteins such as NS1, NS2, and M1 are exported to the nucleus to facilitate the replication and transcription of viral genome (76). Other viral proteins such as NA, HA, and M2 are exported to the plasma membrane where they are used alongside with newly synthesized vRNPs to produce progeny IAV virions (76). The newly assembled IAV virons subsequently buds off from host cell in a process catalyzed by NA (76).

\section{Life Cycle of RSV}

An overview of RSV life cycle is illustrated in Figure 6. RSV genome consist of a single stranded negative-sense RNA which codes for 11 viral proteins (79). RSV RNA-dependent RNA polymerase (RSV-L) encapsulates RSV RNA, RSV nucleoprotein (RSV-N) and RSV phophoprotein (RSV-P) to form the helical RSV ribonucleoprotein (RSV-RNP) complex (80). The transmembrane RSV glycoprotein (RSV-G), RSV fusion protein (RSV-F), and RSV hydrophobic protein (RSV-SH), localized on the surface coats of RSV, functions to attach of RSV to bronchial epithelial cell-resident receptor proteins such as, CX3C chemokine receptor 1 , toll-like receptor 4 , and heparan sulfate proteoglycan $(80,81)$.

Binding of RSV to host cell triggers the endocytosis and internalization of intact RSV into host cells (82). RSV-RNP subsequently associates with inclusion bodies which are localized near the cellular membranes and golgi apparatus $(81,82)$. The inclusion body-RSV-RNP complex forms active replication and transcription units of RSV since they contain viral proteins such as RSV-N, RSV matrix M2-1 (RSV-M2-1), RSV-L, RSV$\mathrm{P}$, and genomic RNA as well as other host factors (inherited from previously infected cells) required for the transcription and replication of RSV genome (81).

RSV-L can generate both RSV mRNA transcripts as well as synthesize full length positive sense antigenomes. The prevailing activity at any given time appears to be regulated by RSV matrix M2-2 (RSV-M2-2) protein which senses the pool of viral proteins (81). Accumulation of viral proteins favors the synthesis of full length positive sense RSV antigenome which forms a template for the synthesis of negative sense RSV genome (81). The generated 
TABLE 1 | Summary table of included in vitro studies.

\begin{tabular}{|c|c|c|c|c|c|c|}
\hline Antiviral PDFGS & Sources & $\begin{array}{l}\text { Susceptible Virus/host } \\
\text { organism }\end{array}$ & Antiviral effect & $\begin{array}{l}\text { Effective antiviral concentration, } \\
\text { cytotoxicity, and selectivity index }\end{array}$ & Antiviral targets & References \\
\hline DMO-CAP & Artemisia rupestris & $\begin{array}{l}\text { IAV (H1N1, H3N2)/MDCK and } \\
\text { RAW } 264.7 \text { cells }\end{array}$ & CPE reduction (IC50) & $\begin{array}{l}31.78-42.91 \mu \mathrm{M}(\mathrm{CC} 50=223 \mu \mathrm{M}) \mathrm{SI} \\
=7.02,5.20\end{array}$ & $\begin{array}{l}\text { Viral replication, } \\
\text { Viral-induced cytotoxicity, } \\
\text { Host defense }\end{array}$ & (42) \\
\hline Curcumin & & IAV (H1N1)/human macrophage & $\begin{array}{l}\text { Significant reduction in } \\
\text { different cytokines }\end{array}$ & $\begin{array}{l}80 \mu \mathrm{M} \text {, no effect on macrophage } \\
\text { viability. }\end{array}$ & Viral-induced cytotoxicity & (43) \\
\hline Gallic, Chlorogenic, Caffeic acid & & HCoV-NL63/LLC-MK2 & Plague reduction (IC50) & $\begin{array}{l}\text { Gallic: } 71.48 \mu \mathrm{M}(\mathrm{CC} 50>500 \mu \mathrm{M}) \\
\text { Chlorogenic: } 43.45 \mu \mathrm{M}(\mathrm{CC} 50 \\
>500 \mu \mathrm{M}) \\
\text { Caffeic: } 3.54 \mu \mathrm{M}(\mathrm{CC} 50>500 \mu \mathrm{M})\end{array}$ & Viral-host interaction & (44) \\
\hline $\begin{array}{l}\text { Hamamelis virginiana tannins } \\
\text { extracts, Polyphenols (Gallic acid, } \\
\text { Pentagalloylglucose, tannic acid, } \\
\text { EGCG) }\end{array}$ & Hamamelis virginiana & IAV (H1N1)/A549 & GFP reduction (IC50) & $\begin{array}{l}\text { Extract: } 1.1-36.2 \mu \mathrm{g} / \mathrm{ml} \\
\text { (CC50 = 223-968 } \mu \mathrm{g} / \mathrm{ml}) \\
\text { Polyphenols: } 5.6-18.3 \mu \mathrm{g} / \mathrm{ml}(\mathrm{CC} 50 \\
144-733 \mu \mathrm{g} / \mathrm{ml}) \\
\mathrm{SI}=15.2-85\end{array}$ & $\begin{array}{l}\text { Virus-host interaction, Viral } \\
\text { replication }\end{array}$ & (41) \\
\hline Hibiscus sabdariffa extract & Hibiscus sabdariffa & IAV (H1N1)/MDCK & - & - & Virus-host interaction & (45) \\
\hline Phlorotannins & Brown Alga Ecklonia & $\begin{array}{l}\text { IAV (H1N1, H3N2, H9N2)/MDCK } \\
\text { cells }\end{array}$ & $\begin{array}{l}\text { Neuraminidases inhibition } \\
\text { (IC50) }\end{array}$ & $4.5-41 \mu \mathrm{M}$ & Viral replication & (40) \\
\hline $\begin{array}{l}\text { A. melanocarpa extract, Ellagic acid, } \\
\text { myricetin }\end{array}$ & Black chokeberry & $\begin{array}{l}\text { IAV (pH1N1, H1N1, H3N2), } \\
\text { IBV/MDCK }\end{array}$ & Plague reduction (60\%) & Plague reduction: 0.625 mg/ml & Viral replication & (46) \\
\hline Adlay tea & $\begin{array}{l}\text { Adlay seeds, barley seeds, } \\
\text { soybeans and cassia seeds }\end{array}$ & IAV (H1N1, H3N2) IBV/MDCK & Plaque reduction (IC50) & $\begin{array}{l}2.11-5.13 \mathrm{mg} / \mathrm{ml} \\
(\mathrm{CC} 50>40 \mathrm{mg} / \mathrm{ml}) \\
\mathrm{SI}>8, \mathrm{Sl}>19\end{array}$ & Virus-host interaction & (16) \\
\hline Peanut skin extract, Resveratrol & Arachis hypogaea $L$ & IAV (H1N1, H3N2), IBV/MDCK & Plaque reduction (IC50) & $\begin{array}{l}\text { Peanut skin: } 1.3-3.2 \mu \mathrm{g} / \mathrm{ml} \\
(C C 50=5.4-9.1 \mu \mathrm{g} / \mathrm{ml}) \\
\mathrm{Sl}=3.6-7.4 \\
\text { Resveratrol: } 5 \mu \mathrm{g} / \mathrm{ml} \\
(\text { CC50 > } 35 \mu \mathrm{g} / \mathrm{ml})\end{array}$ & Early stage & (47) \\
\hline Portulaca oleracea L. Extract & Portulaca oleracea & IAV (H1N1, H3N2)/MDCK & Plaque reduction (EC50) & $\begin{array}{l}112-220 \mu \mathrm{g} / \mathrm{ml} \\
(\mathrm{CC} 50=8,067 \mu \mathrm{g} / \mathrm{ml}) \\
\mathrm{SI}=36-71\end{array}$ & $\begin{array}{l}\text { Virus-host interaction, Viral } \\
\text { replication, Early stage }\end{array}$ & (25) \\
\hline Blackcurrant extract & Blackcurrant & $\begin{array}{l}\text { RSV, IAV, AdV, and IBV/HEp-2, } \\
\text { MDCK }\end{array}$ & Plaque reduction (IC50) & $0.13-2.54 \%$ of blackcurrant extract & Virus-host interaction & (48) \\
\hline Vit D & & RSV A2/HTBE cells & - & - & Virus-induced cytotoxicity & (49) \\
\hline Iridoid glycosides & Fructus Gardeniae & IAV (H1N1)/MDCK & $\begin{array}{l}\text { Replication reduction } \\
(58 \%)\end{array}$ & $320 \mu \mathrm{g} / \mathrm{ml}$ & $\begin{array}{l}\text { Viral replication, Virus- } \\
\text { induced cytotoxicty }\end{array}$ & (50) \\
\hline Glycyrrhizin, $18 \beta-G A$ & $\begin{array}{l}\text { G. uralensis (18ß-GA active } \\
\text { component-a gut metabolic } \\
\text { product of Glycyrrhizin) }\end{array}$ & $\begin{array}{l}\text { RSV (Long strain)/HEp-2, A549 } \\
\text { cells }\end{array}$ & Plaque reduction (IC50) & $\begin{array}{l}4.3-4.5 \mu \mathrm{g} / \mathrm{ml} \\
\text { CC50 }(71.5-76.3 \mu \mathrm{g} / \mathrm{ml}) \\
\mathrm{SI}=15.9-26.8\end{array}$ & $\begin{array}{l}\text { Early stage, Virus -host } \\
\text { interaction, Host defense }\end{array}$ & (20) \\
\hline
\end{tabular}


TABLE 1 | Continued

\begin{tabular}{|c|c|c|c|c|c|c|}
\hline Antiviral PDFGS & Sources & $\begin{array}{l}\text { Susceptible Virus/host } \\
\text { organism }\end{array}$ & Antiviral effect & $\begin{array}{l}\text { Effective antiviral concentration, } \\
\text { cytotoxicity, and selectivity index }\end{array}$ & Antiviral targets & References \\
\hline $\begin{array}{l}\text { Isorhamnetin, Quercetin, Kaempferol, } \\
\text { Diosmetin, Eriodictyol }\end{array}$ & & IAV/MDCK & CPE reduction (EC50) & $\begin{array}{l}23-115 \mu \mathrm{M} \\
(\mathrm{CC} 50>245 \mu \mathrm{M}) \\
\mathrm{SI}=2-12\end{array}$ & $\begin{array}{l}\text { Virus-induced cytotoxicity, } \\
\text { Viral replication, Virus-host } \\
\text { interaction, early stage, } \\
\text { post-infection }\end{array}$ & (51) \\
\hline $\begin{array}{l}\text { G. thunbergii extract, Geraniin (an } \\
\text { ellagitannin) }\end{array}$ & G. thunbergii & IAV (H3N2, H2N1), IBV/MDCK & $\begin{array}{l}\text { Neuraminidase Inhibition } \\
\text { (IC50) }\end{array}$ & $\begin{array}{l}10.9-135 \mu \mathrm{g} / \mathrm{ml} \text { (100\% cell viability at } \\
400 \mu \mathrm{g} / \mathrm{ml})\end{array}$ & $\begin{array}{l}\text { Viral protein synthesis, Viral } \\
\text { replication, post-infection }\end{array}$ & (52) \\
\hline Isocorilagin (an ellagitannin) & Canarium album & IAV (H3N2, H2N1), IBV/MDCK & Plaque reduction (IC50) & $\begin{array}{l}4.64-23.7 \mu \mathrm{M}(\mathrm{CC} 50=263.3 \mu \mathrm{M}) \\
\mathrm{SI}=11.1-56.75\end{array}$ & $\begin{array}{l}\text { Viral replication, Viral protein } \\
\text { synthesis, post-infection }\end{array}$ & (53) \\
\hline Ellagic acid & Strictinin, Pu'er tea & IAV (H1N1)/MDCK & Plaque reduction (50\%) & Ellagic acid: $6 \mu \mathrm{M}$ & Viral replication & (54) \\
\hline Z. officinale extract & Z. officinale & $\begin{array}{l}\text { RSV (long strain)/HEp-2 and } \\
\text { A549 }\end{array}$ & Plaque reduction (IC50) & $\begin{array}{l}73.3-144.9 \mu \mathrm{g} / \mathrm{ml} \\
(\mathrm{CC} 50=1893.8 \mu \mathrm{g} / \mathrm{ml}) \\
\mathrm{SI}=13.15\end{array}$ & $\begin{array}{l}\text { Virus-host interaction, } \\
\text { Virus-induced cytotoxicity, } \\
\text { Viral replication }\end{array}$ & (19) \\
\hline Quercetin, H. cordata extract & H. cordata & $\begin{array}{l}\text { MHV (Surrogate for } \\
\text { coronavirus)/CCL9.1 cells }\end{array}$ & Plaque reduction (IC50) & $\begin{array}{l}\text { Quercetin: } 125 \mu \mathrm{g} / \mathrm{ml}(\mathrm{CC50}= \\
116 \mu \mathrm{g} / \mathrm{ml}) \\
\mathrm{Sl}=0.93 \\
\text { Houttuynia: } 0.98 \mu \mathrm{g} / \mathrm{ml} \\
(\text { CC50 }>3.91 \mu \mathrm{g} / \mathrm{ml}) \mathrm{Sl}>4\end{array}$ & - & (21) \\
\hline Quercetin 3-rhamnoside & H. cordata & IAV/MDCK & CPE reduction (65\%) & $10 \mu \mathrm{g} / \mathrm{ml}(95 \%$ viable at $100 \mu \mathrm{g} / \mathrm{ml})$ & Viral replication & (28) \\
\hline Curcumin & Curcuma longa L & $\begin{array}{l}\text { IAV (H1N1, } \\
\text { H9N2,H5N1,H3N2)/MDCK }\end{array}$ & Plaque reduction (EC50) & $\begin{array}{l}21.36 \mu \mathrm{g} / \mathrm{ml} \\
(\mathrm{CC} 50=140.67 \mu \mathrm{g} / \mathrm{ml}) \\
\mathrm{SI}=12.88\end{array}$ & $\begin{array}{l}\text { Viral replication, Viral protein } \\
\text { synthesis, Virus-host } \\
\text { interaction, Virus-induced } \\
\text { cytotoxicity }\end{array}$ & (10) \\
\hline $\begin{array}{l}\text { R. acetosa Extract, EGCG, } \\
\text { Procyanidin B2 digallate }\end{array}$ & R. acetosa & IAV (H1N1)/MDCK & $\begin{array}{l}\text { Rumex Extract: Plaque } \\
\text { reduction (68\%) } \\
\text { EGCG: Plaque reduction } \\
\text { (80\%) } \\
\text { Procyanidin: Plaque } \\
\text { reduction (80\%) }\end{array}$ & $\begin{array}{l}\text { Rumex Extract: } 0.1 \mu \mathrm{g} / \mathrm{ml} \\
(\mathrm{CC50}=80 \mu \mathrm{g} / \mathrm{ml}) \\
\text { SI }=32,36 \\
\text { EGCG: } 2 \mu \mathrm{M} \\
\text { (CC50 > } 200 \mu \mathrm{M}) \\
\text { Procyanidin: } 0.2 \mu \mathrm{M} \\
\text { (CC50 = } 191 \mu \mathrm{M})\end{array}$ & Viral-host interaction & (55) \\
\hline Black tea & Black Tea & IAV/Chicken egg & $\begin{array}{l}\text { Heamagglutination } \\
\text { inhibition (IC50) }\end{array}$ & $0.41-2 \mathrm{mg} / \mathrm{egg}$ & & (56) \\
\hline Edible bird's nest (EBN) extract & Edible bird's nest & IAV/(H1N1, H3N2)/MDCK & CPE reduction (IC50) & $36-464 \mu \mathrm{g} / \mathrm{ml}$ & Virus-host interaction & (57) \\
\hline Polysaccharide extract & Marine Algae (Ulva lactuca) & IAV/(H1N1, H2N2,H3N2)/MDCK & $\begin{array}{l}\text { Heamagglutination } \\
\text { inhibition (MIC50) }\end{array}$ & $\begin{array}{l}0.12-0.5 \mu \mathrm{g} / \mathrm{ml} \\
\mathrm{SI}=8,16\end{array}$ & Virus-host interaction & (23) \\
\hline Hesperetin, Quercetin & & hPIV-3, RSV (long)/HEp-2 & $\begin{array}{l}\text { Plague reduction } \\
(76-97 \%)\end{array}$ & $200 \mu \mathrm{M}$ (No cytotoxicity at $200 \mu \mathrm{M}$ ) & $\begin{array}{l}\text { Viral replication, Viral-host } \\
\text { interaction }\end{array}$ & (58) \\
\hline Grape seed proanthocyanidin (GSP) & Grape Seed & RSV A2/A549 & - & (No cytotoxicity at $5-10 \mu \mathrm{g} / \mathrm{ml}$ ) & $\begin{array}{l}\text { Viral replication, Viral protein } \\
\text { synthesis, Virus-induced } \\
\text { cytotoxicity }\end{array}$ & (59) \\
\hline
\end{tabular}


TABLE 1 | Continued

\begin{tabular}{|c|c|c|c|c|c|c|}
\hline Antiviral PDFGS & Sources & $\begin{array}{l}\text { Susceptible Virus/host } \\
\text { organism }\end{array}$ & Antiviral effect & $\begin{array}{l}\text { Effective antiviral concentration, } \\
\text { cytotoxicity, and selectivity index }\end{array}$ & Antiviral targets & References \\
\hline EGCG & Green tea & IAV (H1N1, H3N2), IBV/MDCK & CPE reduction (EC50) & $\begin{array}{l}5.7-17.3 \mu \mathrm{M} \\
(\mathrm{CC} 50>60,195 \mu \mathrm{M}) \\
\mathrm{SI}=19.6\end{array}$ & $\begin{array}{l}\text { Viral replication, Viral-host } \\
\text { interaction, }\end{array}$ & (22) \\
\hline $\begin{array}{l}\text { Isoquercetin, Quercetin, Fisetin, } \\
\text { resveratrol, EGCG }\end{array}$ & & IAV (H1N1, H3N2), IBV/MDCK & CPE reduction (EC50) & $\begin{array}{l}1.2-48 \mu \mathrm{M}(\mathrm{TD} 5045-200 \mu \mathrm{M}) \\
\mathrm{SI}=1.5-38\end{array}$ & $\begin{array}{l}\text { Viral replication, Viral protein } \\
\text { synthesis, Virus-induced } \\
\text { cytotoxicity }\end{array}$ & (29) \\
\hline Germacrone & Rhizoma Curcuma & $\begin{array}{l}\text { IAV (H1N1, H3N2), IBV/MDCK, } \\
\text { A549 }\end{array}$ & $\begin{array}{l}\text { MDCK: CPE reduction } \\
\text { (EC50) } \\
\text { A549: CPE } \\
\text { reduction (EC50) }\end{array}$ & 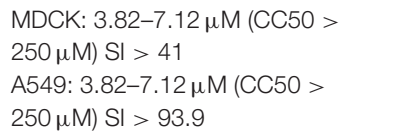 & $\begin{array}{l}\text { Viral replication, Viral protein } \\
\text { synthesis, Virus-host } \\
\text { interaction }\end{array}$ & (60) \\
\hline Sulphated polysaccharide extract & $\begin{array}{l}\text { Edible blue-green algae } \\
\text { (Aphanothece sacrum) }\end{array}$ & IAV(H1N1)/MDCK & Plague reduction (IC50) & $\begin{array}{l}1.2 \mu \mathrm{g} / \mathrm{ml}(\mathrm{CC} 50=7,100 \mu \mathrm{g} / \mathrm{ml}) \mathrm{SI}= \\
6,200\end{array}$ & Virus-host interaction & (61) \\
\hline $\begin{array}{l}\text { 3,4-dicaffeoylquinic acid and } \\
\text { 3,5-dicaffeoylquinic acid }\end{array}$ & Youngia japonica & $\begin{array}{l}\text { RSV (Long strain)/Human } \\
\text { epithelial type } 2 \text { (HEp-2) cells }\end{array}$ & CPE reduction (IC50) & $\begin{array}{l}0.5 \mu \mathrm{g} / \mathrm{ml} \text { (No cytotoxicity up to } \\
100 \mu \mathrm{g} / \mathrm{ml})\end{array}$ & Viral replication & (62) \\
\hline Glycosyl Hesperidin & & IAV (H1N1, H3N2)/MDCK & $\begin{array}{l}\text { Viral titer reduction } \\
(32-60 \%)\end{array}$ & $\begin{array}{l}12 \mathrm{mM} \text { (No cytotoxicity from } 0 \text { to } \\
25 \mathrm{mM})\end{array}$ & Viral replication & (63) \\
\hline $\begin{array}{l}\text { Extracts from } A \text {. digitata fruit, seed } \\
\text { leaves }\end{array}$ & A. digitata (Baobab) & $\begin{array}{l}\text { RSV/H-1 cells } \\
\text { IAV (H3N2)/MDCK }\end{array}$ & CPE reduction (MIC50) & $\begin{array}{l}\text { RSV: } 16.2 \mu \mathrm{g} / \mathrm{ml} \\
\text { IAV: } 0.12 \mu \mathrm{g} / \mathrm{ml} \\
\text { (cytotoxic at > } 130 \mu \mathrm{g} / \mathrm{ml} \text { ) }\end{array}$ & Host defense & (64) \\
\hline $\begin{array}{l}\text { Acteoside (phenylpropanoid } \\
\text { glycoside) }\end{array}$ & Kuding Tea & IAV (H1N1)/Primary lymphocytes & - & $\begin{array}{l}\text { no cytotoxicity between } 1.25 \text { and } \\
160 \mu \mathrm{M}\end{array}$ & Host defense & (65) \\
\hline Green tea, Guava tea & $\begin{array}{l}\text { Green tea leaves, Guava } \\
\text { leaves }\end{array}$ & IAV (H1N1)/MDCK & $\begin{array}{l}\text { Neuraminidase Inhibition } \\
\text { (IC50) }\end{array}$ & $\begin{array}{l}\text { Green tea: } 0.25-1.44 \% \\
\text { Guava tea: } 0.002-0.58 \% \\
\text { no cytotoxicity at } 25 \%\end{array}$ & $\begin{array}{l}\text { Viral replication, Virus-host } \\
\text { interaction }\end{array}$ & (66) \\
\hline Lectin-like compounds & Japanese plum fruit & IAV (H3N2)/MDCK & Plague reduction (IC50) & $\begin{array}{l}0.53-6.35 \mu \mathrm{g} / \mathrm{ml} \\
(1,000 \mu \mathrm{g} / \mathrm{ml} \text { no cytotoxicity) }\end{array}$ & Viral-host interaction & (67) \\
\hline Cirsimaritin & Artemisia scoparia & IAV (H3N2, H1N1)/MDCK & CPE reduction (IC50) & $\begin{array}{l}5.8-11 \mu \mathrm{g} / \mathrm{ml}(\mathrm{TC} 50=153 \mu \mathrm{g} / \mathrm{ml}) \\
\mathrm{SI}=13.8-26.4\end{array}$ & $\begin{array}{l}\text { Viral replication, Viral protein } \\
\text { synthesis, Virus-induced } \\
\text { cytotoxicity }\end{array}$ & (68) \\
\hline $\begin{array}{l}\text { Tangeretin, polymethoxylated } \\
\text { flavones extract }\end{array}$ & $\begin{array}{l}\text { Guangcheni (Citrus } \\
\text { reticulata) }\end{array}$ & RSV (A2, B)/HEp-2 cells & $\begin{array}{l}\text { Tangeretin: Plague } \\
\text { reduction (IC50) } \\
\text { Extract: CPE } \\
\text { reduction (IC50) }\end{array}$ & $\begin{array}{l}\text { Tangeretin: } 5.4-7 \mu \mathrm{M}(\mathrm{CC} 50= \\
375-413 \mathrm{MM}) \\
\text { Extract: } 6.7-15 \mu \mathrm{M} \\
(\mathrm{CC50}=252-417 \mu \mathrm{M}) \\
\mathrm{SI}=16.4-62.3\end{array}$ & Viral replication & (69) \\
\hline Quercetin & & IAV (H3N2, H1N1)/MDCK & CPE reduction (IC50) & $\begin{array}{l}2.74-7.76 \mu \mathrm{g} / \mathrm{ml} \\
\text { (No cytotoxicty at } 250 \mu \mathrm{g} / \mathrm{ml} \text { ) }\end{array}$ & $\begin{array}{l}\text { Viral replication, Viral protein } \\
\text { synthesis, Virus-induced } \\
\text { cytotoxicity }\end{array}$ & (70) \\
\hline Geniposide & Gardenia jasminoides fruit & IAV (H1N1)/MDCK & $\begin{array}{l}\text { MDCK: CPE reduction } \\
\text { (IC50) }\end{array}$ & $\begin{array}{l}\text { MDCK: } 87.68 \mu \mathrm{mol} / \mathrm{L} \\
(95 \% \text { viable at } 1,040 \mu \mathrm{mol} / \mathrm{L})\end{array}$ & Viral replication & (71) \\
\hline
\end{tabular}




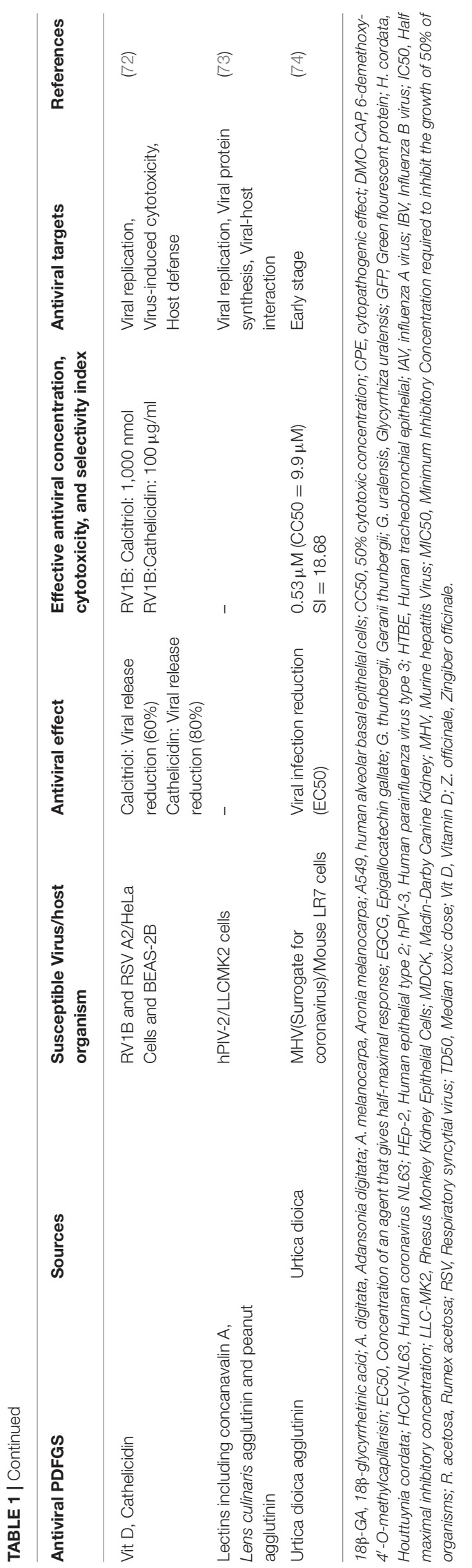

RSV mRNA transcript are subsequently translated with host ribosome complex (81).

Some of the RSV proteins promote further proliferation and infectivity of RSV. For instance, RSV-N mediated inhibition of PKR leads to an unrestricted replication of RSV genome (81). RSV-N protein is known to interacts with MDA and RIG-1, within the inclusion bodies, hereby suppressing innate immune response to RSV (83). RSV non-structural protein 2 (RSV-NS2) have been reported to mediate the sloughing of infected and dead epithelial cells from the upper respiratory tract to the lower respiratory tract region hereby increasing RSV transmission to the lower respiratory tract (81).

\section{PDFGS Suppressed IAV Host Entry}

The data presented in this review showed that different PDFGS interfered with the different stages of IAV lifecycle (Figure 5). Several PDFGS interfered with IAV entry into host cells (Table 4). PDFGS such as edible bird nest (EBN) extracts, lectinlike compounds from Japanese plum, green tea, guava tea, isorhamnetin, tannins, HS, and polysaccharides from marine algae suppressed IAV-host cellular interactions through the inhibition of viral HA activities $(41,45,51,57,66,67)$. PDFGS such as Portulaca oleracea (P. oleracea) extracts, quercetin and EBN are able to prevent virus-host interaction by binding with strong affinity to the surface coats of IAV $(25,57$, 70). Yingsakmongkon (Yingsakmongkon, 2008) reported that a lectin-like compound from Japanese plum which agglutinated pig erythrocytes, prevented virus-host interaction. By virtue of their structural characteristics, lectins can potentially interact with glycoprotein on the cell surface to inhibit viral entry (73). This possibility is supported by evidence from in silico studies which predicted a more stable interactions between Galanthus nivalis agglutinin-related lectins and sialic acid resides of host cells, than with IAV HA (84).

Some PDFGS like epigallocatechin gallate (EGCG) can damage viral surface coat, as such, preventing an efficient virushost interactions (22). In silico analysis by Derksen et al. (55), predicted that procyanidin B2-di-gallate, procyanidin B2, EGCG, and epicatechin had good binding affinity to regions of IAV HA which is responsible for binding to host's sialic acids. The study predicted a better binding affinity for procyanidins that has increased levels of polymerization and galloylation. As such procyanidin B2-di-gallate was predicted to have a better binding affinity with IAV HA than procyanidin B2, EGCG and epicatechin (55). Other computational studies such as those by Ou et al. (85), predicted that curcumin can block the interactions between IAV HA and its cognate receptors by occupying regions on IAV HA responsible for its interaction with host sialic acid residues. Inhibition of viral entry will prevent further propagation of viruses, as such presents an attractive therapeutic target against viruses (70).

\section{PDFGS Suppressed IAV Replication, Transcription, and Proliferation}

The data presented in this review shows that certain PDFGS inhibited the proliferation of IAV by interfering with IAV transcription and replication (Table 2). PDFGS such as quercetin 


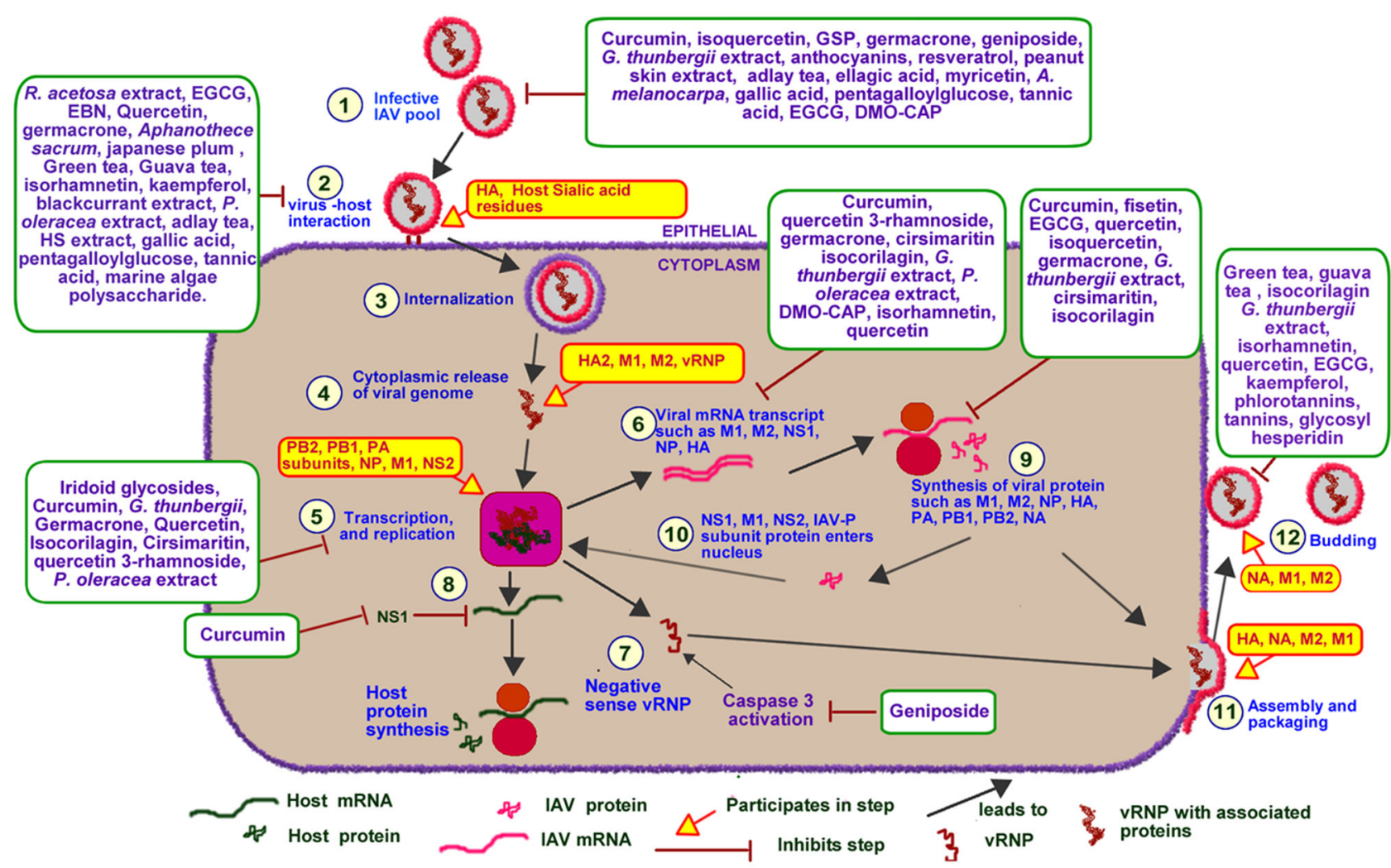

FIGURE 5 | Effect of PDFGS on different stages of IAV lifecycle. Infective IAV enters cellular environment following exposure (1). It interacts with the sialic acid residues of host membrane glycoprotein using its HA protein (2). The virus is internalized into the cytoplasm in a clarithin-dependent and independent mechanism (3). Increased acidic ph of the endosome triggers the activation of M1, fusion of viral genome with the endosomal membrane and release of viral genome into the cytoplasm (4). The viral RNA enters the nucleus where it utilizes host enzymes and some viral proteins such as PA, PB1, PB2, and NP for replication and transcription of viral genome (5). This leads to the production of viral mRNA transcripts (6), viral full length negative sense viral RNA (7), and suppression of host mRNA and protein synthesis (8). The viral mRNA is translated with the host protein synthesis apparatus (9). Some of the synthesized viral proteins are exported to the nucleus to facilitate the transcription and replication of viral genome (10). The others are packaged alongside with viral RNA strands into infective IAV particles (11). The infective IAV buds off from the cell into extracellular spaces and perpetuate further viral infections (12). Different PDFGS as shown in the image, are able to reduce IAV cellular titer, inhibit IAV host interaction, IAV cytoplasmic release, IAV transcription and replication, IAV mRNA transcript and protein synthesis, IAV assembly, packaging, and budding. A. melanocarpa, Aronia melanocarpa; DMO-CAP, 6-demethoxy-4'-O-methylcapillarisin; EBN, edible bird nest; EGCG, Epigallocatechin gallate; G. thunbergii, Geranii thunbergii; GSP, Grape seed proanthocyanidin; HA, hemagglutinin; HA2, Fusion peptide; HS, Hibiscus sabdariffa; IAV-P, IAV polymerase; M1, Matrix protein 1; M2, matrix protein 2; NA, Neuraminidase; NP, nucleoprotein; NS1, Non-structural protein 1; NS2, Non-structural protein 2; P. oleracea, Portulaca oleracea; PA, Polymerase acidic protein; PB1, Polymerase basic protein 1; PB2, Polymerase basic protein 2; R. acetosa, Rumex acetosa; vRNP, Viral ribonucleoprotein.

3-rhamnoside, cirsimaritin, P. oleracea, and 6-demethoxy-4'-Omethylcapillarisin (DMO-CAP) were observed to suppress the generation of mRNA transcripts of IAV matrix protein (IAV-M) in IAV-infected cultured cells $(25,28,42,68)$. Quercetin, Geranii thunbergii (G. thunbergii) extract and isocorilagin were also shown to inhibit the expression of IAV HA mRNA transcripts in IAV infected MDCK cells $(52,53,70)$. G. thunbergii and curcumin were also observed to suppress the levels of IAV NS1 mRNA transcript in in-vitro models $(52,60)$. Suppression of IAV polymerase activities were also reported by Guo et al. (50) following treatments of IAV exposed cells with iridoid glycosides. Suppression of IAV mRNA expression by these PDFGS is suggestive of an impaired IAV transcription and replication activities.

Evidence from this review further showed that PDFGS such as germacrone, green tea, guava tea, isocorilagin, G. thunbergii, isorhamnetin, quercetin, kaempferol, glycosyl hesperidin, EGCG, gallic acid, pentagalloylglucose, and tannic acid inhibited IAV NA activities in infected cell lines $(41,51-53,60,63,66)$. Inhibition of viral NA activities could lead to, or suggest an impaired release of infective progeny IAV virions (87) as well as limits IAV's ability to infect new cells by interfering with the attachment of IAV to host cells $(88,89)$. Reduction in IAV NA activities following treatments with phlorotannins and tannins have been associated with concomitant reduction in IAV titer $(40,41)$.

Inhibition of IAV NA by flavonoids is further supported by evidences from molecular docking stimulations. Such computational studies predicted strong inhibitory binding affinity between different flavonoids and the active sites of IAV NA (90-93). For instance, computational studies by Kannan and Kolandaivel (2018) predicted a stronger interaction between IAV NA and cyanidin-3-sambubiocide, than between oseltamivir-and 


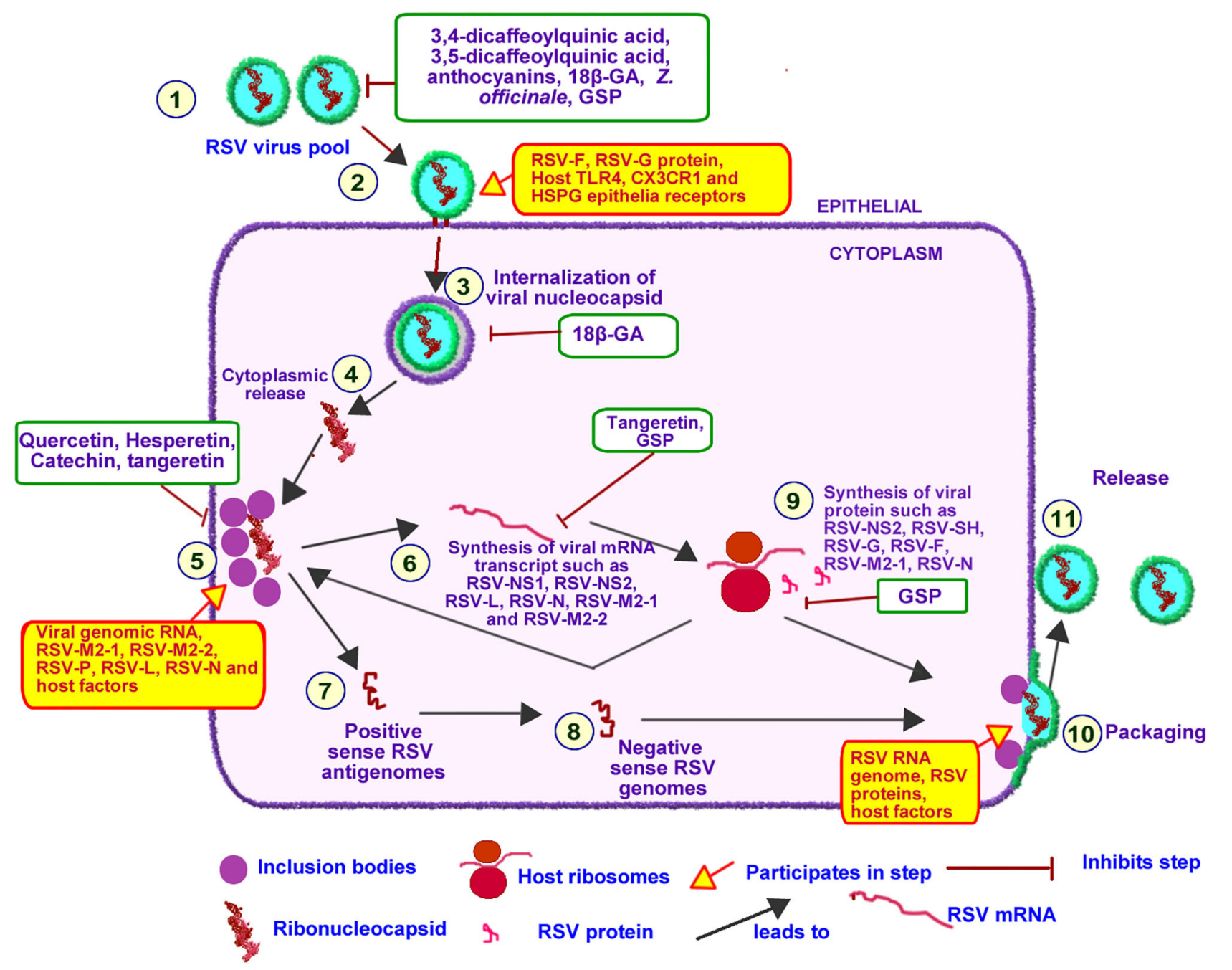

FIGURE 6 | Effect of PDFGS on different stages of RSV lifecycle. Infective RSV gets into the respiratory tract following exposure to RSV viruses (1). RSV interacts with epithelial receptor proteins such as TLR4, CX3CR1 and HSPG using its RSV-F, RSV-G, and RSV-SH proteins (2). Intact RSV enters the host cytosol in an endosome (3). RSV nucleocapsid is released into the cytoplasm (5). Replication and transcription of RSV genome takes place at the inclusion bodies leading to the production of viral mRNA transcript (6) or full length positive sense antigenomes(7) following regulatory control by RSV M2-2. The positive sense antigenome is used as a template to generate the negative sense viral genome (8). The viral mRNA transcript is translated with the host mRNA translation apparatus (9). The negative sense viral RNA genome is packaged alongside with some viral proteins and other host factors required for RSV infectivity (10) this eventually buds off (11) into the pool of infective RSV. PDFGS reduced the cellular pool of infective RSV, suppressed RSV host receptor interaction as well as inhibited RSV internalization, replication, and

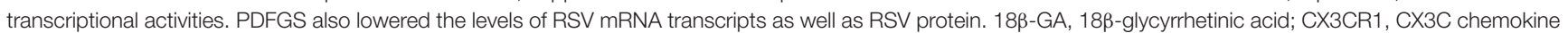
receptor 1; GSP, Grape seed proanthocyanidin; HSPG, Heparan sulfate proteoglycan; RSV, Respiratory syncytial virus; RSV-F, RSV fusion protein; RSV-G,

Glycoprotein; RSV-L, RSV RNA-dependent RNA polymerase; RSV-M2-1, RSV matrix M2-1; RSV-M2-2, RSV matrix M2-2; RSV-N, RSV nucleoprotein; RSV-NS1, RSV non-structural protein 1; RSV-NS2, RSV non-structural protein 2; RSV-P, RSV phophoprotein; RSV-SH, RSV hydrophobic protein; TLR4, Toll-like receptor 4; Z. officinale, Zingiber officinale.

IAV NA. Theaflavin found in tea leaves, was also predicted to have high inhibitory interaction with amino acids of IAV NA (94). Molecular docking studies by Chen et al. (53), predicted the potentials of isocorilagin to bind to highly conserved regions of IAV NA as such making it potentially effective against multiple strains of IAV including those resistant to existing IAV NA inhibitors.

Inhibition of IAV NA is an important therapeutic target in management of IAV infection. Oseltamivir is a commonly prescribed antiviral agent whose mode of action is based on its ability to inhibit NA activities (28). Other PDFGS shown to reduce IAV titer in experimental models of IAV infection includes DMO-CAP, Aronia melanocarpa (A. melanocarpa) extracts, ellagic acids, myricetin, adlay tea, peanut skin extract, resveratrol, $P$. oleracea, anthocyanin, isorhamnetin, gallic acid, geniposide, isoquercetin, and curcumin $(16,25,29,42,46-48,51$, $54,71)$. Taken together, these pieces of evidence show that PDFGS are capable of suppressing IAV proliferations in vitro. 
TABLE 2 | Effect of PDFGS on viral replication.

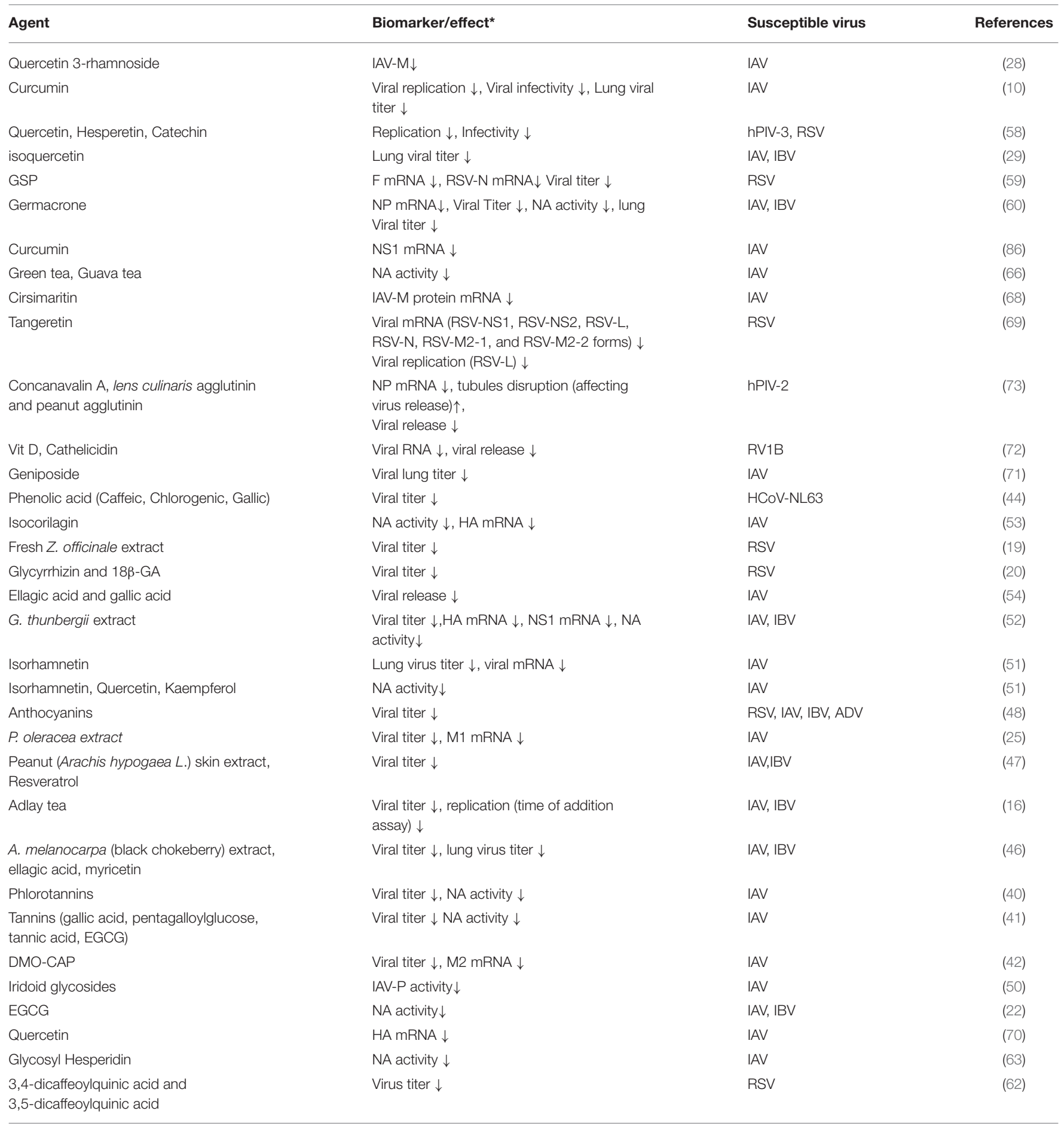

*only effects that are significantly different from the control are shown; $\downarrow$ Parameter is significantly lower than the untreated virally-infected model; $\uparrow$ Parameter is significantly higher than the untreated virally- infected model.

A. melanocarpa, Aronia melanocarpa; DMO-CAP, 6-demethoxy-4'-O-methylcapillarisin; EGCG, Epigallocatechin gallate; F, Fusion protein; G. thunbergii, Geranii. thunbergii; GSP, Grape Seed Proanthocyanidin; HA, hemagglutinin; HCoV-NL63, Human coronavirus NL63; hPIV-2, Human parainfluenza virus type 2; hPIV-3, Human parainfluenza virus type 3; IAV, influenza A virus; IAV-M, IAV matrix protein; IAV-P, IAV polymerase; IBV, Influenza B virus; M1, matrix protein 1; NA, neuraminidase; NP, nucleoprotein; NS1, non-structural protein 1; P. oleracea, Portulaca oleracea; RSV, Respiratory syncytial virus; RSV-L, RSV RNA-dependent RNA polymerase; RSV-L, RSV RNA-dependent RNA polymerase; RSV-M2-1:RSV matrix M2-1; RSVM2-2, RSV matrix M2-2; RSV-N, RSV nucleoprotein; RSV-NS1, RSV non-structural protein 1; RSV-NS2, RSV non-structural protein 2; RV1B, rhinovirus 1B; Vit D, Vitamin D; Z. officinale, Zingiber officinale. 


\section{PDFGS Suppressed the Synthesis of IAV Proteins}

Treatments of IAV infected cells with some PDFGS were observed to suppress the expression of different IAV protein (Table 3). The reduction in the levels of viral proteins following treatments of IAV infected cells with PDFGS suggests that these PDFGS either inhibited the synthesis of such proteins or inhibited IAV proliferation. This is evident from studies that associated the reduction in IAV protein synthesis with a reduced IAV titers, following treatments with germacrone, G. thunbergii extract, and isoquercetin (29, 52, 60). IAVinfected cells that were treated with PDFGS such as germacrone, quercetin, G. thunbergii extract and isocorilagin reduced the levels of IAV NP $(29,52)$. Viral NP functions in protecting viral genomes, facilitating viral entry, evasion of host immune responses and in the expression of viral genes (95). NP also appears to be an elongation factor for the activity of viral RNA polymerase which functions in the replication of the viral RNA genome (96). Suppression of viral NP by PDFGS would therefore impair several viral functions including viral replication, hereby leading to reduction in viral load. Treatments of IAV infected cells with EGCG, quercetin, isoquercetin and G. thunbergii extracts suppressed the levels of HA protein $(29,52)$. Reduction in HA protein levels would impair the assembly and budding processes of progeny IAV virions (76). Reductions in $\mathrm{HA}$ is also potentially capable of impairing the interactions between IAV and host glycoprotein receptors (76).

Inhibition of viral polymerase activities have been observed in IAV-infected cells following treatments with iridoid glycosides (50). G. thunbergii extract was also reported to lower the levels of IAV polymerase transcript products including PA, PB1, and PB2 (52). Reduction in individual subunits of IAV polymerase would further impair the transcription and replication of IAV genome. It would also impair other specific functions of the individual polymerase subunits. For instance, PA-X (a transcript product of PA gene), is known to selectively shuts down the expression of host protein, enhance degradation of host mRNA and suppresses host antiviral responses (3). Therefore, reduction in the expression of PA proteins following treatments with $G$. thunbergii extract may likely impair IAV's ability to suppress host protein synthesis.

The evidence presented in this review shows that some PDFGS suppressed the expression of IAV M1 and M2 proteins in IAV infected cells (Table 3). The IAV-M gene encodes M1 and M2 protein which functions in the stabilization of RNP complex, viral replication and viral budding process $(6,97)$. M2 also function in the modulation of host ion channel activities, causing a $\mathrm{pH}$ dependent alteration in the permeability of ion channels (97). Inhibition of M2 ion channel is exploited in the therapeutic management of IAV infections and forms the mode of action of the commonly prescribed antiviral drug, Amantadine (52). The abilities of PDFGS such as curcumin, cirsimaritin and $G$. thunbergii to reduce the levels of IAV M2 $(10,52,68)$ and G. thunbergii, EGCG, quercetin, isoquercetin and fisetin to reduce IAV M1 protein levels $(29,52)$ in IAV infected cells makes them potentially able to suppress IAV infectivity and proliferation.

\section{PDFGS Interfered With RSV Lifecycle}

PDFGS can interfere with different stages of RSV lifecycle Figure 6. For instance, treatments of RSV-exposed cells with $Z$. officinale extract, $18 \beta$-glycyrrhetinic acid (18 $\beta$-GA) and blackcurrant extract inhibited the attachment of RSV unto host receptor proteins and consequently reduced RSV penetration into host cells $(19,20,48)$. Quercetin was reported to interact irreversibly with RSV, as such, potentially limiting the interactions between RSV and host receptors (58). This explains the observed reduction in the infectivity of quercetin-pretreated RSV particles on tissue culture cell monolayers (TCCM) (58).

Treatment of RSV-infected cells with grape seed proanthocyanidin (GSP) suppressed the levels of RSV mRNA transcripts of fusion protein and nucleoprotein (59). Tangeretin was also reported to suppress the expression of different RSV mRNA transcripts including NS1, NS2, L, NP, M2-1, and M2-2 in RSV infected cells (69). Reduction of the mRNA synthesis is indicative of an impaired RSV transcription and replication functions. This assertion is further supported by the observed reduction in RSV replication in tangeretin treated, RSV infected A549 cells (69). Reduction in RSV replication and transcriptional activities would impair the synthesis of viral proteins as well as reduce the assembly of infective progeny RSV virions. This assertion is supported by the observed concomitant reduction of both mRNA and protein levels of RSV fusion protein following treatments with GSP (59). PDFGS such as 3,4-dicaffeoylquinic acid, 3,5-dicaffeoylquinic acid, fresh $Z$. officinale extracts, anthocyanin and $18 \beta$-GA were also shown to lower RSV titer in RSV-infected cells $(19,20,48,62)$.

\section{Effect of PDFGS on Other Respiratory Viruses}

PDFGS also interfered with the lifecycle of other respiratory viruses (Tables 2-4). Blackcurrant extract suppressed the attachment of $\mathrm{AdV}$ to cultured cell models hereby reducing $\mathrm{AdV}$ infectivity (48). Lectins such as concanavalin A, lens culinaris agglutinin and peanut agglutinin were observed to interact directly with host cell receptors hereby preventing hPIV-2 particles from accessing their cognate host receptor (73). Mannose specific plant lectins are equally capable of masking the cognate receptors of SARS coronaviruses on host cells hereby preventing a successful virus-host cell interaction (73).

Treatment of Rhesus Monkey Kidney Epithelial (LLC-MK2) cells with concanavalin A and lens culinaris agglutinin increased cytoskeletal disruption in hPIV infected cells (73). Disruption of cellular cytoskeleton can potentially interferes with hPIV-3 cellular transport, transcription and replication activities (73). Quercetin was also reported to bind irreversibly with hPIV-3 following a pretreatment of PIV with quercetin (58). This lowered the ability of hPIV-3 to infect tissue culture cell monolayers (58).

Phenolic constituents of Sambucus FormosanaNakai extract, including caffeic acid, chlorogenic acid, and gallic acid were shown to inhibit the attachment of HCoV-NL63 to LLC-MK2 cells (44). Caffeic acid possibly interacted with angiotensinconverting enzyme (ACE) and heparan sulfate on host cell surfaces hereby inhibiting the attachment of HCoV-NL63 to cellular receptors (44). Treatments of HCoV-NL63 exposed LLCMK2 cells with caffeic acid, chlorogenic acid, and gallic acid was 
TABLE 3 | Effect of PDFGS on viral protein synthesis.

\begin{tabular}{|c|c|c|c|}
\hline Agent & Biomarker/Effect* & Viruses & References \\
\hline Curcumin & $\mathrm{M} 2 \downarrow$ & IAV & $(10)$ \\
\hline Fisetin & M1 $\downarrow$ & IAV & (29) \\
\hline EGCG, Quercetin, Isoquercetin & $\mathrm{M} 1 \downarrow, \mathrm{HA} \downarrow$ & IAV & (29) \\
\hline GSP & F protein $\downarrow$ & RSV & $(59)$ \\
\hline Germacrone & $N P \downarrow$ & IAV, IBV & $(60)$ \\
\hline $\begin{array}{l}\text { Concanavalin } \mathrm{A} \text {, lens culinaris agglutinin } \\
\text { and peanut agglutinin }\end{array}$ & $\mathrm{NP} \downarrow, \mathrm{hPIV}-2-\mathrm{F} \downarrow, \mathrm{HA}-\mathrm{NA} \downarrow$ & hPIV-2 & $(73)$ \\
\hline Quercetin & $N P \downarrow$ & IAV & $(70)$ \\
\hline Cirsimaritin & M2 protein $\downarrow$ & IAV & $(68)$ \\
\hline G. thunbergii extract & $\mathrm{NP} \downarrow, \mathrm{PA} \downarrow, \mathrm{M} 1 \downarrow, \mathrm{M} 2 \downarrow, \mathrm{PB} 1 \downarrow, \mathrm{PB} 2 \downarrow, \mathrm{HA} \downarrow, \mathrm{NA} \downarrow$ & IAV, IBV & $(52)$ \\
\hline Isocorilagin (Canarium album) & $N P \downarrow$ & IAV & (53) \\
\hline
\end{tabular}

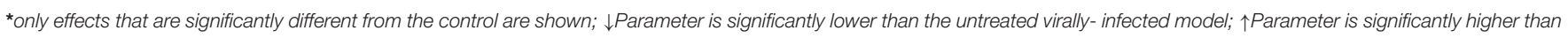
the untreated virally- infected model.

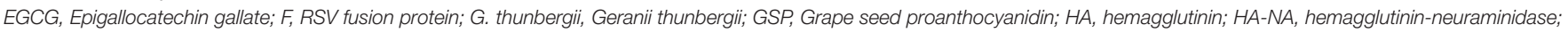

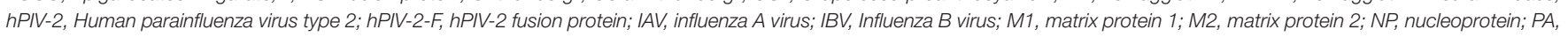
Polymerase acidic protein; PB1, Polymerase basic protein 1; PB2, Polymerase basic protein 2; RSV, Respiratory syncytial virus.

further observed to repress the release of progeny HCoV-NL63 virions (44).

Treatments of hPIV-2 infected cells with concanavalin A, lens culinaris agglutinin and peanut agglutinin significantly decreased the expression of hPIV-2 NP mRNA as well as lower the protein levels of hPIV-2 NP, hPIV-2 fusion protein (hPIV-2-F), and hPIV2 hemagglutinin-neuraminidase (73). This could adversely affect viral entry, replication and release function hereby suppressing the proliferation of hPIV-2 particles (73). Treatments of RV1B infected cells with vitamin D (Vit D) was observed to inhibit the synthesis of viral RNA as well as suppress the release of progeny RV1B virions (72). The infectivity and replication of PIVs was also suppressed following treatment of infected cells with quercetin, hesperetin, and catechin (58).

\section{Effect of PDFGS on Host Antiviral Immune Response} Cell membranes contain pattern recognition receptors (PPR) such as TLR, which senses for pathogenic associated molecular patterns (PAMP), such as viral nucleic acids, around the extracellular spaces (98). Endosomal and lysosomal membrane contains other PPR such as melanoma differentiation-associated protein 5 (MDA-5) and retinoic acid-inducible gene I (RIGI), which senses for viral nucleic acids in cytoplasmic spaces (98). The PPR (TLR, MDA-5, and RIG-1) are activated following recognition and binding of viral nucleic acids (98). Activation of PPR leads to the activation of transcription factors like Nuclear factor kappa B (NF- $\mathrm{B})$, interferon regulatory factor (IRF), activator protein-1 (AP-1) which enhances the downstream expression of type 1 and type 3 interferons, proinflammatory cytokines and ISGs $(3,98)$.

Interferons functions to eradicate viruses by enhancing the expressions of antiviral ISGs such as Myxovirus Resistance Gene A (MxA) and Myxovirus Resistance Gene B (MxB), protein kinase $\mathrm{R}$ (PKR), $2^{\prime}-5^{\prime}$ oligoadenylate synthetase (OAS), ribonuclease $\mathrm{L}$ (RNase $\mathrm{L}$ ) and IFN-induced transmembrane (IFITM) through a signal transducer and activator of transcription (STAT) 1/2, Janus kinase 1 (JAK1) and nonreceptor tyrosine-protein kinase (TYK2)-mediated signaling (3). In humans, MxA can inhibit viral transcription by binding to IAV NP (3). IFITM, largely localized on cell membranes, can prevent viral infection by interfering with virus-host cell interaction, attachment and endocytosis (3). Activated OAS enhances the degradation of viral single-stranded RNA (ssRNA) as such preventing viral replication and proliferation as well as stimulating further RIG-1 mediated antiviral responses (3). Activated PKR inhibits protein synthesis in viral infected cells (3). Detection of viral PAMP also causes the activation of NLR family pyrin domain containing 3 (NLRP3) inflammasome complexes, a component of the innate immune response. This stimulates the expression of proinflammatory interleukin $1 \beta$ (IL-1 $\beta$ ) and interleukin 18 (IL-18) and pyroptosis in a caspase 1 dependent processes $(3,99)$.

The ability of viruses to infect and propagate in host environment depends on their ability to evade host immune systems. Viral proteins such as NS1 of IAV interact with RIG-1 to inhibit its downstream activities (98). Virus-induced shutdown of protein synthesis through the activities of viral PA-X, NS1, and NS2 results in overall downregulation of proteins involved in host's antiviral immune responses such as reduced RIG-1, interferon regulatory factor 3 (IRF3), NFkB, AP-1, PKR, OAS, NLRP3 inflammasome, and poly adenine binding protein II (PABPII) activation (3). NS1 of IAV can prevent Tripartite Motif Containing 25 (TRIM25) induced inhibition of IAV RNP (98).

This review revealed that PDFGS such as Vit D, acteoside, Adansonia digitata (A. digitata) leaves extract, $18 \beta \mathrm{GA}$, and curcumin are able to boost host antiviral immune responses by upregulating various endogenous antiviral mediators (Table 5). VIt D was observed to stimulate the production of antiviral interferon-stimulated genes (ISGs) such as viperin and MxA, against RV1B in in vitro studies (72). Vit D also up-regulated the expression of cathelicidin, an endogenous antimicrobial peptide that was also shown to be virucidal against RV1B (72). Curcumin 
TABLE 4 | Effect of PDFGS on virus-host interaction \& virus-cell entry function.

\begin{tabular}{|c|c|c|c|}
\hline Agent & Targets/Effect* & Viruses & References \\
\hline Curcumin & Antiviral agent-virus binding $\uparrow$ & IAV & (10) \\
\hline R. acetosa extract, EGCG & $\begin{array}{l}\text { Antiviral agent-virus binding } \uparrow \\
\text { Viral penetration } \downarrow \\
\text { Viral attachment to host } \downarrow\end{array}$ & IAV & (55) \\
\hline EBN & $\begin{array}{l}\text { Antiviral Agent-viral interaction } \uparrow, \mathrm{HA} \text { activity } \\
\downarrow\end{array}$ & IAV & (57) \\
\hline EGCG & $\begin{array}{l}\text { Viral envelop damage } \uparrow \text {, Viral penetration to } \\
\text { host } \downarrow\end{array}$ & IAV, IBV & (22) \\
\hline Germacrone & Viral attachment to host cells $\downarrow$ & IAV, IBV & (60) \\
\hline Quercetin & Viral entry $\downarrow$ & IAV & (70) \\
\hline $\begin{array}{l}\text { Sulphated polysaccharide from } \\
\text { Aphanothece sacrum }\end{array}$ & Viral attachment to host cells $\downarrow$ & IAV & (61) \\
\hline Quercetin & Antiviral agent-virus HA2 binding $\uparrow$ & IAV & (70) \\
\hline Green tea, Guava tea & Viral heamagglutination $\downarrow$ & IAV & (66) \\
\hline Z. officinale & Viral attachment $\downarrow$, viral penetration $\downarrow$ & $R S V$ & (19) \\
\hline $18 \beta-G A$ & Viral attachment $\downarrow$, viral penetration $\downarrow$ & RSV & (20) \\
\hline Caffeic, Chlorogenic, Gallic acid & Viral attachment to host cells $\downarrow$ & HCoV-NL63 & (44) \\
\hline $\begin{array}{l}\text { Flavonoids(Isorhamnetin, quercetin, } \\
\text { kaempferol) }\end{array}$ & Viral attachment to host cells $\downarrow$ & IAV & (51) \\
\hline Isorhamnetin & HA activity $\downarrow$ & IAV & (51) \\
\hline Blackcurrant extract & Viral attachment to host cells $\downarrow$ & AdV, IBV, IAV, RSV & (48) \\
\hline
\end{tabular}

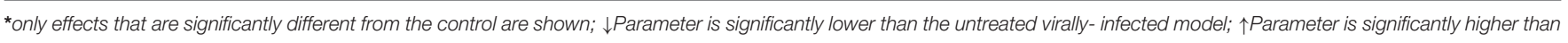
the untreated virally- infected model.

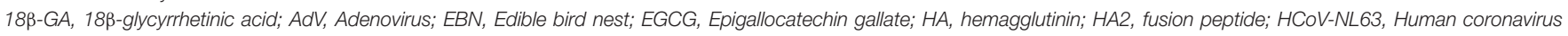

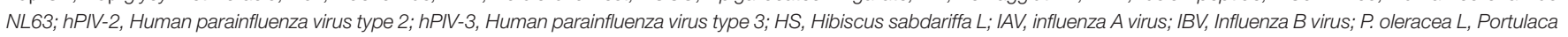
oleracea L; R. acetosa, Rumex acetosa; RSV, Respiratory syncytial virus; Z. officinale, Zingiber officinale.

enhanced the expression of interferon $\beta$ (IFN- $\beta$ ) against IAV in cultured cells (10). Extract from $A$. digitata leaves was observed to increase the expression of IL-8 in RV1A infected lung epithelial cells (64). Acteoside activated T-box expressed in T cells (T-bet) in immune cells with the resultant upregulation of interferon $\gamma$ (IFN- $\gamma$ ) expression (65). Upregulation of these endogenous immune mediators can facilitate virus clearance in infected cells.

The upregulation and activation of signaling cascades that generate endogenous antiviral molecules like interferons (IFN) and ISGs may reverse virus-induced suppression of host immune response and so facilitate the clearance of virus infected cells as well as reduce virus titer. Exogenous interferon $\alpha$ (IFN- $\alpha)$ is commonly administered with ribavirin for the treatment of different viral diseases $(100,101)$. Evidence from this review highlights the prospects of $18 \beta-\mathrm{GA}$, curcumin, Vit D and acteoside in boosting cellular immunity against respiratory viruses, through the upregulation of interferon expression.

\section{Potential Mechanism of Respiratory Virus-Induced Cytotoxicity}

Ordinarily, the TLR and RIG-1 mediated expression of immune and inflammatory mediators is a protective response to viral infection $(3,98)$. Such response is beneficial only when it is localized to the region of infection. It can however trigger a potentially life threatening "cytokine storm" if it becomes systemic (102). As such, Innate immune response is usually under strict regulation so as to ensure that cells produce sufficient but not excessive immune responses to antigens (98). Virus infections are often known to cause hyper active inflammatory responses $(103,104)$. This may be contributed in part by a 
TABLE 5 | Effect of PDFGS on host antiviral defenses.

\begin{tabular}{|c|c|c|c|}
\hline Agent & Biomarker/Effect ${ }^{*}$ & Viruses & References \\
\hline Vit D & Viperin $\uparrow, M \times A \uparrow$, Cathelicidin $\uparrow$ & RV1B & (72) \\
\hline Acteoside & IFN- $\gamma \uparrow$, T-bet $\uparrow$ & IAV & (65) \\
\hline A. digitata leaves extract & $\mathrm{IL}-8 \uparrow$ & $\mathrm{RV} 1 \mathrm{~A}$ & (64) \\
\hline $18 \beta-G A$ & Glycyrrhizin and IFN- $\beta \uparrow$ & RSV & (20) \\
\hline Curcumin & IFN- $\beta \uparrow$ & IAV & (10) \\
\hline
\end{tabular}

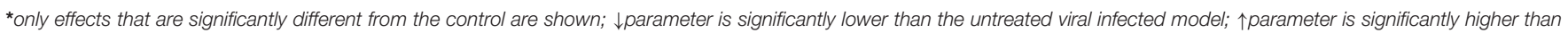
the untreated viral infected model.

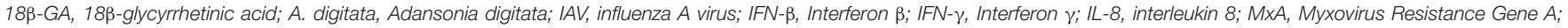
RV1B, rhinovirus 1A; RV1B, rhinovirus 1B; RSV, Respiratory syncytial virus; T-bet, T-box expressed in T cells; Vit D, Vitamin D.

dysfunctional regulation of components of cellular immunity (105) such as a dysregulated post-translational modifications of some key actuators of innate immunity (98). Virus-induced inflammations could also lead to ER stress with further generation of inflammatory mediators (106). The ability of some respiratory viruses to interfere with critical processes such as autophagy and apoptosis $(6,107)$ makes them potentially able to cause dysregulation of different cellular processes including immune responses.

Persistent inflammatory stress signals in cellular environments can lead to alteration of cellular homoeostasis which could potentially lead to increased cellular stress and various pathological consequences $(108,109)$. For instance, inflammatory conditions are known to upregulate the $\mathrm{wnt} / \beta$ catenin pathway $(110,111)$ with resultant enhancement of apoptosis (112). Increased levels of ROS have been observed in some respiratory virus infection (10). ROS have been reported to upregulate phosphatidylinositol-3-kinase (PI3K)/protein kinase B (AKT) signaling in cancer cells (111). MAPK/p38 signaling is activated under cellular stress and can enhance the generation of inflammatory cytokines and apoptosis (113-115). The result presented in this review showed that respiratory viruses promoted the activation of the AKT and MAPK/p38, Wnt3a/catenin signaling cascade $(10,86)$. Increased activity of these signaling pathways can cause endoplasmic reticulum stress and oxidative stress leading to further inflammatory response, autophagy and apoptosis as such causing further cellular damages $(106,116,117)$. A hypothetical virus-mediated processes that builds up to tissue damages is shown in Figure 7.

Increased loss of weight, lung lesions, lung index are some of the respiratory virus derived toxicity that can be promoted by sustained cellular stress conditions (118-120). For instance, COPD, which is characterized by a gradual destruction of the lung parenchyma and alveolar structures, has been associated with increased inflammatory and oxidative stress-induced damage (120). Pulmonary and systemic inflammations induced by severe acute respiratory syndrome coronavirus 2 (SARS-CoV2) infection can cause multi-organ dysfunction and consequently increases the risk of mortality in some patients (121).

\section{PDFGS Suppressed Virus-Induced Cellular Damages}

The data presented in this review showed that certain PDFGS including geniposide, acteoside, curcumin, and flavonoids can reverse respiratory virus-induced cytotoxicity and so increase the survival of virus-infected animal models (Table 6). These PDFGS reduces respiratory virus-induced pathologies by suppressing respiratory virus-induced expression of proinflammatory mediators [such as tumor necrosis factor- $\alpha$ (TNF$\alpha$ ), interleukin 6 (IL-6), IL-8, IFN- $\gamma$, inducible nitric oxide synthase (iNOS), and regulated on activation normal $\mathrm{T}$ cell expressed and secreted (RANTES) (Figure 8)]. DMO-CAP and certain flavonoids are able to suppress virus-induced generation of reactive oxygen species (ROS) and virus-induced depletion of cellular antioxidant capacities including Nrf2, heme oxygenase1 and glutathione/glutathione disulfide $(42,51)$. PDFGS such as GSP, acteoside, and curcumin inhibited virus-induced activation of potentially cytotoxic signaling cascades such as extracellular signal-regulated kinase (ERK), c-Jun N-terminal kinase (JNK) and P38 mitogen-activated protein kinase (MAPK) signaling; TLR, myeloid differentiation primary response 88 (MyD88), TIR-domain-containing adapter-inducing interferon$\beta$ (TRIF), and Tumor necrosis factor receptor (TNFR)associated factor 6 (TRAF6) signaling; IkB kinase (IKK)/NF-kB signaling; Wnt family member $3 \mathrm{a}$ (wnt3a)/ $\beta$-catenin signaling and autophagic signaling $(10,51,59,86)$. Curcumin and GSP also reduced the production of mucin proteins, pulmonary matrix metalloproteinase (MMP) and collagen (10, 59, 86).

Acteoside stimulated an increased phosphorylation of the prosurvival ERK in mice infected with IAV (65). Some PDFGS including Iridoid glycosides, certain flavonoids, curcumin were reported to reduce virus-induced weight loss, lung lesion, lung index, alveolar damages, hemolysis, cellular damages as well as improved survival rates of virus-infected animals (10, 50, 51, 70, 71). Curcumin and geniposide also suppressed virusinduced increase in the numbers of neutrophils, lymphocytes, and macrophages $(43,71)$.

The evidence collated in this review showed that PDFGS such as curcumin, flavonoids, ginger, calcitriol, iridoid glycosides, and geniposide are able to suppress respiratory virus-induced hyperactive immune and inflammatory responses together with their potential cytotoxic effects. Corticosteroids are widely used as adjuvant therapy in managing respiratory virus infection because of their anti-inflammatory and immunomodulatory properties $(122,123)$. The Suppression of AKT, wnt $3 a / \beta$-catenin and TLR signaling by curcumin $(10,86)$; MAPK signaling by curcumin, acteoside and flavonoids (10, 51, 65); IFN expression by curcumin, calcitriol, geniposide, and isoquercetin $(29,60,71,72)$ in respiratory virus exposed organisms have the 
TABLE 6 | Effects of PDFGS on virus-induced cytotoxicity.

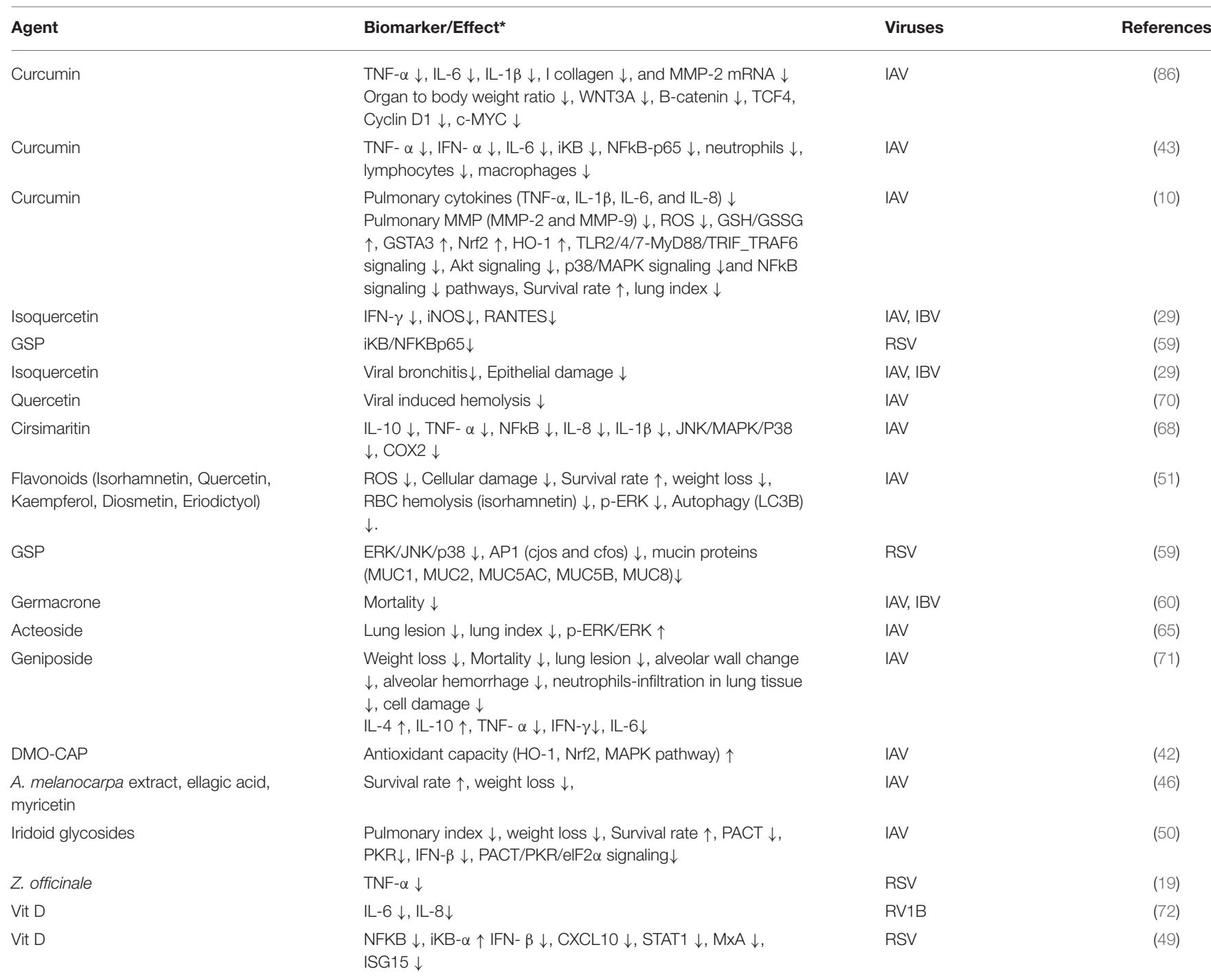

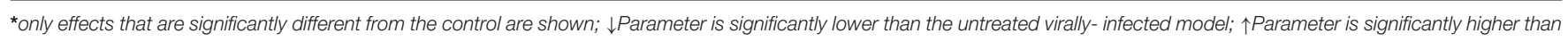
the untreated virally- infected model.

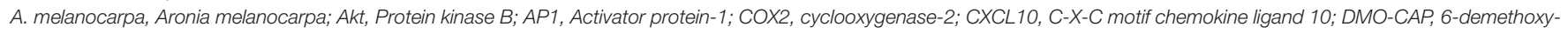

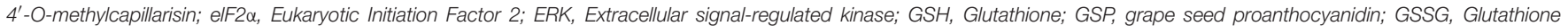

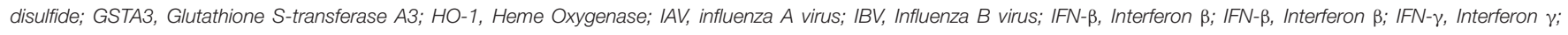

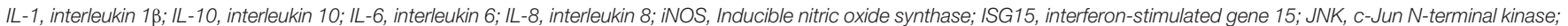

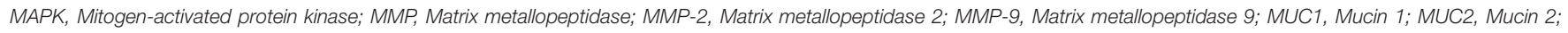

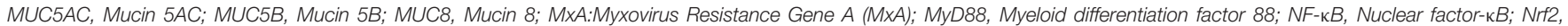

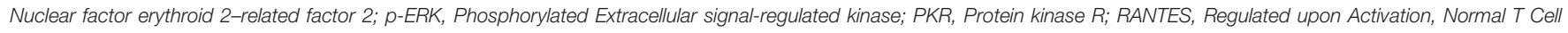

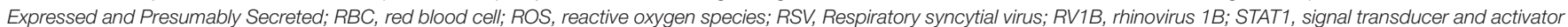

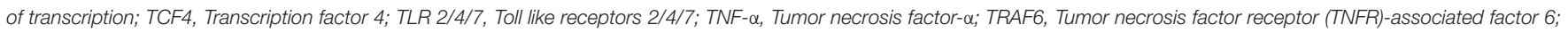
TRIF, TIR-domain-containing adapter-inducing interferon- $\beta$; Vit $D$, Vitamin $D$; wnt3a, Wnt family member 3a; Z. officinale, Zingiber officinale.

potential to suppress inflammation and its associated cellular consequences. Enhancement of cellular antioxidant capacity by some of the PDFGS such as curcumin, DMO-CAP and different flavonoids $(10,42,51)$, would reduce virus-induced oxidative stress and their potential cytotoxic effects. The cumulative effect of these PDFGS is the amelioration of viral induced cellular damages. This is evident from the observed reduction in lung lesions, pulmonary index, weight loss and lungs index as well as the increased survival rates of virus-infected organisms treated with some of the PDFGS highlighted in this review $(10,29,50,51,71)$.

\section{PDFGS Ameliorated Respiratory Viral Infections in Mice Experiments}

Data obtained from in vivo studies indicates that PDFGS equally exerted beneficial effects against mice models of 
TABLE 7 | Summary table of included in vivo studies.

\begin{tabular}{|c|c|c|c|c|c|c|c|}
\hline Antiviral PDFGS & Sources & $\begin{array}{l}\text { Susceptible Virus/host } \\
\text { organism }\end{array}$ & Intervention & Antiviral effect & $\begin{array}{l}\text { Effective antiviral } \\
\text { concentration }\end{array}$ & Antiviral targets & References \\
\hline Isoquercetin & & $\begin{array}{l}\text { mouse-adapted } \\
\text { IAV(H1N1)/mice }\end{array}$ & $\begin{array}{l}5,10 \mathrm{mg} / \mathrm{kg} / \text { day for } 8 \text { days, } \\
\text { intraperitoneally }\end{array}$ & $\begin{array}{l}\text { Reduction in lung viral titer } \\
\text { (19-folds) }\end{array}$ & $10 \mathrm{mg} / \mathrm{kg}$ & $\begin{array}{l}\text { Viral titer reduction, } \\
\text { virus-induced cytotoxicity }\end{array}$ & (10) \\
\hline Curcumin & & $\mathrm{IAV}(\mathrm{H} 1 \mathrm{~N} 1) /$ mice & $\begin{array}{l}50,150 \mathrm{mg} / \mathrm{kg} \text {, twice daily for } 6 \\
\text { days, orally }\end{array}$ & $\begin{array}{l}\text { Improved Survival rate } \\
(70 \%)\end{array}$ & $150 \mathrm{mg} / \mathrm{kg}$ & $\begin{array}{l}\text { Viral titer reduction, } \\
\text { virus-induced cytotoxicity }\end{array}$ & (29) \\
\hline Curcumin & & IAV (H1N1)/mice & $\begin{array}{l}\text { 50-400 mg/kg administered } \\
\text { daily intraperitoneally for } 4 \text { days }\end{array}$ & $\begin{array}{l}\text { Reduction immune cell } \\
\text { count }(75 \%) \\
\text { Reduction in } \\
\text { lymphocytes (66\%) }\end{array}$ & $400 \mathrm{mg} / \mathrm{kg}$ & Viral-induced cytotoxicity & (43) \\
\hline Geniposide & Gardenia jasminoides fruit & IAV (H1N1)/mice & $\begin{array}{l}5,10,20 \mathrm{mg} / \mathrm{kg} \text {, intraperitoneally } \\
\text { for } 14 \text { days }\end{array}$ & $\begin{array}{l}\text { Lung Viral titer reduction } \\
(36 \%)\end{array}$ & 20 mg/kg & $\begin{array}{l}\text { Viral replication, } \\
\text { Virus-induced cytotoxicity }\end{array}$ & (71) \\
\hline $\begin{array}{l}\text { Acteoside (phenylpropanoid } \\
\text { glycoside) }\end{array}$ & Kuding Tea & IAV (H1N1)/Mice & $\begin{array}{l}80 \mathrm{mg} / \mathrm{kg} \text { administered } \\
\text { intraperitoneally }\end{array}$ & $\begin{array}{l}>20 \text {-folds increase in } \\
\text { IFN- } \gamma \text { production }\end{array}$ & 80 mg/kg & Host defense & (65) \\
\hline Curcumin & Curcuma longa $\mathrm{L}$ & IAV (H1N1)/Mice & 100 mg/kg/day for 5 days orally & $\begin{array}{l}\text { Significant reduction in the } \\
\text { expression of } \\
\text { proinflammatory genes }\end{array}$ & $100 \mathrm{mg} / \mathrm{kg}$ & Virus-induced cytotoxicity & (86) \\
\hline Germacrone & Rhizoma Curcuma & IAV (H1N1)/Mice & $\begin{array}{l}50-100 \mathrm{mg} / \mathrm{kg} / \text { day administered } \\
\text { intraperitoneally for } 5 \text { days }\end{array}$ & Mortality reduction (50\%) & 100 mg/kg & Virus-induced cytotoxicity & (60) \\
\hline $\begin{array}{l}\text { Isorhamnetin, Quercetin, } \\
\text { Kaempferol, Diosmetin, } \\
\text { Eriodictyol }\end{array}$ & & $\mathrm{IAV}(\mathrm{H} 1 \mathrm{~N} 1) /$ mice & $\begin{array}{l}1 \mathrm{mg} / \mathrm{kg} / \text { day administered } \\
\text { intranasally for } 5 \text { days }\end{array}$ & $\begin{array}{l}\text { Lung titer reduction } \\
\text { (2-folds), Improved } \\
\text { survival rate (70-80\%) }\end{array}$ & $1 \mathrm{mg} / \mathrm{kg}$ & $\begin{array}{l}\text { Virus-induced cytotoxicity, } \\
\text { Viral proliferation }\end{array}$ & (51) \\
\hline $\begin{array}{l}\text { A. melanocarpa extract, } \\
\text { Ellagic acid, myricetin }\end{array}$ & Black chokeberry & $\mathrm{IAV}(\mathrm{H} 1 \mathrm{~N} 1) /$ mice & $\begin{array}{l}1 \mathrm{mg} / \mathrm{kg} \text { administered twice daily } \\
\text { for } 5 \text { days. } \\
\text { A. melanocarpa extract was } \\
\text { administered orally, while Ellagic } \\
\text { acid and myricetin were } \\
\text { given intraperitoneally }\end{array}$ & $\begin{array}{l}\text { Lung titer reduction (> } \\
50 \%), \text { Reduction in viral } \\
\text { replication (15-30\%) }\end{array}$ & $1 \mathrm{mg} / \mathrm{kg}$ & $\begin{array}{l}\text { Virus-induced cytotoxicty, } \\
\text { viral replication }\end{array}$ & (46) \\
\hline Hibiscus sabdariffa extract & Hibiscus sabdariffa & IAV (H1N1)/mice & $\begin{array}{l}8 \mathrm{mg} / \text { mice of Hibiscus sabdariffa } \\
\text { tea extract was administered } \\
\text { orally twice daily for } 14 \text { days. }\end{array}$ & $\begin{array}{l}\text { No significant difference in } \\
\text { IAV induced mortality }\end{array}$ & & - & (45) \\
\hline Iridoid glycosides & Fructus Gardeniae & IAV (H1N1)/mice & $5,10,20 \mathrm{mg} / \mathrm{kg}$ orally for 4 days & Mortality reduction (52\%) & 20 mg/kg & $\begin{array}{l}\text { Viral replication, Virus- } \\
\text { induced cytotoxicty }\end{array}$ & (50) \\
\hline
\end{tabular}

IAV, influenza A virus; IBV, Influenza B virus; IC50, Half maximal inhibitory concentration; LLC-MK2, Rhesus Monkey Kidney Epithelial Cells; MDCK, Madin-Darby Canine Kidney; MHV, Murine hepatitis Virus; MIC50, Minimum Inhibitory Concentration required to inhibit the growth of $50 \%$ of organisms; R. acetosa, Rumex acetosa; RSV, Respiratory syncytial virus; TD50, Median toxic dose; Vit D, Vitamin D; Z. officinale, Zingiber officinale. 


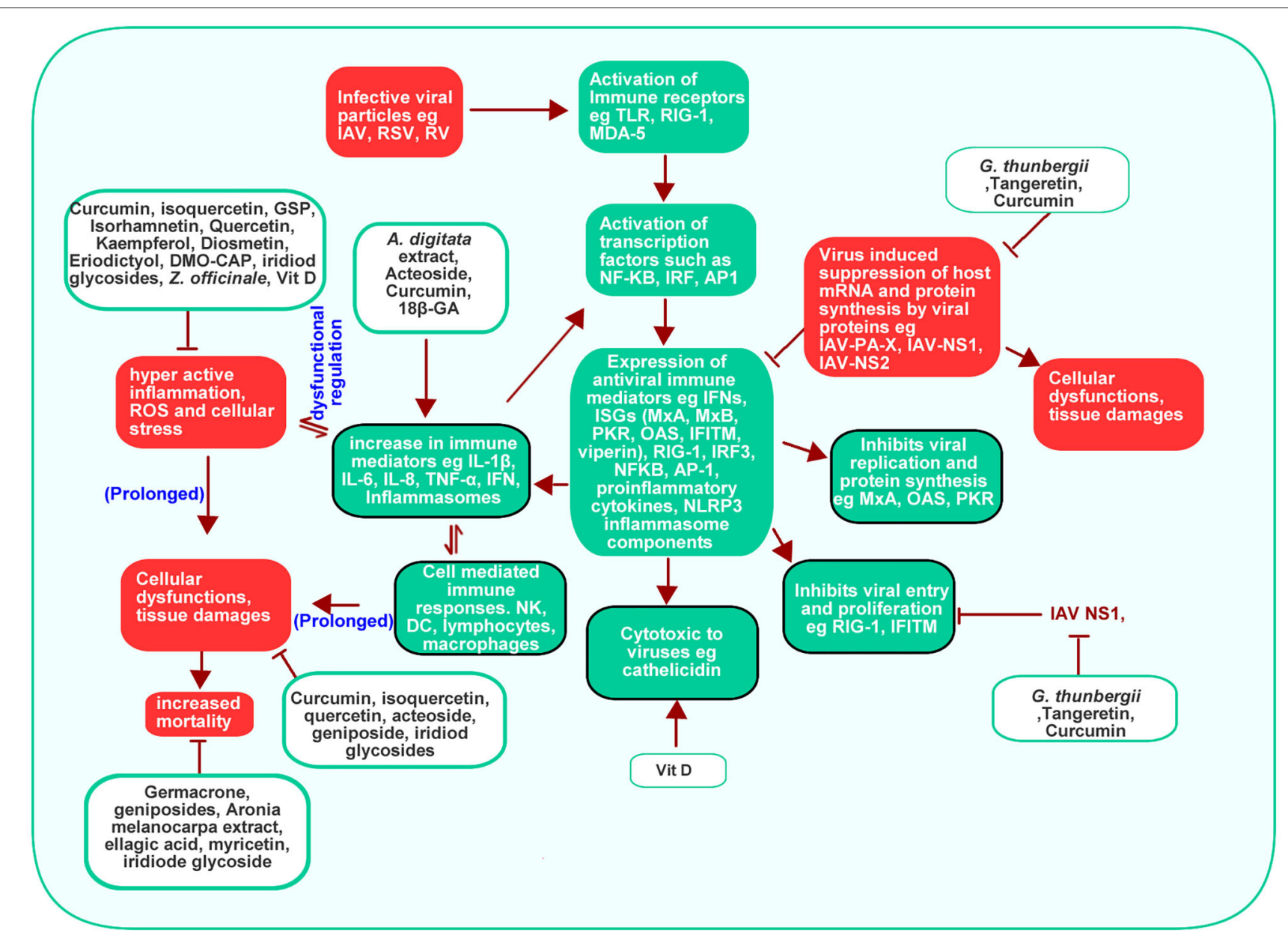

FIGURE 7 | Hypothetical mechanism of respiratory viruses-induced cellular damages. Activation of TLR receptor by viral RNA leads to the generation of localized inflammation at sites of infection. This inflammation may progress into hyper-inflammation if the virus succeeds in evading host antiviral defenses or if viral infection is prolonged. This consequently leads to the distortion of cellular homeostasis including the upregulation of wnt/b-catenin, AKT, and MAPK signaling. Persistent activation of these signaling cascade may trigger endoplasmic reticulum stress resulting in further oxidative stress and inflammation which eventually leads to tissue damages. AKT, Protein kinase B; MAPK, Mitogen-activated protein kinase; NF-кB, Nuclear factor-кB; ROS, Reactive oxygen species; TLR, Toll-like receptor.

IAV infections (Table 7). Treatments of mice infected with pandemic influenza A/Jiangsu/i/09 (H1N1) virus, with 20 $\mathrm{mg} / \mathrm{kg}$ of geniposide administered intraperitoneally for 14 days, ameliorated IAV-induced weight loss, reduced IAV-induced lung lesions, improved mice survival rates and decreased viral proliferation in infected mice models (71). Geniposide also reduced the expression of IAV NP in IAV-infected mice as well as reduced the levels of inflammatory mediators such as TNF$\alpha$, IL-6, and IFN-y (71). Geniposide-mediated suppression of caspase 3 activation in IAV-infected epithelial cells, suppressed the export of IAV RNP complexes to the cell membrane (71). This can potentially inhibit the packaging of infectious progeny virions (71).

Treatment of recombinant IAV H1N1/PR8 expressing green fluorescent protein (rPR8-GFP)—infected mice, with 1 $\mathrm{mg} / \mathrm{kg}$ of either A. melanocarpa extract (orally), ellagic acid [intraperitoneal (i.p)] or myricetin (i.p), for 3 days, significantly lowered IAV lung titer and viral replication as well as enhanced survival in IAV infected mice (46). The anti-IAV activity of
A. melanocarpa was attributed to its rich polyphenol contents (46). Significant reduction in lung IAV titer, decreased weight loss, and increased survival rates were observed following intranasal administration of isorhamnetin $(1 \mathrm{mg} / \mathrm{kg} /$ day for 5 days) to IAV (A/Puerto Rico/8/34 H1N1) infected mice (51). A significant reduction in lung virus titer (19-folds) as well as reduced expression of lung IFN-y, iNOS, and RANTES was observed following the treatment of IAV-infected mice models with isoquercetin (10 mg/kg/day, intraperitoneally, 8 days) (29). Intraperitoneal administration of acteoside $(80 \mathrm{mg} / \mathrm{kg})$ to mice infected with mice-adapted IAV FM1 strain (A/FM/1/47 H1N1) significantly reduced the severity of IAV-induced damages to the lung tissues of the IAV infected mice (65). The protective effect of acteoside was attributed to a possible enhancement of antiviral immune response without its associated inflammatory damages (65).

Treatment of mice models of IAV (Influenza A/Puerto Rico/8/34 H1N1) infection with curcumin (100 mg/kg, taken orally for 5 days) led to a significant reduction in the cardiac 
myocarditis, weight loss and heart inflammations, induced by IAV (86). Curcumin treatment also reduced IAV-induced increase in the expression of TNF, IL-1B, IL-6, and MMP-2 mRNA as well as suppressed IAV-induced increase in wnt $/ \beta$ catenin signaling in IAV infected mice (86). Oral administration of curcumin $(50,150 \mathrm{mg} / \mathrm{kg})$ was also reported to inhibit IAV replication, reduce lung viral titer and suppress virus-induced injuries in IAV infected mice (10). In a similar way, I.p injection of curcumin $(100,200$, and $400 \mathrm{mg} / \mathrm{kg}$ for 4 days) to Influenza A/Puerto Rico/8/34 (H1N1; PR/8) virus-infected mice model significantly reduced IAV-induced increase in the numbers of macrophages, total immune cells, neutrophils and Lymphocytes (43). It also suppressed IAV-induced increase in the expression of TNF, IFN-alpha and IL-6 in bronchoalveolar lavage fliud of mice infected with IAV (43). The evidence reported by Liu et al. (86) suggests that the inhibition of wnt/ $\beta$-catenin signaling by curcumin may be responsible for the suppression of IAV-induced cardiac myocarditis, following treatments of IAV-infected mice with curcumin. The ability of curcumin to suppress IAV NS1 gene expression in mice (86), also implies that curcumin can potentially inhibit the proliferation of IAV in vivo.

Intravenous injection of germacrone $(100 \mathrm{mg} / \mathrm{kg} / \mathrm{day}$ for 5 days) to IAV (influenza A/Puerto Rico/8/34 H1N1) exposed mice, significantly inhibited IAV in vivo and enhanced survival of IAV infected mice (60). The evidence presented by Liao et al. (60), further suggests that an additive anti-IAV benefit could be derived when germacrone is used in combination with oseltamivir. Treatment of virus (influenza virus strain A/FM/1/47) infected mice with iridiod glycosides, administered orally $(5-20 \mathrm{mg} / \mathrm{kg}$ ) for 5 day, protected infected mice from IAV-induced lung injury (50). Furthermore, a 52\% reduction in mortality was observed following treatments of IAV-infected mice models with $20 \mathrm{mg} / \mathrm{kg}$ of iridiod glycosides. The observed antiviral effect was attributed to a possible PACT-dependent inhibition of IAV replication (50).

$\mathrm{HS}$, despite having an in vitro anti-IAV activity, in vivo studies showed that the aqueous extract of HS $(8 \mathrm{mg})$, neither improved survival nor reduce virus titer in PR8 infected mice (45). Furthermore, the evidence they presented suggested that the observed in vitro anti-IAV activity of HS was due to the acidic nature of HS extract (45). In a separate experiment where they vaccinated mice with IAV inactivated by acidic HS, they observed an improvement in survival rate following subsequent IAV challenge. They however argued that the acidic nature of HS extract makes it unsuitable for vaccine development due to the possible alteration of IAV HA conformation and antigenic characteristics (45).

Cumulatively, the evidence obtained from the animal studies, as presented in this review, shows some reasonable agreement with those obtained from in vitro studies.

\section{Safety, Bioavailability, and Clinical Translation of PDFGS Against Respiratory Viral Infections}

The evidence presented in this review indicates that some PDFGS are able to suppress viral release, viral titer, viral cytopathic effects, and plague formation at doses that are not cytotoxic to the models considered. Majority of the PDFGS exerted their antiviral effects at doses that ranged between 0.1 and $600 \mu \mathrm{g} / \mathrm{ml}$ or $0.1-$ $200 \mu \mathrm{M}$ (Table 1). In almost all the studies, the half maximal inhibitory concentration (IC50 or EC50) was lower than the $50 \%$ cytotoxic doses (TC50 or CC50) by a reasonable margin. Some of the PDFGS had IC50 that was within the range reported for antiviral drugs like ribavirin $(2.4-22 \mu \mathrm{M})$, oseltamivir $(0.01-$ $0.5 \mu \mathrm{M})$, and amantadine $(0.51-100 \mu \mathrm{M})(22,29,60,61,68)$.

The potency of an agent depends on its ability to attain the therapeutic dose at cellular sites of action. The in vitro nature of most of the included studies made attaining these effective antiviral doses possible. In reality, several factors such as intestinal metabolism, intestinal absorption, liver metabolism, gut microbiota metabolism, renal clearance and organ selective uptake affects the concentration of a particular agents at target cellular environments (124-129). Evidence obtained from some other studies suggests that the concentrations at which some of the PDFGS (highlighted in this review) elicited their antiviral effect might not be attainable from normal dietary intake of these PDFGS. For instance Sablok et al. (130) and Mark et al. (131) reported a blood Vit D level of $<100 \mathrm{nmol}$ in humans whereas $1,000 \mathrm{nmol}$ Vit $\mathrm{D}$ was reported to suppress viral release by $60 \%$ (72). Intake of 8 grams of curcumin in human subject gave a peak plasma level of $1.77 \mu \mathrm{M}(0.683 \mu \mathrm{g} / \mathrm{ml}$ equivalent) (126), which is less than the antiviral dose of $21.36 \mu \mathrm{g} / \mathrm{ml}$ reported by Dai (10). A peak plasma level (Cmax) of $385 \mathrm{nmol}$ chlorogenic acid was attained in human subjects after ingestion of $412 \mu \mathrm{M}$ of chlorogenic acid (125). Intake of pomegranate juice containing $318 \mathrm{mg}$ of the elagitannin, punicalagins, gave a Cmax of 60 $\mathrm{nmol} / \mathrm{L}$ ellagic acid after an hour (125). These values are less than the antiviral-effective doses of $2.78-43.45 \mu \mathrm{M}$ and 3.64$119 \mu \mathrm{M}$ reported for chlorogenic acids and tannin derivatives $(41,44,62)$, respectively.

The bioavailability of many PDFGS following oral intake are largely limited by poor intestinal absorption. FernandezArroyo et al. (132) reported that only about $1 \%$ of the ingested polyphenol is absorbed after an intake of polyphenol-rich extract of HS. The bioavailability of curcumin is further limited by its binding to enterocyte proteins (126). Since bioavailability of phytochemicals such as polyphenols are dose dependent, an unusually high amount of the plant agent needs to be consumed in order to attain plasma levels that are comparable to doses reported to elicit antiviral effect. Alternatively, the bioactive components may be enriched from the parent materials and consumed as supplements. Fernandez-Arroyo et al. (132) reported a plasma level of $5 \mu \mathrm{M}(1.51 \mathrm{mg} / \mathrm{ml}$ quercetin equivalent) flavonols within $2 \mathrm{~h}$ of ingesting of $1,200 \mathrm{mg} / \mathrm{kg}$ of HS polyphenol extract by human subjects. Human subjects that ingested grape seed juice containing $10 \mathrm{mg}$ of quercetin had Cmax of $16 \mu \mathrm{M}$ (133) which falls within the antiviral-active concentrations of $5.4-17.3 \mu \mathrm{M}$ as reported by Kim et al. (22) and $\mathrm{Xu}$ et al. (69). Potential biotransformation of the PDFGS under cellular conditions can affect the antiviral efficacy of PDFGS in human subjects. An instance is the recently reported association of the in vitro antiviral effects of HS extracts to their acidic properties (45). The buffering capacity of human cellular environment could potentially neutralize the HS acidity and so attenuate the observed in vitro antiviral effects of HS. 
- viral immune evasiveness

- Prolonged and persistence infection

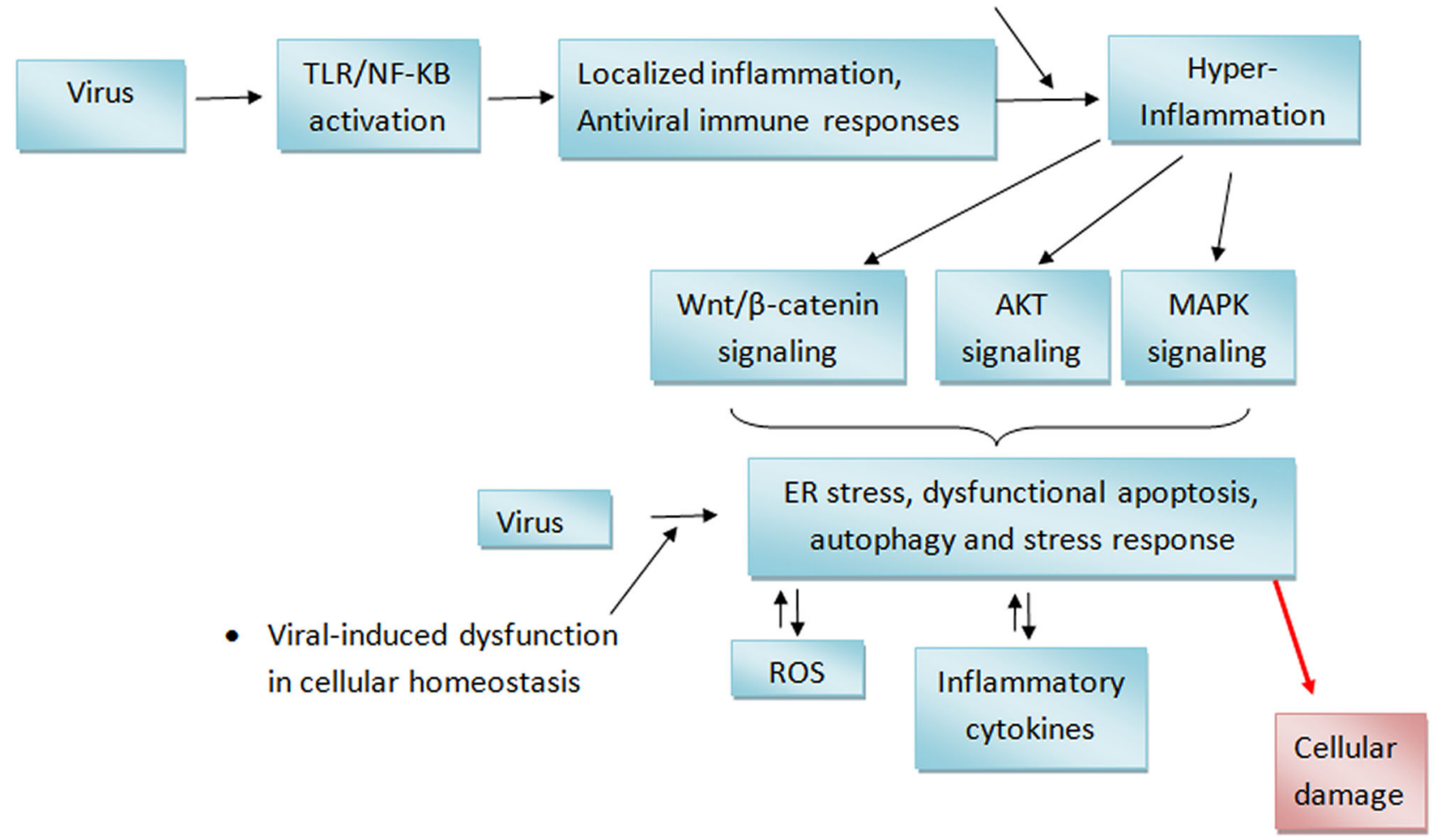

FIGURE 8 | Effect of PDFGS on host antiviral immune responses. Membrane resident immune receptors such as TLR senses viral RNA. This stimulates the expression of transcription factors which subsequently enhance the production of antiviral peptides and other immune mediators. Viruses induced suppression of host protein synthesis can downregulate the synthesis of antiviral immune mediator and can potentially lead to a dysfuntional cellular homeostasis. This could lead to inflammation and consequently, cause damages to tissues. PDFGS suppresses viral proteins, enhances the exepression of antiviral proteins as well as suppress virus-induced inflammations. 18 $\beta$-GA, 18 $\beta$-glycyrrhetinic acid; A. digitata, Adansonia digitata; AP-1, Activator protein-1; DC, Dendritic cells; DMO-CAP, 6-demethoxy-4'-O-methylcapillarisin; G. thunbergii, Geranii thunbergii; GSP, Grape seed proanthocyanidin; IAV, Influenza A virus; IAV-NS1, IAV non-structural protein 1 ; IAV-NS2, IAV non-structural protein 2; IAV-PA-X, transcript product of IAV polymerase; IFITM, IFN-induced transmembrane; IFN, Interferons; IL-1 $\beta$, Interleukin $1 \beta$; IL-6, Interleukin 6; IL-8, Interleukin 8; IRF, Interferon regulatory factor; IRF3, Interferon regulatory factor 3; MDA-5, Melanoma differentiation-associated protein 5; MxA, Myxovirus Resistance Gene A; MxB, Myxovirus Resistance Gene B; NF-кB, Nuclear factor kappa B; NK, Natural Killer cells; OAS, 2'-5' oligoadenylate synthetase; PKR, Protein kinase R; RIG-1, Retinoic acid-inducible gene I; RNase L, Ribonuclease L; ROS, Reactive oxygen species; RSV, Respiratory syncytial virus; RV, Rhinovirus; TLR, Toll-like receptor; TNF- $\alpha$, Tumor necrosis factor- $\alpha$; Vit D, Vitamin D; Z. officinale, Zingiber officinale.

With the exceptions of a few studies, most of the other in vivo evidences presented in this review administered PDFGS intraperitoneally. These non-oral routes of delivery, coupled to the relatively high doses of the PDFGS administered to model animals, further underscores the challenge inherent in attaining therapeutic concentrations of the PDFSG at target sites of action. Derksen et al. (55), suggested formulating the PDFGS into chewing gums, inhaling devices and as lozenges as a way to increased their bioavailability at target respiratory tract sites. Dayem et al. (51), was able to achieve antiviral efficacy at lower concentration $(1 \mathrm{mg} / \mathrm{kg}$ ) by administering the PDFGS intranasally, to IAV-infected mice.

\section{Categories and Food Sources of the Antiviral PDFGS}

This review collated evidences on the potential roles of dietary constituents in the management of respiratory viral diseases. This review identified antiviral PDFGS which falls into the categories of flavonoids, tannins, phenolic acids and other polyphenols, polysaccharides, lectins, Vit D, and plant glycosides.

\section{Flavonoids}

Flavonoids are ubiquitous polyphenols commonly found in fruits and vegetables. Evidence presented in this study indicates that different flavonoids including myricetin, isorhamnetin, quercetin, kaempferol, diosmetin, eriodictyol, quercetin 3-rhamnoside, procyanidin B2 digallate, grape seed proanthocyanidin, isoquercetin, fisetin, glycosyl hesperidin, tangeretin, and 6-demethoxy-4'-O-methylcapillarisin, interfered with different stages of respiratory virus's lifecycle and suppressed virus-induced pathologies. Myricetin, quercetin, isoquercetin, kaempferol are constituents of tea, onions, red wine, grapes, blackcurrants, and many edible berries $(29,134-$ 136). Isorhamnetin is contained in onions (137). Diosmetin is abundant in oregano spice and in citrus fruits (138). Eriodictyol 
are constituent of wine, tea, and coffee (139). Cirsimaritin is present in Ocimum gratissimum (140), Rosmarinus officinalis leaves [used as spices and flavoring agent (141)] and in Artemisia scoparia [a herbal and culinary plant $(68,142)]$. Catechin is abundant in cocoa and tea plant (124)]. Fisetin is abundant in fruits (strawberries, apples, persimmons, mangoes, kiwis, and grapes etc.), vegetables (tomatoes, onions, and cucumbers etc.), nuts, and wine $(143,144)$. Hesperitin, hesperidin and tangeretin are abundant in citrus fruits $(145,146)$. Glucosyl hesperidin is a synthetic and soluble derivative of hesperidin and possess similar metabolic and pharmacokinetic properties as the natural hesperidin (147). Powdered grape seed (containing procyanidins, gallic acid, catechin, epicatechin etc.) or proanthocyanidin rich extracts of grape seed are often consumed as supplement (148). Oligomeric proanthocyanidin are also present in red apple, cocoa, cinnamon, grapes etc. (149). DMO-CAP is a prenylated flavonoids and a constituent of artemisia spp such as Artemisia dracunculus L (42). Essential oils from Artemisia dracunculus $L$. are used as food spices and in herbal preparations (150).

\section{Phenolic Acids}

Phenolic acids, comprising the hydroxybenzoic derivatives such as gallic, vanillic, and syringic acids and their hydroxycinnamic acids derivatives such as caffeic, ferulic, sinapic, and p-coumaric are common constituents of fruits and vegetables including cocoa, tea, wines and whole grains (124). 3,4-dicaffeoylquinic acid and 3,5-dicaffeoylquinic acid is found in Lonicera japonica, a widely consumed plant (151). Globe artichoke (Cynara cardunculus $L$ ) also contain other derivatives of dicaffeoylquinic acid (152).

\section{Tannin}

Tannins are classified as condensed tannins (proanthocyanidin) and hydrolysable tannins (124). Hydrolysable tannins are further classified as gallotannins or ellagitannins based on their monomeric constituent and hydrolytic products, with gallotannins and ellagitannins possessing gallic acid and ellagic acid monomeric units, respectively (153). Tannins are common constituents of cocoa, nuts (including almonds, walnuts, and hezelnuts) and fruits (such as apples, grapes, pomegranates, plums and edible berries) (153).

\section{Others Phenolic Plant Extracts}

Evidence from this review also indicated that extracts from $A$. melanocarpa, blackcurrant berries, Japanese plum, G. thunbergii, Pomegranate fruits, Hamamelis virginiana, Canarium album, Brown Alga Ecklonia, tea and guava leaves extract suppressed respiratory viruses in vitro. Blackcurrant berries are edible fruits that are rich in vitamins, antioxidants and polyphenols such as flavonols, anthocyanins, and phenolic acids (154). A. melanocarpa (i.e., Black chokeberry) is a rich source of different polyphenols and natural antioxidants including quercetin, epicatechin, anthocyanins, hydroxycinnamic acid, and 3 -caffeoylquinic $(46,155,156)$. It is used in the production of wine, juices and as food grade colors (156). Japanese plum is a common type of anthocyanin-rich, red, and dark redfleshed plums (157). G. thunbergii is an edible plant used for herbal preparations and likely a food additive by virtue of being listed in Korean Food Standards Codex (52). G. thunbergii is rich in geraniin, a type of ellagitannin which is active against different viruses like HIV-1, HSV, and IAV (52). Pomegranate fruits (Punica granatum) are functional food rich in different polyphenols and tannins including anthocyanins and hydrolysable tannins like isocorilagin (158). The antiviral activities of Hamamelis virginiana extract were associated with its tannic acid contents such as gallic acid, pentagalloylglucose, tannic acid, and EGCG (41), commonly found in many edible plants. The isocorilagin-containing edible drupe fruit of Canarium album (Chinese olive tree), is consumed as a digestive aid and for other medicinal values $(53,159)$. The antiviral activities of isocorilagin, an hydrolysable tannins, against IAV has been reported (53). Isocorilagin is also present in pomegranate fruits (158). Brown Alga Ecklonia is an edible algae that is widely consumed in Korea and Japan for its nutritional and health benefit (160). It is rich in polyphenols such as phlorotannins which was demonstrated to suppress influenza virus activities (40). Tea is a commonly consumed beverage drink, obtained from Camellia sinensis and rich in polyphenols including catechin, gallic acid, theaflavins (such as derivatives of EGCG), amino acids and alkaloids such as caffeine and theobromine (161). They are processed into black, green or oblong tea with black and green tea accounting for 78 and $20 \%$ of worldwide consumption, respectively (161). Guava leaves tea is a functional drink that is highly rich in several polyphenols including catechin, ellagic acid, and quercetin $(162,163)$.

\section{Resveratrol, Curcumin, Germacrone}

The evidence presented in this review indicates that resveratrol, curcumin and germacrone inhibited respiratory viruses by interfering with different stages of its pathological pathways. Resveratrol, a type of stilbenes polyphenol, is abundant in grapes, wine, peanuts, and peanut products $(124,164)$. Curcumin is a yellow colored, non-polar polyphenol abundant in tumeric (Curcuma longa) (124). Germacrone is a common constituent of different species of Ginger (Zingiber spp.) and tumeric (Curcuma $s p p$.) which are commonly used as food spices and flavoring agents $(165,166)$.

\section{Polysaccharides and Lectins}

Lectins are heat and acid resistant glycoproteins that binds to specific carbohydrates moieties and are constituents of many dietary grains and legumes $(167,168)$. There are varieties of lectins, each having different specificity for different types of carbohydrates. Concanavalin A obtained from Jackbeans binds specifically to mannose and glucose moiety (169), peanut agglutinin, from peanut seed (Arachis hypogaea), binds to terminal galactose-B1,3-N-acetylgalactosamine (167), Lens culinaris agglutinin, from lentils, binds to fucosylated glycans (73). Jack-beans, peanut seed and lentils are consumed worldwide. Lentils are particularly rich in polyphenol (170). Lectins have been reported to have antiviral $(73,171)$, anticancers (169), antibacterial, and antifungal (171) activities. Some lectins such as concanavalin A, Lens culinaris agglutinin, and Pisum sativum agglutinin are able to interact with viral envelope 
and sialic acid residues of glycoproteins (171). Many lectins can escape digestion and enter enterocytes or systemic circulations in intact active forms to elicit different biologic effects $(169,172$, 173). EBN is consumed amongst the Chinese for its numerous health benefits such as its immune enhancing effects (57). The antiviral effects of EBN against respiratory viruses has been attributed to its sialylglycoprotein lectin contents which has an exposed $\mathrm{O}$-acetylated sialic acid moiety that can potentially interact with many viruses (57). The antiviral effect of EBN extract was enhanced on digestion with pancreatin $\mathrm{F}$ which generated smaller $10-25 \mathrm{kDa}$ sialylglycoproteins (57). Lectinlike compounds with antiviral properties have also been isolated from Japanese plums (67). Sulphated polysaccharides from Aphanothece sacrum have been shown to possess activity against influenza viruses (61). Aphanothece sacrum is an edible bluegreen algae (or cyanobacteria) that has been consumed as food over many years in Japan (174).

\section{Vit D}

Active forms of Vit D (1,25-dihydroxyvitamin D3, calcitriol) can modulate the expressions and activities of antiviral genes such as IFN, cathelicidin, $\beta$-defensins and ISGs (49) resulting in an enhanced virus clearance and suppressed virus-induced pathologies. Active Vit D are produced locally within different tissues from circulating 25-hydroxyvitamin D (25(OH)D3, calcidiol) through activities of 25-hydroxyvitamin D-1 alpha hydroxylase enzymes, resident in different organs such as liver, kidney, airway epitheliums etc. $(72,175)$. D2 and D3, obtained from the dietary sources [such as plant oil, UVB irradiated yeast cells, fish oil, mushrooms etc. (176)] or from the skin (through a UVB radiation dependent process), are converted to circulating $25(\mathrm{OH})$ Vit D through the activities of D-25-hydroxylase (175, 177).

\section{Glycosides}

Plant glycosides such as glycyrrhizin, acteoside, geniposide, and iridoid glycosides were observed to possess antiviral effects against respiratory viruses. Glycyrrhizin, a glycosylated saponin (178), is the major bioactive constituent of G. uralensis extract (20). G. uralensis, also known as licorice, is used in herbal preparation and also consumed as food supplement in many parts of the world (20). Extracts from G. uralensis roots also contains flavonoids, chalcones and other agents with estrogenic activities (179). Metabolism of Glycyrrhizin by gut microorganisms generated $18 \beta-\mathrm{GA}$ as its primary metabolite (20). 18 $\beta$-GA has been shown to inhibit RSV and induced inflammatory responses (20). Acteoside is a phenylethanoid glycoside with potent anti-inflammatory properties. It is the bioactive constituent of cistanche tea (from Cistanche spp), which is commonly consumed as herbal and functional drink in many Asian countries (180). Acteoside is also present in Kuding tea (prepared from leaves of Ilex kudingcha), a commonly consumed polyphenol-rich functional drink in Asian countries (181). Geniposide and other iridoid glycosides isolated from Fructus Gardenia and Gardenia jasminoides J. Ellis fruit have been demonstrated to possess antiviral properties against influenza viruses (50). Iridoid are monoterpenoids with a six membered ring structure and often associated with carbohydrates (182). Iridoid are also present in honeysuckle berry, guelder berry, Morinda citrifolia, Cornus officinalis, and Olea europaea which are edible dietary components (183186). Iridoids have been reported to have anti-inflammatory, antibacterial, and antiglycation properties $(183,185)$.

\section{Adlay Tea, Houttuynia Cordata, Rumex Acetosa, Portulaca Oleracea, and Adansonia Digitata Extracts}

This review showed that extracts from adlay tea, $H$. cordata, Rumex acetosa, $P$. oleracea, and $A$. digitata inhibited respiratory virus in vitro. Adlay tea is consumed in parts of Asia and made from ingredients consisting of adlay seeds (Coix lacrymajobi), cassia (Cassia obtusifolia L.), soybeans (Glycine max), and barley (Hordeum vulgare var. nudum) seeds (16). The antiviral effects of adlay tea have been associated with its nonpolyphenolic contents (16). H. cordata Thunb is used in herbal preparations and consumed as edible vegetable in some parts of Asia $(187,188)$. It is rich in volatile oil, water soluble polysaccharide and flavonoid, and reported to exerts antiinflammatory, antimutagenic, and antiviral activities $(187,188)$. $H$ cordata have been reported to enhance the secretion of interleukin and increase the proliferation of CD4+ and CD8+ cells in response to SARS coronavirus infection (187). Some of the antiviral bioactivities of $H$. cordata have been attributed to its quercetin content $(21,187)$. Rumex acetosa $L$ is a wild vegetable, rich in important nutrients but contains a high level of oxalic acid (189). The succulent leaves are consumed as vegetable and as medicinal plants (189). Purslane (P. oleracea) is an edible leafy plant with a high nutritive value as well as contains high levels of the antinutrient, oxalic acid (190). The leaves, seeds and fruit of A. digitata are consumed in many African countries as food and also used in traditional medicine for their antioxidant and anti-inflammatory properties (191).

\section{Summary and Recommendations}

This review highlighted the potential benefits of different PDFGS agents against viruses that can infect human respiratory tracts. Cumulatively, the evidence presented in this review shows that some PDFGS posses both in vitro and in vivo activities against different respiratory viruses. However, these evidence needs to be interpreted with cautious since it has not been demonstrated in human models of respiratory viral infection. As such, further clinical studies are required to ascertain their anti-viral potencies in human subjects. In the absence of more conclusive evidence from human studies, we recommend the following nutrition amongst populations that are highly prone to respiratory virus infections. These recommendations are based largely on the in vitro data presented in this review as well as on the merits of other nutritive health benefits inherent in the PDFGS.

We recommend an increased intake of many edible fruits and tea due to their abundant flavonoids, phenolic acids, and tannin contents.

We recommend an increased intake of legumes and other lectin-rich foods due to their abundant lectin contents. Increased consumption of fruits, and legumes was recently observed to lower the mortality due to COVID-19 infection $(35,192)$. 
We recommend an increased culinary usage of spice herbs such as tumeric, ginger, garlic due to their curcumin, and germacrone content.

We recommend the consumption of plant oils, fatty fish, beef liver, egg yolks, and other sources of Vit D precursors as well as a decent exposure to sunlight or other UVB radiations may boost overall immunity against respiratory viruses and other infectious diseases (177). The beneficial effect of Vit D is further supported by recent studies that associated the severity of the COVID-19 infection with Vit D deficiency (193-195).

Decent consumption of herbal teas such as licorice tea, cistanche tea, kuding tea, EBN, adlay tea due to their antiviral components. Glycyrrhizin from licorice tea was recently proposed as a potential therapeutic agent against COVID-19 as a result of its anti-inflammatory and angiotensin-converting enzyme 2 (ACE2) suppressing capabilities (196).

\section{Limitation of the Study}

This systematic review is limited by all the various limitations of the individual studies used for the review. The review is also limited by the inherent deficiencies of systematic reviews one of which includes a reliance on only available literature. For instance, majority of the available evidences were derived from in vitro studies as well as from IAV models of respiratory virus infections. This suggests that findings from this review may not be generalized for all kinds of respiratory viruses or for animal or clinical manifestations of IAV infections. This review is also limited by possible omissions of some relevant studies due to the choices of keywords used as well as the choice of databases used for literature search. The potential presence of publication bias in the information used for this review was not tested and cannot be ruled out.

\section{CONCLUSIONS}

This systematic review presented evidence that showed the antiviral potentials of PDFGS against cells and animal models of respiratory virus infections. Respiratory viruses susceptible to some of the PDFGS highlighted in this review includes IAV (H1N1, H2N1, H3N2, H9N2, and H5N1 subtypes), IBV, AdV, RSV (A2, B, and long strain), mouse hepatitis virus, hPIV

\section{REFERENCES}

1. Ajibade TO, Oyagbemi AA, Omobowale TO, Asenuga ER, Adigun KO. Quercetin and vitamin C mitigate cobalt chloride-induced hypertension through reduction in oxidative stress and nuclear factor kappa beta (NF$\mathrm{Kb})$ expression in experimental rat model. Biol Trace Elem Res. (2017) 175:347-59. doi: 10.1007/s12011-016-0773-5

2. Kabir M. Pathogenic viruses of the respiratory tract - A review. Asian Pac J Trop Dis. (2017) 7:316-20. doi: 10.12980/apjtd.7.2017D6-423

3. Nogales A, Martinez-Sobrido L, Topham DJ, DeDiego ML. Modulation of innate immune responses by the influenza A NS1 and PA-X proteins. Viruses. (2018) 10:708. doi: 10.3390/v10120708

4. van de Wakker SI, Fischer MJE, Oosting RS. New drug-strategies to tackle viral-host interactions for the treatment of influenza virus infections. Eur J Pharmacol. (2017) 809:178-90. doi: 10.1016/j.ejphar.2017. 05.038

5. Martin-Vicente M, González-Riaño C, Barbas C, Jiménez-Sousa MÁ, Brochado-Kith O, Resino S, et al. Metabolic changes during respiratory (type 2 and type 3), RV1B and HCoV-NL63. PDFGS including flavonoids (such as quercetin and isorhamnetin), phenolic acids (such as caffeic), tannins (such as proanthocyanidin and ellagitannins), lectins (such as concanavalin A, peanut agglutinin, and Lens culinaris agglutinin), glycosides (such as glycyrrhizin, acteoside, geniposide, and iridoid glycosides), resveratrol, curcumin, germacrone, Vit D, and plant extracts (such as adlay tea, $H$. cordata, Rumex acetosa, P. oleracea, EBN, and $A$. digitata) were shown to be active against some categories of these respiratory viruses. These PDFGS inhibited different stages of respiratory virus's pathogenic life cycle including virus cell entry, replication, protein synthesis and release functions. The PDFGS also enhanced host antiviral immune response as well as suppress virus-induced cellular damages to host tissues. Low bioavailability of these PDFGS in human subjects as well as the in vitro nature of the evidence presented in this review potentially limits the translation of this evidence to clinical practices. This notwithstanding, we are of the opinion that a nutrition that is rich in a number of the PDFGS highlighted in this study, would act at multiple points in respiratory virus's pathogenic life cycle, to create a cumulative antiviral effect which could limit the infectivity, proliferation or virus-induced cellular damage of respiratory viruses. The validity of this claim is a subject for future animal and clinical studies.

\section{DATA AVAILABILITY STATEMENT}

The original contributions presented in the study are included in the article/supplementary material, further inquiries can be directed to the corresponding author/s.

\section{AUTHOR CONTRIBUTIONS}

FU participated in literature search, data extraction, wrote the results and discussion section, conceptualized and designed the Figures 5-8, and collated the entire work. BE-E participated in literature search, data extraction, and wrote the introduction section. KP-I and JZ reviewed manuscript for clarity. OO supervised, conceptualized the project, and reviewed manuscript for clarity. All the authors read and approved the final manuscript.

syncytial virus infection of epithelial cells. Plos ONE. (2020) 15:e0230844 doi: 10.1371/journal.pone.0230844

6. Boncristiani HF, Criado MF, Arruda E. Respiratory viruses. Encyclop Microbiol. (2009) 2009:500-18. doi: 10.1016/B978-012373944-5. 00314-X

7. Nichols WG, Campbell AJP, Boeckh M. Respiratory viruses other than influenza virus: impact and therapeutic advances. Clin Microbiol Rev. (2008) 21:274-90. doi: 10.1128/CMR.00045-07

8. Navaratnarajah CK, Generous AR, Yousaf I, Cattaneo R. Receptormediated cell entry of paramyxoviruses: mechanisms, and consequences for tropism and pathogenesis. J Biol Chem. (2020) 295:2771-86. doi: 10.1074/jbc.REV119.009961

9. Bouillier C, Cosentino G, Léger T, Rincheval V, Richard CA, Desquesnes A, et al. The interactome analysis of the respiratory syncytial virus protein M21 suggests a new role in viral mRNA metabolism post-transcription. Sci Rep. (2019) 9:1-13. doi: 10.1038/s41598-019-51746-0

10. Dai J, Gu L, Su Y, Wang Q, Zhao Y, Chen X, et al. Inhibition of curcumin on influenza A virus infection and influenzal pneumonia via oxidative stress, 
TLR2/4, p38/JNK MAPK and NF-\$K\$B pathways. Int Immunopharmacol. (2018) 54:177-87. doi: 10.1016/j.intimp.2017.11.009

11. Manjarrez-Zavala ME, Rosete-Olvera DP, Gutiérrez-González LH, OcadizDelgado R, Cabello-Gutiérrez C. Pathogenesis of viral respiratory infection. Respiratory Disease and Infection: A New Insight. 1 (2013).

12. Calder PC, Carr AC, Gombart AF, Eggersdorfer M. Optimal nutritional status for a well-functioning immune system is an important factor to protect against viral infections. Nutrients. (2020) 12:1181. doi: 10.3390/nu12041181

13. Ahmad A, Rehman MU, Alkharfy KM. An alternative approach to minimize the risk of coronavirus (Covid-19) and similar infections. Eur Rev Med Pharmacol Sci. (2020) 24:4030-4. doi: 10.26355/eurrev_202004_20873

14. Grant WB, Lahore H, McDonnell SL, Baggerly CA, French CB, Aliano $\mathrm{JL}$, et al. Evidence that vitamin D supplementation could reduce risk of influenza and COVID-19 infections and deaths. Nutrients. (2020) 12:988. doi: 10.20944/preprints202003.0235.v2

15. Shittu MO, Afolami OI. Improving the efficacy of chloroquine and hydroxychloroquine against SARS-CoV-2 may require zinc additives-A better synergy for future COVID-19 clinical trials. Infez Med. (2020) 28:192-7.

16. Nagai E, Iwai M, Koketsu R, Sogabe R, Morimoto R, Suzuki Y, et al. Inhibition of influenza virus replication by adlay tea. J Sci Food Agric. (2018) 98:1899-905. doi: 10.1002/jsfa.8671

17. Yin J, Li G, Li J, Yang Q, Ren X. In vitro and in vivo effects of Houttuynia cordata on infectious bronchitis virus. Avian Pathol. (2011) 40:491-8. doi: 10.1080/03079457.2011.605107

18. Gasmi A, Noor S, Tippairote T, Dadar M, Menzel A, Bjørklund G. Individual risk management strategy and potential therapeutic options for the COVID-19 pandemic. Clin Immunol. (2020) 215:108409. doi: 10.1016/j.clim.2020.108409

19. San Chang J, Wang KC, Yeh CF, Shieh DE, Chiang LC. Fresh ginger (Zingiber officinale) has anti-viral activity against human respiratory syncytial virus in human respiratory tract cell lines. J Ethnopharmacol. (2013) 145:146-51. doi: 10.1016/j.jep.2012.10.043

20. Yeh CF, Wang KC, Chiang LC, Shieh DE, Yen MH, San Chang J. Water extract of licorice had anti-viral activity against human respiratory syncytial virus in human respiratory tract cell lines. J Ethnopharmacol. (2013) 148:46673. doi: $10.1016 /$ j.jep.2013.04.040

21. Chiow KH, Phoon MC, Putti T, Tan BKH, Chow VT. Evaluation of antiviral activities of Houttuynia cordata Thunb. Extract, quercetin, quercetrin and cinanserin on murine coronavirus and dengue virus infection. Asian Pac J Trop Med. (2016) 9:1-7. doi: 10.1016/j.apjtm.2015.12.002

22. Kim M, Kim SY, Lee HW, Shin JS, Kim P, Jung YS, et al. Inhibition of influenza virus internalization by (-)-epigallocatechin-3-gallate. Antivir Res. (2013) 100:460-72. doi: 10.1016/j.antiviral.2013.08.002

23. Ivanova V, Rouseva R, Kolarova M, Serkedjieva J, Rachev R, Manolova N. Isolation of a polysaccharide with antiviral effect from Ulva lactuca. Prep Biochem Biotechnol. (1994) 24:83-97. doi: 10.1080/108260694080 10084

24. Kannan S, Kolandaivel P. Antiviral potential of natural compounds against influenza virus hemagglutinin. Computat Biol Chem. (2017) 71:207-18. doi: 10.1016/j.compbiolchem.2017.11.001

25. Li YH, Lai CY, Su MC, Cheng JC, Chang YS. Antiviral activity of Portulaca oleracea L. Against influenza A viruses. J Ethnopharmacol. (2019) 241:112013. doi: 10.1016/j.jep.2019.112013

26. Messina G, Polito R, Monda V, Cipolloni L, Di Nunno N, Di Mizio G, et al. Functional role of dietary intervention to improve the outcome of COVID-19: A hypothesis of work. Int J Mol Sci. (2020) 21:3104. doi: 10.3390/ijms21093104

27. Mani JS, Johnson JB, Steel JC, Broszczak DA, Neilsen PM, Walsh $\mathrm{KB}$, et al. Natural product-derived phytochemicals as potential agents against coronaviruses: a review. Virus Res. (2020) 284:197989. doi: 10.1016/j.virusres.2020.197989

28. Choi HJ, Song JH, Park KS, Kwon DH. Inhibitory effects of quercetin 3-rhamnoside on influenza A virus replication. Eur J Pharm Sci. (2009) 37:329-33. doi: 10.1016/j.ejps.2009.03.002

29. Kim Y, Narayanan S, Chang KO. Inhibition of influenza virus replication by plant-derived isoquercetin. Antivir Res. (2010) 88:227-35. doi: 10.1016/j.antiviral.2010.08.016
30. Wu R, Wang L, Kuo HCD, Shannar A, Peter R, Chou PJ, et al. An update on current therapeutic drugs treating COVID-19. Curr Pharmacol Rep. (2020). doi: 10.1007/s40495-020-00216-7. [Epub ahead of print].

31. Hensley SE, Das SR, Gibbs JS, Bailey AL, Schmidt LM, Bennink JR, et al. Influenza A virus hemagglutinin antibody escape promotes neuraminidase antigenic variation and drug resistance. PLoS ONE. (2011) 6:e15190. doi: 10.1371/journal.pone.0015190

32. Hussain M, Galvin HD, Haw TY, Nutsford AN, Husain M. Drug resistance in influenza A virus: the epidemiology and management. Infect Drug Resist. (2017) 10:121-34. doi: 10.2147/IDR.S105473

33. Holtz LR, Cao S, Zhao G, Bauer IK, Denno DM, Klein EJ, et al. Geographic variation in the eukaryotic virome of human diarrhea. Virology. (2014) 468:556-64. doi: 10.1016/j.virol.2014.09.012

34. Sorci G, Faivre B, Morand S. Explaining among-country variation in COVID-19 case fatality rate. Sci Rep. (2020) 10:1-11. doi: 10.1038/s41598-020-75848-2

35. Abdulah DM, Hassan AB. Relation of dietary factors with infection and mortality rates of COVID-19 across the World. J Nutr Health Aging. (2020) 24:1011-8. doi: 10.1007/s12603-020-1434-0

36. Weger-Lucarelli J, Carrau L, Levi LI, Rezelj V, Vallet T, Blanc H, et al. Host nutritional status affects alphavirus virulence, transmission, and evolution. PLoS Pathog. (2019) 15:e1008089. doi: 10.1371/journal.ppat.1008089

37. Moher D, Liberati A, Tetzlaff J, Altman DG, PRISMA Group. Preferred reporting items for systematic reviews and metaanalyses: the PRISMA statement. PLoS Med. (2009) 6:e1000097. doi: 10.1371/journal.pmed.1000097

38. Seyedpour S, Khodaei B, Loghman AH, Seyedpour N, Kisomi MF, Balibegloo $\mathrm{M}$, et al. Targeted therapy strategies against SARS-CoV-2 cell entry mechanisms: a systematic review of in vitro and in vivo studies. J Cell Physiol. (2020). doi: 10.1002/jcp.30032. [Epub ahead of print].

39. Hooijmans CR, Rovers MM, De Vries RBM, Leenaars M, Ritskes-Hoitinga M, Langendam MW. SYRCLE's risk of bias tool for animal studies. BMC Med Res Methodol. (2014) 14:43. doi: 10.1186/1471-2288-14-43

40. Ryu YB, Jeong HJ, Yoon SY, Park JY, Kim YM, Park SJ, et al. Influenza virus neuraminidase inhibitory activity of phlorotannins from the edible brown alga Ecklonia cava. J Agric Food Chem. (2011) 59:6467-73. doi: $10.1021 / \mathrm{jf} 2007248$

41. Theisen LL, Erdelmeier CAJ, Spoden GA, Boukhallouk F, Sausy A, Florin L, et al. Tannins from Hamamelis virginiana bark extract: characterization and improvement of the antiviral efficacy against influenza A virus and human papillomavirus. PLoS ONE. (2014) 9:e88062. doi: 10.1371/journal.pone.0088062

42. Zhong M, Wang H, Ma L, Yan H, Wu S, Gu Z, et al. DMO-CAP inhibits influenza virus replication by activating heme oxygenase-1-mediated IFN response. Virol J. (2019) 16:1-9. doi: 10.1186/s12985-019-1125-9

43. Xu Y, Liu L. Curcumin alleviates macrophage activation and lung inflammation induced by influenza virus infection through inhibiting the NF-\$к\$B signaling pathway. Influenza Other Respir Viruses. (2017) 11:45763. doi: 10.1111/irv.12459

44. Weng JR, Lin CS, Lai HC, Lin YP, Wang CY, Tsai YC, et al. Antiviral activity of Sambucus FormosanaNakai ethanol extract and related phenolic acid constituents against human coronavirus NL63. Virus Res. (2019) 273:197767. doi: 10.1016/j.virusres.2019.197767

45. Takeda Y, Okuyama Y, Nakano H, Yaoita Y, Machida K, Ogawa H, et al. Antiviral activities of Hibiscus sabdariffa L. Tea Extract Against Human Influenza A Virus Rely Largely on Acidic pH but Partially on a Low-pH-Independent Mechanism. Food Environ Virol. (2020) 12:9-19. doi: 10.1007/s12560-019-09408-x

46. Park S, Kim JI, Lee I, Lee S, Hwang MW, Bae JY, et al. Aronia melanocarpa and its components demonstrate antiviral activity against influenza viruses. Biochem Biophys Res Commun. (2013) 440:14-9. doi: 10.1016/j.bbrc.2013.08.090

47. Makau JN, Watanabe K, Mohammed MMD, Nishida N. Antiviral activity of peanut (Arachis hypogaea L.) skin extract against human influenza viruses. $J$ Med Food. (2018) 21:777-84. doi: 10.1089/jmf.2017.4121

48. Ikuta K, Hashimoto K, Kaneko H, Mori S, Ohashi K, Suzutani T. Anti-viral and anti-bacterial activities of an extract of blackcurrants (Ribes nigrum L.). Microbiol Immunol. (2012) 56:805-9. doi: 10.1111/j.1348-0421.2012.00510.x 
49. Hansdottir S, Monick MM, Lovan N, Powers L, Gerke A, Hunninghake GW. Vitamin D decreases respiratory syncytial virus induction of NF-\$ $\kappa$ \$B-linked chemokines and cytokines in airway epithelium while maintaining the antiviral state. J Immunol. (2010) 184:965-74. doi: 10.4049/jimmunol.0902840

50. Guo S, Bao L, Li C, Sun J, Zhao R, Cui X. Antiviral activity of iridoid glycosides extracted from Fructus Gardeniae against influenza A virus by PACT-dependent suppression of viral RNA replication. Sci Rep. (2020) 10:1897. doi: 10.1038/s41598-020-58443-3

51. Dayem AA, Choi HY, Kim YB, Cho SG. Antiviral effect of methylated flavonol isorhamnetin against influenza. PLoS ONE. (2015) 10:e0121610. doi: 10.1371/journal.pone.0121610

52. Choi JG, Kim YS, Kim JH, Chung HS. Antiviral activity of ethanol extract of Geranii Herba and its components against influenza viruses via neuraminidase inhibition. Sci Rep. (2019) 9:12132. doi: 10.1038/s41598-019-48430-8

53. Chen F, Yang L, Huang Y, Chen Y, Sang H, Duan W, et al. Isocorilagin, isolated from Canarium album (Lour.) Raeusch, as a potent neuraminidase inhibitor against influenza A virus. Biochem Biophys Res Commun. (2020) 523:183-9. doi: 10.1016/j.bbrc.2019.12.043

54. Chen GH, Lin YL, Hsu WL, Hsieh SK, Tzen JTC. Significant elevation of antiviral activity of strictinin from Pu'er tea after thermal degradation to ellagic acid and gallic acid. J Food Drug Anal. (2015) 23:116-23. doi: 10.1016/j.jfda.2014.07.007

55. Derksen A, Hensel A, Hafezi W, Herrmann F, Schmidt TJ, Ehrhardt C, et al. 3-O-galloylated procyanidins from Rumex acetosa L. inhibit the attachment of influenza A virus. PLoS ONE. (2014) 9:e110089. doi: 10.1371/journal.pone.0110089

56. Green RH. Inhibition of multiplication of influenza virus by extracts of tea. Proc Soc Exp Biol Med. (1949) 71:84-5. doi: 10.3181/00379727-71$17089 \mathrm{P}$

57. Guo CT, Takahashi T, Bukawa W, Takahashi N, Yagi H, Kato K, et al. Edible bird's nest extract inhibits influenza virus infection. Antivir Res. (2006) 70:140-6. doi: 10.1016/j.antiviral.2006.02.005

58. Kaul TN, Middleton EJr, Ogra PL. Antiviral effect of flavonoids on human viruses. J Med Virol. (1985) 15:71-9. doi: 10.1002/jmv.18901 50110

59. Lee JW, Kim YI, Im CN, Kim SW, Kim SJ, Min S, et al. Grape seed proanthocyanidin inhibits mucin synthesis and viral replication by suppression of AP-1 and NF-\$к\$B via p38 MAPKs/JNK signaling pathways in respiratory syncytial virus-infected A549 cells. J Agric Food Chem. (2017) 65:4472-83. doi: 10.1021/acs.jafc.7b00923

60. Liao Q, Qian Z, Liu R, An L, Chen X. Germacrone inhibits early stages of influenza virus infection. Antivir Res. (2013) 100:578-88. doi: 10.1016/j.antiviral.2013.09.021

61. Ogura F, Hayashi K, Lee JB, Kanekiyo K, Hayashi T. Evaluation of an edible blue-green alga, Aphanothece sacrum, for its inhibitory effect on replication of herpes simplex virus type 2 and influenza virus type A. Biosci Biotechnol Biochem. (2010) 74:1687-90. doi: 10.1271/bbb.100336

62. Ooi LSM, Wang H, He Z, Ooi VEC. Antiviral activities of purified compounds from Youngia japonica (L.) DC (Asteraceae, Compositae). J Ethnopharmacol. (2006) 106:187-91. doi: 10.1016/j.jep.2005. 12.028

63. Saha RK, Takahashi T, Suzuki T. Glucosyl hesperidin prevents influenza a virus replication in vitro by inhibition of viral sialidase. Biol Pharm Bull. (2009) 32:1188-92. doi: 10.1248/bpb.32.1188

64. Selvarani V, Hudson JB. Multiple inflammatory and antiviral activities in Adansonia digitata (Baobab) leaves, fruits and seeds. J Med Plants Res. (2009) 3:576-82.

65. Song X, He J, Xu H, Hu XP, Wu XL, Wu HQ, et al. The antiviral effects of acteoside and the underlying IFN-\$ $\gamma \$$-inducing action. Food Funct. (2016) 7:3017-30. doi: 10.1039/C6FO00335D

66. Sriwilaijaroen N, Fukumoto S, Kumagai K, Hiramatsu H, Odagiri T, Tashiro M, et al. Antiviral effects of Psidium guajava Linn.(guava) tea on the growth of clinical isolated H1N1 viruses: its role in viral hemagglutination and neuraminidase inhibition. Antivir Res. (2012) 94:13946. doi: 10.1016/j.antiviral.2012.02.013
67. Yingsakmongkon S, Miyamoto D, Sriwilaijaroen N, Fujita K, Matsumoto K, Jampangern $\mathrm{W}$, et al. In vitro inhibition of human influenza A virus infection by fruit-juice concentrate of japanese plum (Prunus mume S IEB. et Z UCC). Biol Pharm Bull. (2008) 31:511-5. doi: 10.1248/bpb.31.511

68. Yan H, Wang H, Ma L, Ma X, Yin J, Wu S, et al. Cirsimaritin inhibits influenza A virus replication by downregulating the NF-\$к\$B signal transduction pathway. Virol J. (2018) 15:88. doi: 10.1186/s12985-018-0995-6

69. Xu JJ, Wu X, Li MM, Li GQ, Yang YT, Luo HJ, et al. Antiviral activity of polymethoxylated flavones from "Guangchenpi", the edible and medicinal pericarps of Citrus reticulata 'Chachi.' J Agric Food Chem. (2014) 62:2182-9. doi: 10.1021/jf404310y

70. Wu W, Li R, Li X, He J, Jiang S, Liu S, et al. Quercetin as an antiviral agent inhibits influenza A virus (IAV) entry. Viruses. (2016) 8:6. doi: 10.3390/v8010006

71. Zhang Y, Yao J, Qi X, Liu X, Lu X, Feng G. Geniposide demonstrates anti-inflammatory and antiviral activity against pandemic A/Jiangsu/1/2009 (H1N1) influenza virus infection in vitro and in vivo. Antivir Ther. (2017) 22:599-611. doi: 10.3851/IMP3152

72. Telcian AG, Zdrenghea MT, Edwards MR, Laza-Stanca V, Mallia P, Johnston SL, et al. Vitamin D increases the antiviral activity of bronchial epithelial cells in vitro. Antivir Res. (2017) 137:93-101. doi: 10.1016/j.antiviral.2016.11.004

73. Uematsu J, Koyama A, Takano S, Ura Y, Tanemura M, Kihira S, et al. Legume lectins inhibit human parainfluenza virus type 2 infection by interfering with the entry. Viruses. (2012) 4:1104-15. doi: 10.3390/v4071104

74. Van der Meer F, de Haan CAM, Schuurman NMP, Haijema BJ, Peumans WJ, Van Damme EJM, et al. Antiviral activity of carbohydrate-binding agents against Nidovirales in cell culture. Antivir Res. (2007) 76:21-9. doi: 10.1016/j.antiviral.2007.04.003

75. Edinger TO, Pohl MO, Stertz S. Entry of influenza A virus: host factors and antiviral targets. J Gen Virol. (2014) 95:263-77. doi: 10.1099/vir.0.059477-0

76. Dou D, Revol R, Östbye H, Wang H, Daniels R. Influenza A virus cell entry, replication, virion assembly and movement. Front Immunol. (2018) 9:1581. doi: 10.3389/fimmu.2018.01581

77. Matsuoka Y, Matsumae H, Katoh M, Eisfeld AJ, Neumann G, Hase T, et al. A comprehensive map of the influenza A virus replication cycle. BMC Syst Biol. (2013) 7:97. doi: 10.1186/1752-0509-7-97

78. Samji T. Influenza A: understanding the viral life cycle. Yale J Biol Med. (2009) 82:153-9.

79. Kleiner VA, Fearns R. RSV M2-1 protein in complex with RNA: old questions are answered and a new one emerges. Structure. (2020) 28:977-8. doi: 10.1016/j.str.2020.08.007

80. Kiss G, Holl JM, Williams GM, Alonas E, Vanover D, Lifland AW, et al. Structural analysis of respiratory syncytial virus reveals the position of M21 between the matrix protein and the ribonucleoprotein complex. J Virol. (2014) 88:7602-17. doi: 10.1128/JVI.00256-14

81. Griffiths C, Drews SJ, Marchant DJ. Respiratory syncytial virus: infection, detection, and new options for prevention and treatment. Clin Microbiol Rev. (2017) 30:277-319. doi: 10.1128/CMR.00010-16

82. Krzyzaniak MA, Zumstein MT, Gerez JA, Picotti P, Helenius A. Host cell entry of respiratory syncytial virus involves macropinocytosis followed by proteolytic activation of the F protein. PLoS Pathog. (2013) 9:e1003309. doi: 10.1371/journal.ppat.1003309

83. Lifland AW, Jung J, Alonas E, Zurla C, Crowe JE, Santangelo PJ. Human respiratory syncytial virus nucleoprotein and inclusion bodies antagonize the innate immune response mediated by MDA5 and MAVS. J Virol. (2012) 86:8245-58. doi: 10.1128/JVI.00215-12

84. Xu H, Li C, He X, Niu K, Peng H, Li W, et al. Molecular modeling, docking and dynamics simulations of GNA-related lectins for potential prevention of influenza virus (H1N1). J Mol Model. (2012) 18:27-37. doi: 10.1007/s00894-011-1022-7

85. Ou JL, Mizushina Y, Wang SY, Chuang DY, Nadar M, Hsu WL. Structureactivity relationship analysis of curcumin analogues on anti-influenza virus activity. FEBS J. (2013) 280:5829-40. doi: 10.1111/febs.12503

86. Liu X, Liu M, Yuan W, Chang H, Li Y, Chen Z, et al. Anti-viral effects of curcumin on influenza A virus-induced myocarditis via inhibiting Wnt/\$ $\beta \$$-catenin signaling. Centr Eur J Immunol. (2013) 38:328-35. doi: $10.5114 /$ ceji.2013.37756 
87. Hutchinson EC. Influenza virus. Trends Microbiol. (2018) 26:809-10. doi: 10.1016/j.tim.2018.05.013

88. Benton DJ, Wharton SA, Martin SR, McCauley JW. Role of neuraminidase in influenza A (H7N9) virus receptor binding. J Virol. (2017) 91:e02293-16. doi: 10.1128/JVI.02293-16

89. Wen F, Wan XF. Influenza neuraminidase: underrated role in receptor binding. Trends Microbiol. (2019) 27:477-9. doi: 10.1016/j.tim.2019.03.001

90. Kannan S, Kolandaivel P. The inhibitory performance of flavonoid cyanidin3-sambubiocide against $\mathrm{H} 274 \mathrm{Y}$ mutation in H1N1 influenza virus. J Biomol Struct Dyn. (2018) 36:4255-69. doi: 10.1080/07391102.2017.1413422

91. Lu SJ, Chong FC. Combining molecular docking and molecular dynamics to predict the binding modes of flavonoid derivatives with the neuraminidase of the 2009 H1N1 influenza A virus. Int J Mol Sci. (2012) 13:4496-507. doi: $10.3390 /$ ijms 13044496

92. Mehrbod P, Ebrahimi SN, Fotouhi F, Eskandari F, Eloff JN, McGaw LJ, et al. Experimental validation and computational modeling of anti-influenza effects of quercetin-3-O- $\alpha$-L-rhamnopyranoside from indigenous south African medicinal plant Rapanea melanophloeos. BMC Complement Altern Med. (2019) 19:346. doi: 10.1186/s12906-019-2774-3

93. Sadati SM, Gheibi N, Ranjbar S, Hashemzadeh MS. Docking study of flavonoid derivatives as potent inhibitors of influenza H1N1 virus neuraminidase. Biomed Rep. (2019) 10:33-8. doi: 10.3892/br.2018.1173

94. Sahoo M, Jena L, Rath SN, Kumar S. Identification of Suitable Natural Inhibitor against Influenza A (H1N1) neuraminidase protein by molecular docking. Genomics Inform. (2016) 14:96-103. doi: 10.5808/GI.2016. 14.3.96

95. Bhella D. Virus proteins and nucleoproteins: an overview. In: Harris J, Bhella D, editors. Virus Protein and Nucleoprotein Complexes. Singapore: Springer (2018). p. 1-18. doi: 10.1007/978-981-10-8456-0_1

96. Turrell L, Lyall JW, Tiley LS, Fodor E, Vreede FT. The role and assembly mechanism of nucleoprotein in influenza A virus ribonucleoprotein complexes. Nat Commun. (2013) 4:1591. doi: 10.1038/ncomms 2589

97. Manzoor R, Igarashi M, Takada A. Influenza A virus M2 protein: roles from ingress to egress. Int J Mol Sci. (2017) 18:2649. doi: 10.3390/ijms18122649

98. Takaoka A, Yamada T. Regulation of signaling mediated by nucleic acid sensors for innate interferon-mediated responses during viral infection. Int Immunol. (2019) 31:477-88. doi: 10.1093/intimm/dxz034

99. Kelley N, Jeltema D, Duan Y, He Y. The NLRP3 inflammasome: an overview of mechanisms of activation and regulation. Int J Mol Sci. (2019) 20:3328. doi: 10.3390/ijms20133328

100. Cameron CE, Castro C. The mechanism of action of ribavirin: lethal mutagenesis of RNA virus genomes mediated by the viral RNAdependent RNA polymerase. Curr Opin Infect Dis. (2001) 14:757-64. doi: 10.1097/00001432-200112000-00015

101. Feld JJ, Hoofnagle JH. Mechanism of action of interferon and ribavirin in treatment of hepatitis C. Nature. (2005) 436:967-72. doi: 10.1038 /nature 04082

102. Mangalmurti N, Hunter CA. Cytokine Storms: Understanding COVID-19. Immunity. (2020) 53:19-25. doi: 10.1016/j.immuni.2020.06.017

103. Walsh KB, Teijaro JR, Wilker PR, Jatzek A, Fremgen DM, Das SC, et al. Suppression of cytokine storm with a sphingosine analog provides protection against pathogenic influenza virus. Proc Natl. Acad Sci USA. (2011) 108:12018-23. doi: 10.1073/pnas.1107024108

104. Ye Q, Wang B, Mao J. Cytokine storm in COVID-19 and treatment. J Infect. (2020) 80:607-13. doi: 10.1016/j.jinf.2020.03.037

105. Welliver RC, Kaul A, Ogra PL. Cell-mediated immune response to respiratory syncytial virus infection: relationship to the development of reactive airway disease. J Pediatr. (1979) 94:370-5. doi: 10.1016/S0022-3476(79)80573-9

106. Hasnain SZ, Lourie R, Das I, Chen ACH, McGuckin MA. The interplay between endoplasmic reticulum stress and inflammation. Immunol Cell Biol. (2012) 90:260-70. doi: 10.1038/icb.2011.112

107. Wang R, Zhu Y, Zhao J, Ren C, Li P, Chen H, et al. Autophagy promotes replication of influenza A virus in vitro. J Virol. (2019) 93:e01984-18. doi: 10.1128/JVI.01984-18

108. Dinh QN, Drummond GR, Sobey CG, Chrissobolis S. Roles of inflammation, oxidative stress, and vascular dysfunction in hypertension. BioMed Res Int. (2014) 2014:406960. doi: 10.1155/2014/406960
109. Eguchi K, Manabe I. Toll-like receptor, lipotoxicity and chronic inflammation: the pathological link between obesity and cardiometabolic disease. J Atheroscler Thromb. (2014) 21:629-39. doi: 10.5551/jat.22533

110. Silva-Garcia O, Valdez-Alarcón JJ, Baizabal-Aguirre VM. The Wnt/ $\beta$ catenin signaling pathway controls the inflammatory response in infections caused by pathogenic bacteria. Mediat Inflamm. (2014) 2014:310183. doi: $10.1155 / 2014 / 310183$

111. Vallée A, Lecarpentier Y. Crosstalk between peroxisome proliferatoractivated receptor gamma and the canonical $\mathrm{WNT} / \$ \beta \$$-catenin pathway in chronic inflammation and oxidative stress during carcinogenesis. Front Immunol. (2018) 9:745. doi: 10.3389/fimmu.2018.00745

112. Wu X, Deng G, Hao X, Li Y, Zeng J, Ma C, et al. A caspase-dependent pathway is involved in $\mathrm{Wnt} / \$ \beta \$$-catenin signaling promoted apoptosis in Bacillus Calmette-Guerin infected RAW264. 7 macrophages. Int J Mol Sci. (2014) 15:5045-62. doi: 10.3390/ijms15035045

113. Cheng YJ, Yang BC, Liu MY. Lead increases lipopolysaccharide-induced liver injury through tumor necrosis factor- $\$ \alpha \$$ overexpression by monocytes/macrophages: role of protein kinase $\mathrm{C}$ and p42/44 mitogenactivated protein kinase. Environ Health Perspect. (2006) 114:507-13. doi: 10.1289/ehp. 8550

114. Guo TL, Mudzinski SP, Lawrence DA. The heavy metal lead modulates the expression of both TNF- $\alpha \$$ and TNF- $\alpha \$$ receptors in lipopolysaccharideactivated human peripheral blood mononuclear cells. J Leukoc Biol. (1996) 59:932-9. doi: 10.1002/jlb.59.6.932

115. Kyriakis JM. Making the connection: coupling of stress-activated ERK/MAPK signalling modules to extracellular stimuli and biological responses. Biochem Soc Symp. (1999) 64:29-48.

116. Darling NJ, Cook SJ. The role of MAPK signalling pathways in the response to endoplasmic reticulum stress. Biochim Biophys Acta Mol Cell Res. (2014) 1843:2150-63. doi: 10.1016/j.bbamcr.2014.01.009

117. Pal PB, Sinha K, Sil PC. Mangiferin, a natural xanthone, protects murine liver in $\mathrm{Pb}$ (II) induced hepatic damage and cell death via MAP kinase, NF\$К\$B and mitochondria dependent pathways. PLoS ONE. (2013) 8:e56894. doi: 10.1371/journal.pone.0056894

118. Imai $\mathrm{Y}$, Kuba K, Neely GG, Yaghubian-Malhami R, Perkmann $\mathrm{T}$, van Loo G, et al. Identification of oxidative stress and Toll-like receptor 4 signaling as a key pathway of acute lung injury. Cell. (2008) 133:235-49. doi: 10.1016/j.cell.2008.02.043

119. Lee KY, Rhim JW, Kang JH. Hyperactive immune cells (T cells) may be responsible for acute lung injury in influenza virus infections: a need for early immune-modulators for severe cases. Med Hypotheses. (2011) 76:64-9. doi: 10.1016/j.mehy.2010.08.032

120. Neofytou E, Tzortzaki EG, Chatziantoniou A, Siafakas NM. DNA damage due to oxidative stress in chronic obstructive pulmonary disease (COPD). Int J Mol Sci. (2012) 13:16853-64. doi: 10.3390/ijms131216853

121. Chen T, Wu D, Chen H, Yan W, Yang D, Chen G, et al. Clinical characteristics of 113 deceased patients with coronavirus disease 2019: retrospective study. BMJ. (2020) 368:m1295. doi: 10.1136/bmj.m1091

122. Lansbury L, Rodrigo C, Leonardi-Bee J, Nguyen-Van-Tam J, Lim WS. Corticosteroids as adjunctive therapy in the treatment of influenza. Cochrane Database Syst Rev. (2019) 2:CD010406. doi: 10.1002/14651858.CD010406.pub3

123. Rodrigo C, Leonardi-Bee J, Nguyen-Van-Tam J, Lim WS. Corticosteroids as adjunctive therapy in the treatment of influenza. Cochrane Database Syst Rev. (2016) 3:CD010406. doi: 10.1002/14651858.CD010406.pub2

124. Cione E, La Torre C, Cannataro R, Caroleo MC, Plastina P, Gallelli L. Quercetin, epigallocatechin gallate, curcumin, and resveratrol: from dietary sources to human microRNA modulation. Molecules. (2020) 25:63. doi: $10.3390 /$ molecules 25010063

125. Crozier A, Del Rio D, Clifford MN. Bioavailability of dietary flavonoids and phenolic compounds. Mol Aspects Med. (2010) 31:446-67. doi: 10.1016/j.mam.2010.09.007

126. Dei Cas M, Ghidoni R. Dietary curcumin: Correlation between bioavailability and health potential. Nutrients. (2019) 11:2147. doi: $10.3390 /$ nu1 1092147

127. Hollman PCH. Absorption, bioavailability, and metabolism of flavonoids. Pharm Biol. (2004) 42:74-83. doi: 10.3109/13880200490 893492 
128. Scalbert A, Morand C, Manach C, Rémésy C. Absorption and metabolism of polyphenols in the gut and impact on health. Biomed Pharmacother. (2002) 56:276-82. doi: 10.1016/S0753-3322(02)00205-6

129. Talavéra S, Felgines C, Texier O, Besson C, Gil-Izquierdo A, Lamaison $\mathrm{JL}$, et al. Anthocyanin metabolism in rats and their distribution to digestive area, kidney, and brain. J Agric Food Chem. (2005) 53:3902-8. doi: 10.1021/jf050145v

130. Sablok A, Batra A, Thariani K, Batra A, Bharti R, Aggarwal AR, et al. Supplementation of vitamin D in pregnancy and its correlation with feto-maternal outcome. Clin Endocrinol. (2015) 83:536-41. doi: $10.1111 /$ cen.12751

131. Mark S, Lambert M, Delvin EE, O’loughlin J, Tremblay A, Gray-Donald K. Higher vitamin D intake is needed to achieve serum $25(\mathrm{OH}) \mathrm{D}$ levels greater than $50 \mathrm{nmol} / \mathrm{l}$ in Quebec youth at high risk of obesity. Eur J Clin Nutr. (2011) 65:486-92. doi: 10.1038/ejcn.2011.5

132. Fernández-Arroyo $\mathrm{S}$, Herranz-López M, Beltrán-Debón R, Borrás-Linares I, Barrajón-Catalán E, Joven J, et al. Bioavailability study of a polyphenolenriched extract from $\mathrm{H}$ ibiscus sabdariffa in rats and associated antioxidant status. Mol Nutr Food Res. (2012) 56:1590-5. doi: 10.1002/mnfr.201200091

133. Kasikci MB, N. Bioavailability of quercetin. Curr Res Nutri Food Sci J. (2016) 2016:146-51. doi: 10.12944/CRNFSJ.4.Special-Issue-October.20

134. Hakkinen SH, Karenlampi SO, Heinonen IM, Mykkanen HM, Torronen AR. Content of the flavonols quercetin, myricetin, and kaempferol in 25 edible berries. J Agric Food Chem. (1999) 47:2274-9. doi: 10.1021/jf9811065

135. Marin L, Gutierrez-del-Rio I, Entrialgo-Cadierno R, Villar CJ, Lombó F. De novo biosynthesis of myricetin, kaempferol and quercetin in Streptomyces albus and Streptomyces coelicolor. PLoS ONE. (2018) 13:e0207278. doi: 10.1371/journal.pone. 0207278

136. Tsanova-Savova S, Ribarova F. Free and conjugated myricetin, quercetin, and kaempferol in Bulgarian red wines. J Food Compos Anal. (2002) 15:639-46. doi: 10.1006/jfca.2002.1099

137. Somerset SM, Johannot L. Dietary flavonoid sources in Australian adults. Nutr Cancer. (2008) 60:442-9. doi: 10.1080/01635580802143836

138. Choi J, Lee DH, Park SY, Seol JW. Diosmetin inhibits tumor development and block tumor angiogenesis in skin cancer. Biomed Pharmacother. (2019) 117:109091. doi: 10.1016/j.biopha.2019.109091

139. Lee ER, Kim JH, Kang YJ, Cho SG. The anti-apoptotic and anti-oxidant effect of eriodictyol on UV-induced apoptosis in keratinocytes. Biol Pharm Bull. (2007) 30:32-7. doi: 10.1248/bpb.30.32

140. Ola SS, Catia G, Marzia I, Francesco VF, Afolabi AA, Nadia M. HPLC/DAD/MS characterisation and analysis of flavonoids and cynnamoil derivatives in four Nigerian green-leafy vegetables. Food Chem. (2009) 115:1568-74. doi: 10.1016/j.foodchem.2009.02.013

141. Borrás-Linares I, Stojanović Z, Quirantes-Piné R, Arráez-Román D, ŠvarcGajić J, Fernández-Gutiérrez A, et al. Rosmarinus officinalis leaves as a natural source of bioactive compounds. Int J Mol Sci. (2014) 15:20585-606. doi: 10.3390/ijms151120585

142. Nigam M, Atanassova M, Mishra AP, Pezzani R, Devkota HP, Plygun S, et al. Bioactive compounds and health benefits of artemisia species. Nat Prod Commun. (2019) 14:1934578X19850354. doi: 10.1177/1934578X19850354

143. Lall RK, Adhami VM, Mukhtar H. Dietary flavonoid fisetin for cancer prevention and treatment. Mol Nutr Food Res. (2016) 60:1396-405. doi: $10.1002 / \mathrm{mnfr} .201600025$

144. Pal HC, Pearlman RL, Afaq F. Fisetin and its role in chronic diseases. In: Gupta S, Prasad S, Aggarwal B, editors. Anti-inflammatory Nutraceuticals and Chronic Diseases. Cham: Springer (2016). p. 213-44. doi: 10.1007/978-3-319-41334-1_10

145. Ho SC, Kuo CT. Hesperidin, nobiletin, and tangeretin are collectively responsible for the anti-neuroinflammatory capacity of tangerine peel (Citri reticulatae pericarpium). Food Chem Toxicol. (2014) 71:176-82. doi: 10.1016/j.fct.2014.06.014

146. Peng H, Wei Z, Luo H, Yang Y, Wu Z, Gan L, et al. Inhibition of fat accumulation by hesperidin in Caenorhabditis elegans. J Agric Food Chem. (2016) 64:5207-14. doi: 10.1021/acs.jafc.6b02183

147. Yamada M, Tanabe F, Arai N, Mitsuzumi H, Miwa Y, Kubota M, et al. Bioavailability of glucosyl hesperidin in rats. Biosci Biotechnol Biochem. (2006) 70:1386-94. doi: 10.1271/bbb.50657
148. Georgiev V, Ananga A, Tsolova V. Dietary supplements/nutraceuticals made from grapes and wines. In: Moreno-Arribas MV, Bartolomé Suáldea, editors. Wine Safety, Consumer Preference, and Human Health. Cham: Springer (2016). p. 201-27. doi: 10.1007/978-3-319-24514-0_10

149. Bahadoran Z, Mirmiran P, Azizi F. Dietary polyphenols as potential nutraceuticals in management of diabetes: a review. J Diabetes Metab Disord. (2013) 12:43. doi: 10.1186/2251-6581-12-43

150. Obolskiy D, Pischel I, Feistel B, Glotov N, Heinrich M. Artemisia dracunculus L.(tarragon): a critical review of its traditional use, chemical composition, pharmacology, and safety. J Agric Food Chem. (2011) 59:1136784. doi: $10.1021 / \mathrm{jf} 202277 \mathrm{w}$

151. Lee J, Park G, Chang YH. Nutraceuticals and antioxidant properties of Lonicera japonica Thunb. as affected by heating time. Int J Food Prop. (2019) 22:630-45. doi: 10.1080/10942912.2019.15 99389

152. Lattanzio V, Kroon PA, Linsalata V, Cardinali A. Globe artichoke: a functional food and source of nutraceutical ingredients. J Funct Foods. (2009) 1:131-44. doi: 10.1016/j.jff.2009.01.002

153. Seeram NP. Bioactive Polyphenols From Foods and Dietary Supplements: Challenges and Opportunities. New York, NY: Oxford University Press. (2006) doi: 10.1021/bk-2006-0925.ch003

154. Gopalan A, Reuben SC, Ahmed S, Darvesh AS, Hohmann J, Bishayee A. The health benefits of blackcurrants. Food Funct. (2012) 3:795-809. doi: $10.1039 / \mathrm{c} 2 \mathrm{fo} 30058 \mathrm{c}$

155. Denev P, Ciz M, Kratchanova M, Blazheva D. Black chokeberry (Aronia melanocarpa) polyphenols reveal different antioxidant, antimicrobial and neutrophil-modulating activities. Food Chem. (2019) 284:108-17. doi: 10.1016/j.foodchem.2019.01.108

156. Denev P, Kratchanova M, Petrova I, Klisurova D, Georgiev Y, Ognyanov $\mathrm{M}$, et al. Black chokeberry (Aronia melanocarpa (Michx.) Elliot) fruits and functional drinks differ significantly in their chemical composition and antioxidant activity. J Chem. (2018) 2018:1-11. doi: 10.1155/2018/9574587

157. Fanning KJ, Topp B, Russell D, Stanley R, Netzel M. Japanese plums (Prunus salicina Lindl.) and phytochemicals-breeding, horticultural practice, postharvest storage, processing and bioactivity. J Sci Food Agric. (2014) 94:2137-47. doi: 10.1002/jsfa.6591

158. Wu S, Tian L. Diverse phytochemicals and bioactivities in the ancient fruit and modern functional food pomegranate (Punica granatum). Molecules. (2017) 22:1606. doi: 10.3390/molecules22101606

159. He C. Canarium album (Lour.) Raeusch. 青果(Qingguo, Chinese Olive). In: Liu Y, Wang Z, Zhang J, editors. Dietary Chinese Herbs. Vienna: Springer (2015). p. 307-13. doi: 10.1007/978-3-211-99448-1_34

160. Park EY, Kim EH, Kim MH, Seo YW, Lee JI, Jun HS. Polyphenolrich fraction of brown alga Ecklonia cava collected from Gijang, Korea, reduces obesity and glucose levels in high-fat diet-induced obese mice. Evid Based Complement Alternat Med. (2012) 2012:418912. doi: 10.1155/2012/4 18912

161. Li S, Lo CY, Pan MH, Lai CS, Ho CT. Black tea: chemical analysis and stability. Food Funct. (2013) 4:10-8. doi: 10.1039/C2FO 30093A

162. Kaneko K, Suzuki K, Iwadate-Iwata E, Kato I, Uchida K, Onoue M. Evaluation of food-drug interaction of guava leaf tea. Phytother Res. (2013) 27:299-305. doi: 10.1002/ptr.4724

163. Rahman MM, Zaman S, Mamun F, Gias ZT, Alam MN, Ulla A, et al. Phenolic content analysis in Psidium guajava leaves powder by HPLCDAD system and in vivo renoprotective and antioxidant activities in fludrocortisone acetate-induced rats. J Food Biochem. (2018) 42:e12687. doi: $10.1111 / \mathrm{jfbc} .12687$

164. Wenzel E, Somoza V. Metabolism and bioavailability of trans-resveratrol. Mol Nutr Food Res. (2005) 49:472-81. doi: 10.1002/mnfr.200500010

165. Barrero AF, Herrador MM, Arteaga P, Catalan JV. Germacrone: occurrence, synthesis, chemical transformations and biological properties. Nat Prod Commun. (2008) 3:1934578X0800300418. doi: $10.1177 / 1934578 X 0800300418$

166. Ye L, Wu J, Chen W, Feng Y, Shen Z. Novel anti-cancer agents based on germacrone: design, synthesis, biological activity, docking studies and MD simulations. RSC Adv. (2017) 7:3760-7. doi: 10.1039/C6RA26944C 
167. Kiss R, Camby I, Duckworth C, De Decker R, Salmon I, Pasteels JL, et al. In vitro influence of Phaseolus vulgaris, Griffonia simplicifolia, concanavalin A, wheat germ, and peanut agglutinins on HCT-15, LoVo, and SW837 human colorectal cancer cell growth. Gut. (1997) 40:253-61. doi: 10.1136 /gut.40.2.253

168. Nasi A, Picariello G, Ferranti P. Proteomic approaches to study structure, functions and toxicity of legume seeds lectins. Perspect Assess Food Qual Saf J Proteom. (2009) 72:527-38. doi: 10.1016/j.jprot.2009.02.001

169. Carbonaro M, Maselli P, Nucara A. Structural aspects of legume proteins and nutraceutical properties. Food Res Int. (2015) 76:19-30. doi: 10.1016/j.foodres.2014.11.007

170. Ganesan K, Xu B. Polyphenol-rich lentils and their health promoting effects. Int J Mol Sci. (2017) 18:2390. doi: 10.3390/ijms18112390

171. Lagarda-Diaz I, Guzman-Partida AM, Vazquez-Moreno L. Legume lectins: proteins with diverse applications. Int J Mol Sci. (2017) 18:1242. doi: $10.3390 / \mathrm{ijms} 18061242$

172. De Mejia EG, Bradford T, Hasler C. The anticarcinogenic potential of soybean lectin and lunasin. Nutr Rev. (2003) 61:239-46. doi: 10.1301/nr.2003.jul.239-246

173. De Mejia EG, Valadez-Vega MDC, Reynoso-Camacho R, Loarca-Pina G. Tannins, trypsin inhibitors and lectin cytotoxicity in tepary (Phaseolus acutifolius) and common (Phaseolus vulgaris) beans. Plant Foods Hum Nutr. (2005) 60:137-45. doi: 10.1007/s11130-005-6842-0

174. Matsuda S, Sugawa H, Shirakawa J, Ohno RI, Kinoshita S, Ichimaru K, et al. Aphanothece sacrum (Sur.) Okada prevents cataractogenesis in type 1 diabetic mice. J Nutr Sci Vitaminol. (2017) 63:263-8. doi: 10.3177/jnsv.63.263

175. Tsiaras WG, Weinstock MA. Factors influencing vitamin D status. Acta Derm Venereol. (2011) 91:115-24. doi: 10.2340/00015555-0980

176. Baur AC, Brandsch C, König B, Hirche F, Stangl GI. Plant oils as potential sources of vitamin D. Front Nutr. (2016) 3:29. doi: 10.3389/fnut.2016.00029

177. Wacker M, Holick MF. Sunlight and Vitamin D: a global perspective for health. Derm Endocrinol. (2013) 5:51-108. doi: 10.4161/derm.24494

178. Ashfaq UA, Masoud MS, Nawaz Z, Riazuddin S. Glycyrrhizin as antiviral agent against hepatitis C virus. J Transl Med. (2011) 9:1-7. doi: 10.1186/1479-5876-9-112

179. Boonmuen N, Gong P, Ali Z, Chittiboyina AG, Khan I, Doerge DR, et al. Licorice root components in dietary supplements are selective estrogen receptor modulators with a spectrum of estrogenic and antiestrogenic activities. Steroids. (2016) 105:42-9. doi: 10.1016/j.steroids.2015. 11.006

180. Cui Q, Pan Y, Zhang W, Zhang Y, Ren S, Wang D, et al. Metabolites of dietary acteoside: profiles, isolation, identification, and hepatoprotective capacities. J Agric Food Chem. (2018) 66:2660-8. doi: 10.1021/acs.jafc. $7 \mathrm{~b} 04650$

181. Yi R, Zhang J, Sun P, Qian Y, Zhao X. Protective effects of kuding tea (Ilex kudingcha CJ Tseng) polyphenols on UVB-induced skin aging in SKH1 hairless mice. Molecules. (2019) 24:1016. doi: 10.3390/molecules24 061016

182. Ludwiczuk A, Skalicka-Wozniak K, Georgiev MI. Terpenoids. In: Badal S, Delgoda S, editors. Pharmacognosy: Fundamentals, Applications and Strategy. Massachusetts: Elsevier (2017). p. 233-66. doi: 10.1016/B978-0-12-802104-0.00011-1

183. Gołba M, Sokol-Letowska A, Kucharska AZ. Health properties and composition of honeysuckle berry Lonicera caerulea L. an update on recent studies. Molecules. (2020) 25:749. doi: 10.3390/molecules 250 30749
184. Perova IB, Zhogova AA, Cherkashin AV, Éller KI, Ramenskaya GV, Samylina IA. Biologically active substances from European guelder berry fruits. Pharm Chem J. (2014) 48:332-9. doi: 10.1007/s11094-014-1105-8

185. West BJ, Uwaya A, Isami F, Deng S, Nakajima S, Jensen CJ. Antiglycation activity of iridoids and their food sources. Int J Food Sci. (2014) 2014:276950. doi: 10.1155/2014/276950

186. Kucharska AZ, Sokół-Łketowska A, Oszmiański J, Piórecki N, Fecka I. Iridoids, phenolic compounds and antioxidant activity of edible honeysuckle berries (Lonicera caerulea var. kamtschatica Sevast). Molecules. (2017) 22:405. doi: $10.3390 /$ molecules 22030405

187. Kumar M, Prasad SK, Hemalatha S. A current update on the phytopharmacological aspects of Houttuynia cordata Thunb. Pharmacogn Rev. (2014) 8:22-35. doi: $10.4103 / 0973-7847.1$ 25525

188. Yang L, Jiang JG. Bioactive components and functional properties of Hottuynia cordata and its applications. Pharm Biol. (2009) 47:1154-61. doi: $10.3109 / 13880200903019200$

189. Korpelainen H, Pietiläinen M. Sorrel (Rumex acetosa L.): not only a weed but a promising vegetable and medicinal plant. Bot Rev. (2020) 86:234-46. doi: 10.1007/s12229-020-09225-z

190. Szalai G, Dai N, Danin A, Dudai N, Barazani O. Effect of nitrogen source in the fertilizing solution on nutritional quality of three members of the Portulaca oleracea aggregate. J Sci Food Agric. (2010) 90:2039-45. doi: $10.1002 /$ jsfa.4049

191. De Caluwé E, Halamová K, Van Damme P. Adansonia digitata L. -A review of traditional uses, phytochemistry and pharmacology. Afrika Focus. (2010) 23:5307. doi: 10.21825/af.v23i1.5037

192. Orisakwe OE, Orish CN, Nwanaforo EO. Coronavirus disease (COVID19) and Africa: acclaimed home remedies. Sci Afr. (2020) 10:e00620. doi: 10.1016/j.sciaf.2020.e00620

193. Im JH, Je YS, Baek J, Chung MH, Kwon HY, Lee JS. Nutritional status of patients with coronavirus disease 2019 (COVID-19). Int J Infect Dis. (2020) 100:390-3. doi: 10.1016/j.ijid.2020.08.018

194. Pereira M, Dantas Damascena A, Galvão Azevedo LM, de Almeida Oliveira T, da Mota Santana J. Vitamin D deficiency aggravates COVID19: systematic review and meta-analysis. Crit Rev Food Sci Nutr. (2020). doi: 10.1080/10408398.2020.1841090. [Epub ahead of print].

195. Mardani R, Alamdary A, Nasab SDM, Gholami R, Ahmadi N, Gholami A. Association of vitamin D with the modulation of the disease severity in COVID-19. Virus Res. (2020) 289:198148. doi: 10.1016/j.virusres.2020.198148

196. Murck H. Symptomatic protective action of glycyrrhizin (Licorice) in COVID-19 infection? Front Immunol. (2020) 11:1239. doi: $10.3389 /$ fimmu.2020.01239

Conflict of Interest: The authors declare that the research was conducted in the absence of any commercial or financial relationships that could be construed as a potential conflict of interest.

Copyright (๑) 2021 Umeoguaju, Ephraim-Emmanuel, Patrick-Iwuanyanwu, Zelikoff and Orisakwe. This is an open-access article distributed under the terms of the Creative Commons Attribution License (CC BY). The use, distribution or reproduction in other forums is permitted, provided the original author(s) and the copyright owner(s) are credited and that the original publication in this journal is cited, in accordance with accepted academic practice. No use, distribution or reproduction is permitted which does not comply with these terms. 